Illinois State University

ISU ReD: Research and eData

Theses and Dissertations

10-19-2020

\title{
Factors That Influence Parent Communication Decisions For Their Deaf Or Hard Of Hearing Child In Illinois
}

Karla A. Giese

Illinois State University, karlagiese@gmail.com

Follow this and additional works at: https://ir.library.illinoisstate.edu/etd

Part of the Special Education Administration Commons

\section{Recommended Citation}

Giese, Karla A., "Factors That Influence Parent Communication Decisions For Their Deaf Or Hard Of Hearing Child In Illinois" (2020). Theses and Dissertations. 1321.

https://ir.library.illinoisstate.edu/etd/1321

This Dissertation is brought to you for free and open access by ISU ReD: Research and eData. It has been accepted for inclusion in Theses and Dissertations by an authorized administrator of ISU ReD: Research and eData. For more information, please contact ISUReD@ilstu.edu. 


\section{FACTORS THAT INFLUENCE PARENT COMMUNICATION DECISIONS FOR THEIR DEAF OR HARD OF HEARING CHILD IN ILLINOIS}

\section{KARLA A GIESE}

\section{Pages}

The development of language in a deaf or hard of hearing child is dependent upon early and effective communication access (Marschark, 2018; Marschark \& Hauser, 2012; Pittman et al., 2016; Scott \& Dostal, 2019; Scott \& Henner, 2020). For many parents of deaf and hard of hearing children, the most common early decisions that are made are related to communication and supporting language development, which is recognized by many in the field as a prime factor in early language acquisition (Decker et al., 2012; Sass-Lehrer, 2018). However, there are a lack of effective strategies for sharing information on specific communication approaches with families across the wide span of opinions regarding how deaf and hard of hearing children communicate. The focus of this dissertation study examined the parent perspective of their experience in gathering information about communication approaches for their child and how that ties into the recommended guidelines related to informed choice, decision-making, and information sharing within the early intervention process. Surveys and interviews were used. The major findings of this study indicate that parents in Illinois receive inconsistent information regarding communication approaches; primary sources of information for parents in Illinois appear to be early intervention professionals and the parents themselves; access to opportunities in addition to satisfaction/dissatisfaction with the information emerged as top influencers in the process of making decisions; and the idea of a reference chart or communication matrix was 
deemed a potential desirable and beneficial resource. The potential implications for enhancing early intervention practices include standardization of practices to enhance informed choice and support decision-making.

KEYWORDS: deaf; hard of hearing; communication; early intervention; parents; informed choice; decision making 


\title{
FACTORS THAT INFLUENCE PARENT COMMUNICATION DECISIONS FOR THEIR
}

DEAF OR HARD OF HEARING CHILD IN ILLINOIS

\author{
KARLA A GIESE
}

\begin{abstract}
A Dissertation Submitted in Partial
Fulfillment of the Requirements

for the Degree of

DOCTOR OF EDUCATION

Department of Special Education

ILLINOIS STATE UNIVERSITY
\end{abstract}


(C) 2020 Karla A Giese 


\title{
FACTORS THAT INFLUENCE PARENT COMMUNICATION DECISIONS FOR THEIR DEAF OR HARD OF HEARING CHILD IN ILLINOIS
}

\author{
KARLA A GIESE
}

COMMITTEE MEMBERS:

Christina M. Borders, Co-Chair

Stephanie Gardiner-Walsh, Co-Chair

Maribeth N. Lartz 


\section{ACKNOWLEDGMENTS}

I would like to first and foremost acknowledge my family. Without their constant support, I would not have survived this journey. Both my family and many friends made sure I had the time, space, resources, and cheerleading I needed to cross the finish line. For that, I thank you! I would also like to say thank you to my committee members Dr. Borders, Dr. GardinerWalsh, and Dr. Lartz. They were unwavering in their dedication in ensuring I was on the right path by asking the hard questions and providing feedback that ultimately pushed me to grow as an academic and writer. I will cherish the resulting friendships that have developed over these past few years while connecting with each of you, and I look forward to working alongside each one of you in the field! Dr. Sara Jozwik and Dr. Amy Otis-Wilborn were also sources of constant encouragement and reminders of the light at the end of the tunnel, which was much appreciated, especially in the last few months.

I would also like to say thank you to my Illinois State University (ISU) Doctoral Cohort. Their constant check-ins and words of encouragement were incredibly helpful. I will always value their friendship and support. I must also acknowledge my cohort through National Leadership Consortium in Sensory Disabilities (NLCSD). It was through them that I started this journey. Because of these connections, I have learned so much and made many new friends along the way. I would like to give an extra big shout out to my fellow ISU NLCSD Scholar, Lauralyn Randles, for her unwavering support, wit, and words of wisdom as we went through this journey together. And last, but not least, a big thank you to my mentor, Stef, for her personal and professional support. I am blessed to have you in my life.

K.A.G. 


\section{CONTENTS}

Page

ACKNOWLEDGMENTS

TABLES vii

FIGURES

CHAPTER I: INTRODUCTION 1

Early Intervention for Infants and Toddlers with Disabilities $\quad 2$

Early Intervention Recommended Practices for Working with Families of Children with

$\begin{array}{ll}\text { Disabilities } & 4\end{array}$

Family-Centered Practices $\quad 5$

Family Capacity-Building Practices 5

Family and Professional Collaboration $\quad 6$

$\begin{array}{ll}\text { Current Trends in Early Intervention } & 7\end{array}$

Current Practice in Early Intervention in Illinois 12

Information Sharing and Decision-Making 16

Parent Information Needs Across All Disability Areas 19

Parent Information Needs for Children Who Are Deaf or Hard of Hearing 21

Sources of Information: Formal and Informal 23

Best Practice Recommendations for Working with Families of Deaf and Hard of Hearing

$\begin{array}{ll}\text { Children } & 25\end{array}$

Joint Committee on Infant Hearing (JCIH) 25

Family Centered Early Intervention $\quad 29$

Information on Communication Approaches $\quad 35$ 
CHAPTER II: LITERATURE REVIEW 40

$\begin{array}{ll}\text { Amplification and Communication } & 40\end{array}$

$\begin{array}{ll}\text { Informed Choice } & 41\end{array}$

$\begin{array}{ll}\text { Methods } & 45\end{array}$

$\begin{array}{ll}\text { Results } & 48\end{array}$

Theme 1: Parent Values and Desires for Child's Future 59

$\begin{array}{ll}\text { Theme 2: Needs of the Child } & 61\end{array}$

$\begin{array}{ll}\text { Theme 3: Accessibility } & 63\end{array}$

Theme 4: Sources of Information $\quad 64$

$\begin{array}{ll}\text { Discussion } & 66\end{array}$

$\begin{array}{ll}\text { Conclusion } & 74\end{array}$

$\begin{array}{ll}\text { CHAPTER III: METHODOLOGY } & 76\end{array}$

$\begin{array}{ll}\text { Problem Statement } & 76\end{array}$

$\begin{array}{lr}\text { Purpose of the Study } & 83\end{array}$

$\begin{array}{ll}\text { Research Questions } & 84\end{array}$

$\begin{array}{ll}\text { Theoretical Framework } & 84\end{array}$

$\begin{array}{ll}\text { Methods } & 86\end{array}$

$\begin{array}{lr}\text { Research Design } & 86\end{array}$

$\begin{array}{lr}\text { Sample and Participants } & 88\end{array}$

$\begin{array}{lr}\text { Survey Population Sample Description } & 88\end{array}$

Hearing Levels, Technology, and Additional Delays 90

$\begin{array}{ll}\text { Interview Population Sample Description } & 93\end{array}$ 
$\begin{array}{ll}\text { Recruitment } & 94\end{array}$

Data Collection Techniques $\quad 94$

$\begin{array}{ll}\text { Survey Design } & 96\end{array}$

$\begin{array}{ll}\text { Individual Interviews } & 97\end{array}$

$\begin{array}{ll}\text { Survey Dissemination } & 98\end{array}$

$\begin{array}{ll}\text { Data Analysis } & 98\end{array}$

Codebook Development Process 99

$\begin{array}{ll}\text { Coder Training } & 106\end{array}$

Inter-Rater Reliability $\quad 114$

$\begin{array}{ll}\text { Pilot Inter-Rater Reliability } & 118\end{array}$

Study Inter-Rater Reliability 121

$\begin{array}{ll}\text { Thematic Analysis } & 122\end{array}$

$\begin{array}{ll}\text { Ethical Issues } & 129\end{array}$

Ensuring Validity and Reliability 130

$\begin{array}{ll}\text { Validity } & 130\end{array}$

$\begin{array}{ll}\text { Reliability } & 131\end{array}$

CHAPTER IV: STUDY RESULTS 133

Information Received Regarding Communication Approaches 136

Rating of Information Received 136

Ease of Information Seeking 137

Information Given 139



Source of Information 141 
Who Provided the Information

Sources of Information: People and Resources

People Source: Medical, Cultural, and Early Intervention Professionals

Medical Professionals

Cultural Professionals

Early Intervention Professionals

Self (Research/Prior Knowledge)

Resources: References Items and Places

Influencing Factors

The Decision-Making Process

Factors Influencing Decision-Making

Additional Disabilities

Input from Others and Self

Self: Wishes, Self-Desires, Values, Decisions

Access to Opportunities

Implications of a Reference Chart

Benefits: Access to Information

Drawbacks: Access to Information

Thematic Analysis 
Information Received

$\begin{array}{ll}\text { Sources of Information } & 172\end{array}$

$\begin{array}{ll}\text { Factors Influencing Decision Making } & 174\end{array}$

$\begin{array}{ll}\text { Implications of a Reference Chart } & 177\end{array}$

$\begin{array}{ll}\text { Implications of Current Practice } & 178\end{array}$

Study Limitations and Recommendations for Future Research 179

$\begin{array}{ll}\text { Limitations } & 179\end{array}$

$\begin{array}{ll}\text { Future Research } & 182\end{array}$

$\begin{array}{ll}\text { Conclusion } & 182\end{array}$

$\begin{array}{ll}\text { REFERENCES } & 184\end{array}$

APPENDIX A: REFERENCE CHART 202

$\begin{array}{ll}\text { APPENDIX B: COPYRIGHT PERMISSION } & 203\end{array}$

$\begin{array}{ll}\text { APPENDIX C: SURVEY } & 204\end{array}$

$\begin{array}{ll}\text { APPENDIX D: INTERVIEW QUESTIONS } & 211\end{array}$

$\begin{array}{ll}\text { APPENDIX E: INTERVIEW CONSENT } & 212\end{array}$

$\begin{array}{ll}\text { APPENDIX F: SURVEY CONSENT } & 215\end{array}$

$\begin{array}{ll}\text { APPENDIX G: RECRUITMENT LETTER } & 217\end{array}$

$\begin{array}{ll}\text { APPENDIX H: PERMISSION LETTERS } & 218\end{array}$ 


\section{TABLES}

Table

Page

1. Summary of JCIH Guidelines for Early Intervention Programs 28

2. Best Practice Principles for Family-Centered Early Intervention (FCEI)

3. Comparison of Recommended Practices: Informed Choice, Decision-making and Sharing Information

4. Studies Focusing on Factors Influencing Parents' Choice of Communication

5. Literature Review Thematic Analysis

6. Communication Approaches

7. Survey Respondent Demographic Information

8. Crosswalk of Research, Survey, and Interview Questions

9. Codebook for Training and Coding

10. Codebook Code Numbers and Revisions

11. Inter-Rater Reliability Coding by Statement

12. Percent of Agreements and Disagreements Among Coders

13. Inter-Rater Reliability from Pilot Coding

14. Inter-Rater Reliability of Study Coding

15. Thematic Analysis Categorization

16. Frequency of Codes within Survey and Interview Responses

17. Ranking of Information Received

18. Ease of Receiving Information

19. Information Received from Whom 
21. Decision-making Regarding Communication Approaches by Percentage

22. Code Frequency and Prevalence for Influences

23. Factors that Influence Parent Communication Decisions for their Deaf or Hard of Hearing Child

24. Study Findings

25. Theme Comparison: Literature Review and Current Study

26. Findings Compared to Recommended Practice 


\section{FIGURES}

Figure

Page

1. Total Number of Infants and Toddlers served under IDEA Part C 8

2. Percentage of Infants and Toddlers Served Under IDEA Part C by Setting 9

3. Parent Satisfaction Early Intervention Outcomes 10

4. Number of U.S. States and Territories with $50 \%$ or More of Infants and Toddlers Meeting Indicator 3 Expectations

5. Flowchart of Early Intervention Process in Illinois 13

6. Parent Satisfaction with Early Intervention Outcomes: IL vs. National 15

7. Flowchart of Literature Search 46

8. Self-Reported Ethnicity/Race of the Child 90

9. Reported Current Unaided Hearing Level of the Child, Right Ear and Left Ear 91

10. Reported Hearing Technology Currently Being Used by the Child, Right Ear and Left Ear 92

11. Additional Delays as Reported by Parents 93

12. Coder Training Process 107

13. Inter Rater Reliability Flowchart 119

14. Histogram of Code Frequencies in Pilot 120

15. Flowchart of Thematic Analysis Process 124 


\section{CHAPTER I: INTRODUCTION}

For many parents, learning about information, resources, supports, networking, and educational opportunities for their child with a disability is a new and complex journey. Due to the advances in federal and state law mandating early intervention services for these families, parents now have more resources available to them than ever before. This chapter explores the guiding factors in the development of early intervention, current recommendations and practices in parent support, and the process of information seeking by parents across all disability areas including those with deaf and hard of hearing children. Parent informational needs and sources of information are presented along with a discussion of informed choice, decision-making and how providers can support parents in this process while remaining focused on family-centered practices.

When confronted with the unknown, a natural human instinct is to seek out information. Expecting and new parents often search for and seek out information regarding how to care for and raise their newborn: feeding, sleeping, clothing, disciplining, and purchasing equipment such as cribs, car seats, or highchairs (Cowan \& Cowan, 2000). However, when a child is identified as having a disability at birth or during the early childhood years, this often sets parents into unfamiliar territory in which they must now learn about the disability and how to support their child. Statistics released by the Centers for Disease Control and Prevention (CDC, n.d.) show that one in 33 babies (about 120,000 total) in the United States are born with a birth defect each year. Of the total U.S. population, $0.8 \%$ of children under age 5 have a disability and $5.4 \%$ of children ages 5-17 have a disability (Kraus, 2017). In looking at the data for babies identified as deaf or hard of hearing, the most recent data released by the CDC in 2017 indicates that there is a prevalence rate of 1.7 per 1,000 babies screened, which translated to approximately 6,537 babies. 
In the United States, federal mandates assist parents of children with disabilities as they seek information and support in raising their child with a disability, including those who are identified as deaf or hard of hearing.

\section{Early Intervention for Infants and Toddlers with Disabilities}

Education for children with disabilities was first addressed in the passage of Public Law 94-142 or Education of All Handicapped Children Act (EAHCA) in 1975. At that time, the focus was only on school-aged children and their rights to access a free and appropriate public education. Early intervention, or the focus on infants and toddlers with disabilities, did not appear in special education law until 1986 as part of the EACHA reauthorization that recognized the need to support infants and toddlers with disabilities and their families (EACHA, 1986). In 1990, the name was changed to what is now more commonly known as the Individuals with Disabilities Education Act (IDEA) with early intervention covered under Part C of the IDEA (EACHA, 1990).

A 2016 report from the U.S. Department of Education stated there was a total of 723,543 infants and toddlers receiving early intervention services under Part C of IDEA in the United States and outlying areas (U.S. Department of Education, Special Education-Technical Assistance on State Data Collection- IDEA General Supervision Enhancement Grant, 2016). While the IDEA stipulates how infants and toddlers will be identified, deemed eligible for services, and served, there are no specific parameters regarding the delivery of early intervention services. However, it is required that early intervention services occur within the natural environment, which is typically the home or community settings frequented by infants and toddlers without a disability (IDEA, 2004). In addition, Part C specifically states that early intervention includes "family training, counseling, home visits; special instruction; speech- 
language pathology and audiology services, and sign language and cued language services; occupational therapy; physical therapy; psychological services; service coordination services; medical services only for diagnostic or evaluation purposes; early identification, screening, and assessment services; health services necessary to enable the infant or toddler to benefit from the other early intervention services; social work services; vision services; assistive technology devices and assistive technology services; and transportation and related costs (IDEA, 2004, $\S 1432(4)(\mathrm{E}))$.

Among other things, Part $\mathrm{C}$ of IDEA stipulates that each child and family choosing to receive early intervention services must have an Individual Family Service Plan (IFSP) that specifies how the needs of the child and family will be met, in addition to listing targeted outcomes for both the child and the family. Specifically, to address family needs, the IFSP must include a "family-directed assessment of the resources, priorities, and concerns of the family and the identification of the supports and services necessary to enhance the family's capacity to meet the developmental needs of the infant or toddler" (IDEA, 2004, §1436(a)(2).

Part C of IDEA does not specify the manner in which early intervention must be carried out. Instead, that is left up to each state and their designated lead agency responsible for implementing early intervention services and ensuring compliance with the mandates. To support parents as they seek to learn about the disability and how it affects their child, family training is listed as a potential early intervention service in Part $\mathrm{C}$ of the IDEA. Family training can encompass a wide range of services and should be determined based on the individual needs, as identified by each family. Although there are no specifics as to what family training might look like, IDEA stipulates that family training be provided by qualified providers "to assist the family 
of an infant or toddler with a disability in understanding the special needs of the child and enhancing the child's development” (IDEA, 2004, §303.13(b)(3)).

\section{Early Intervention Recommended Practices for Working with Families of Children with Disabilities}

Prior to federal mandates for early intervention, professionals were viewed as the experts who needed to train the parents of a child with a disability (Rhoades, 2010). With the establishment of IDEA Part C in 1986 and the requirement to provide services in the natural environment, there has since been a gradual shift in service delivery, moving away from the "professionals as experts" model to a shared partnership between professionals and families (Keen, 2007; Workgroup on Principles and Practices in Natural Environments, 2008). Since the early 1990's, the Division for Early Childhood (DEC), a Division of the Council for Exceptional Children, has recognized the benefits of a family-centered approach within early intervention (Epley et al., 2010). The DEC Recommended Practices in Early Intervention/Early Childhood Special Education (2014) list guidelines for providers as they work with families of young children with disabilities. These recommendations emphasize the use of practices known to enhance the outcomes of children and families with disabilities, are supported by research, and applicable across all disability areas (DEC, 2014). Active family involvement is strongly emphasized throughout the early intervention process, from the initial assessment and development of the service plan through the provision of intervention services. The guidelines recommend that service delivery practices revolve around three themes: family-centered, family capacity-building, and family and professional collaboration (DEC, 2014). 


\section{Family-Centered Practices}

These practices specify mindfulness and respect of individual families, recognition that each situation is unique and ever-changing, encouragement of active family engagement, focus strengthened family functioning, and responsiveness to specific concerns and priorities of the family (DEC, 2014; Dunst \& Espe-Sherwindt, 2016). A core component of family-centered practice includes family choice and decision-making, with information shared by qualified personnel in an unbiased manner as a method to support families in the process of making informed decisions regarding the care of their child with a disability (Davis \& Gavidia-Payne, 2009; DEC, 2014; Dunst \& Espe-Sherwindt, 2016; Woods et al., 2011). The Early Childhood Technical Assistance Center (ECTA) also addresses the concept of providing families with "complete and unbiased information in order for them to make informed choices and decisions" as a part of their Family Centered Practices Checklist available on their website (ECTA, n.d.).

The concept of family-centered practice, including the practice of information sharing, has been shown to positively impact family outcomes. Information sharing supports a higher family quality of life and impacts overall family outcomes (Davis \& Gavidia-Payne, 2009), is deemed to be an effective source of support (Eleweke et al., 2008; Hiebert-Murphy et al., 2011), and alleviates some of the stress of the disability (Eleweke et al., 2008). This process can be driven by other parents, such as parent-to-parent support; by professionals in the form of training, education, or information sharing; or adults with disabilities (Eleweke et al., 2008; Epley et al., 2010).

\section{Family Capacity-Building Practices}

The DEC (2014) defines family capacity-building practices as activities that include opportunities and experiences that allow families to learn new skills and increase their 
confidence in their ability to effectively support and parent their child with a disability. This can be done using coaching and teaching as a process in which "one person shares information or skills with another person with the explicit intention that learning will occur" (Woods et al., 2011, p. 380). The emphasis should be on the desired goals of the family; what kinds of information, supports, resources, and skills are needed to achieve them; and how the providers can support that process (Raver \& Childress, 2015). Parents also report higher satisfaction and feelings of efficacy when interventions are embedded within their daily routines (Kingsley \& Mailloux, 2013). In fact, 67 out of 87 families of deaf and hard of hearing children said they wanted supports from professionals to learn the skills necessary to work with their child (Jackson, 2009). Using a coaching and teaching model to support parents can be an effective approach to increasing parental self-efficacy and confidence in applying new skills to support the growth and development of their child (Roberts et al., 2014).

\section{Family and Professional Collaboration}

Finally, the consideration of family and professional collaboration opportunities ensures positive relationships between providers and families and allows a shared focus on family outcomes to support family capacity and overall child development (DEC, 2014). This concept is supported throughout the literature as a benefit to families (DesGeorges, 2018; Dunst \& EspeSherwindt, 2016; Hiebert-Murphy et al., 2011; Sass-Lehrer, 2018). In one study, several parents emphasized responsiveness and listening as key behaviors from providers to establish trust between the parent and professional (Hiebert-Murphy et al., 2011). Strong relationships between families and professionals with mutual respect, trust, and honesty can be an integral part of laying the groundwork for shared decision-making practices (Keen, 2007; Sass-Lehrer, 2018). 


\section{Current Trends in Early Intervention}

Since the implementation of IDEA, states have made significant progress in ensuring family involvement within early intervention. States have also increased activity related to public awareness and early identification of children with disabilities, including those considered at-risk (Trohanis, 2008). IDEA requires individual states to develop State Performance Plans and Annual Performance Reports to evaluate its success in implementation of early intervention services. Implementation is measured against various indicators that include measures of child and family outcomes, along with compliance with IDEA parameters. In the 41st Annual Report to Congress on the Implementation of the Individuals with Disabilities Education Act, it was reported that 386,155 infants and toddlers were served in the U.S. 50 states, plus DC, under IDEA Part C in 2017, comprising 3.2 percent of the total population up to age three (U.S. Department of Education, 2020). Figure 1 illustrates the data that the US Department of Education reported for 2013-2017and shows the total number of infants and toddlers with disabilities served from 2013-2017 has steadily increased. The most recent data from 2017 shows that of those being served under Part C, 89.6 percent received their services primarily in the home, 7.6 percent were based in community settings, and 2.8 percent were in other settings (see Figure 2) (U.S. Department of Education, 2020). 


\section{Figure 1}

Total Number of Infants and Toddlers Served Under IDEA Part C

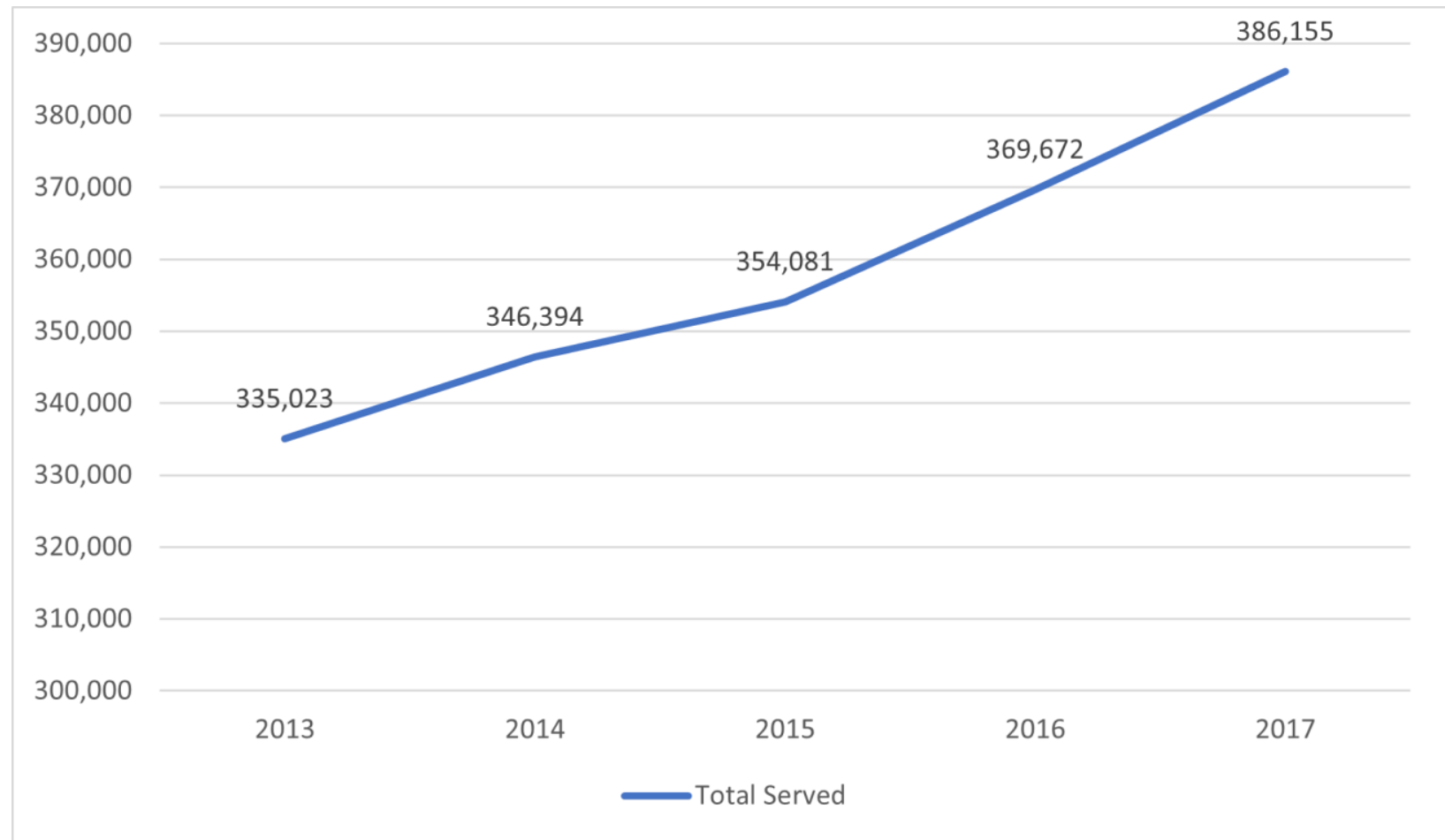




\section{Figure 2}

Percentage of Infants and Toddlers Served Under IDEA Part C by Setting

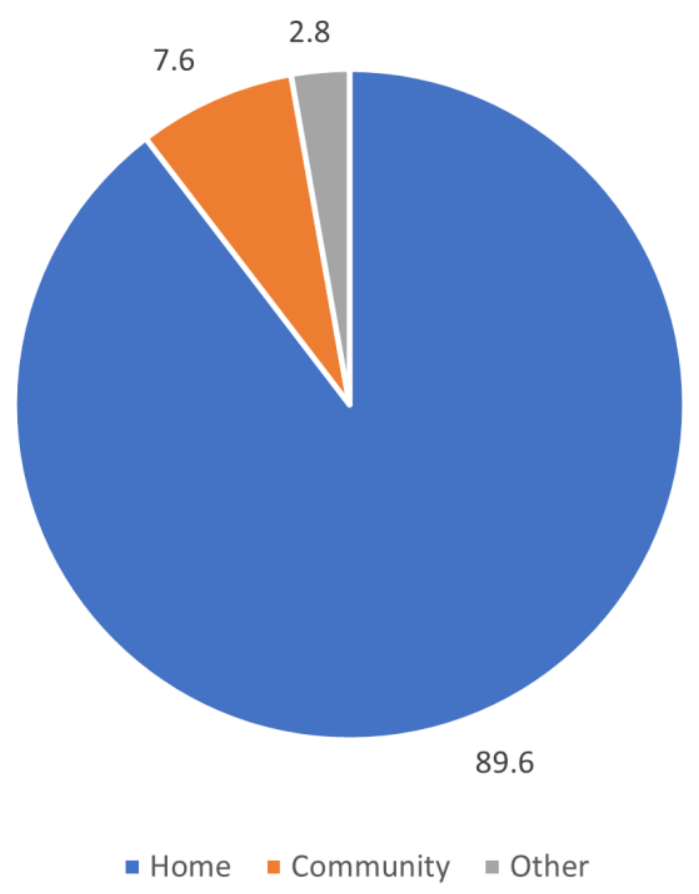

The Early Childhood Technical Assistance Center (ECTA) and Center for IDEA Early Childhood Data Systems collect information annually regarding parent satisfaction with early intervention, also known as Part C, Indicator 4. This national survey asks parents to report their satisfaction with three outcomes: (a) knowing their rights, (b) communicating their child's needs, and (c) helping their child develop and learn. The most recent data obtained from ECTA \& Center for IDEA Early Childhood Data Systems (2020) for federal fiscal years 2013-2017 show steady, positive trends in parent satisfaction with early intervention services, with the annual outcomes ranging from $88-92 \%$ satisfaction (see Figure 3). When considering the relationship between family support and family outcomes, parent satisfaction is higher when they feel supported (Kyzar et al., 2012). However, neither the literature nor the legal statues (EACHA, 
IDEA) indicate a standard definition of either family support or family outcomes. As a result, outcomes, such as the ones indicated in Figure 3, should be viewed with caution. Regardless, early intervention providers are encouraged to continue to examine how they provide support to the families they serve to ensure high levels of parental satisfaction.

\section{Figure 3}

\section{Parent Satisfaction Early Intervention Outcomes}

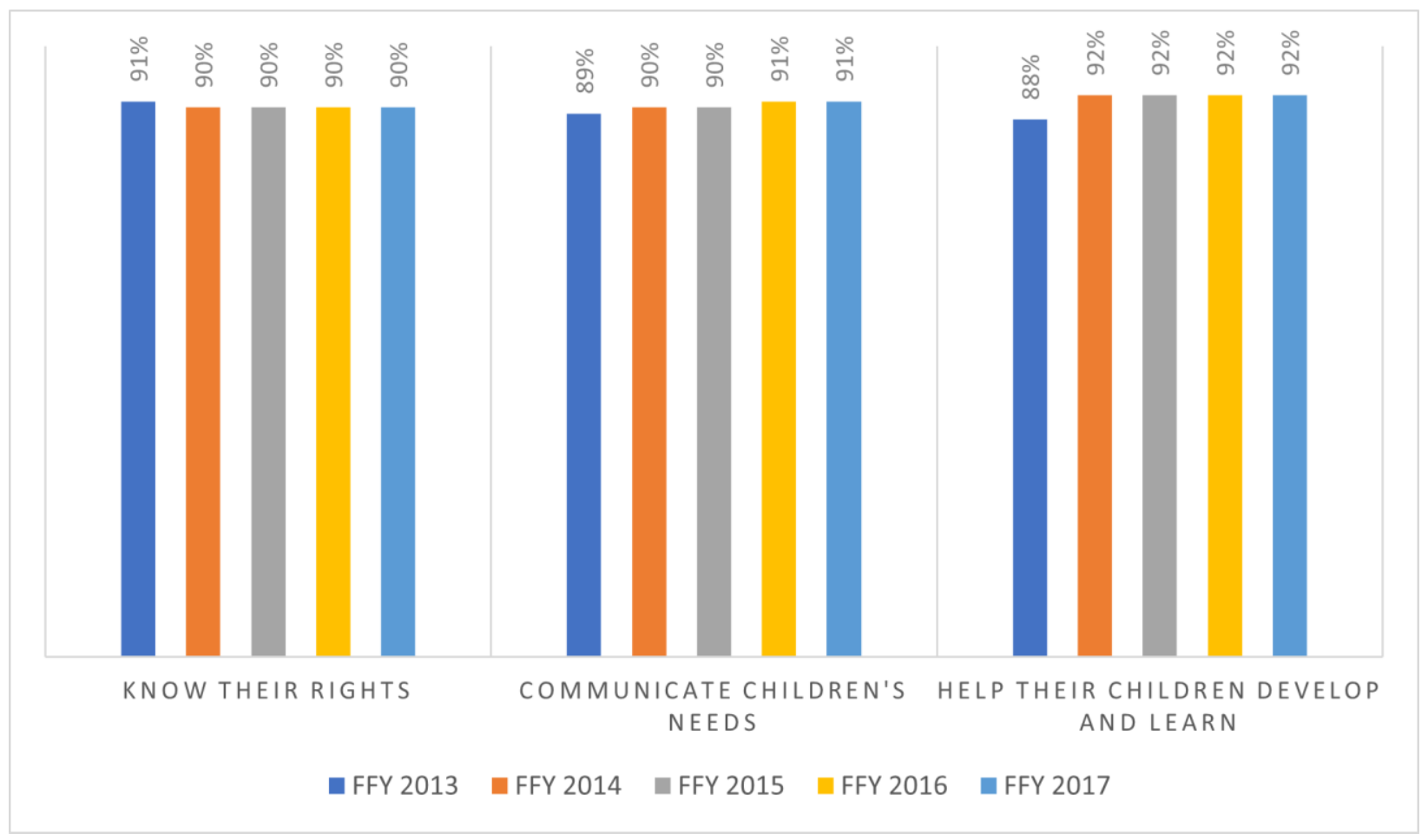

Outcomes of infants and toddlers served under IDEA Part $\mathrm{C}$ are measured by a variety of indicators as established by the U.S. Department of Education Secretary as part of each state's performance plan to monitor compliance with IDEA (U.S. Department of Education, 2020). Indicator 3 measures infants and toddlers meeting age appropriate expectations in (a) positive social emotional skills, (b) acquisition and use of age appropriate early language, literacy, and communication skills, and (c) use of appropriate behaviors to meet their needs (U.S. Department 
of Education, 2020). Figure 4 shows a comparison of the number of states reporting percentage of infants and toddlers exhibiting age appropriate skills upon entrance and exit from Part C, which indicates a positive impact of early intervention services. However, this same report shows that only 31 out of 56 total states and territories (including DC, American Samoa, Guam, Northern Mariana Islands, Virgin Islands, and Puerto Rico), or 55\%, met the implementation requirements of Part C (U.S. Department of Education, 2020).

\section{Figure 4}

Number of U.S. States and Territories with 50\% or More of Infants and Toddlers Meeting

\section{Indicator 3 Expectations}

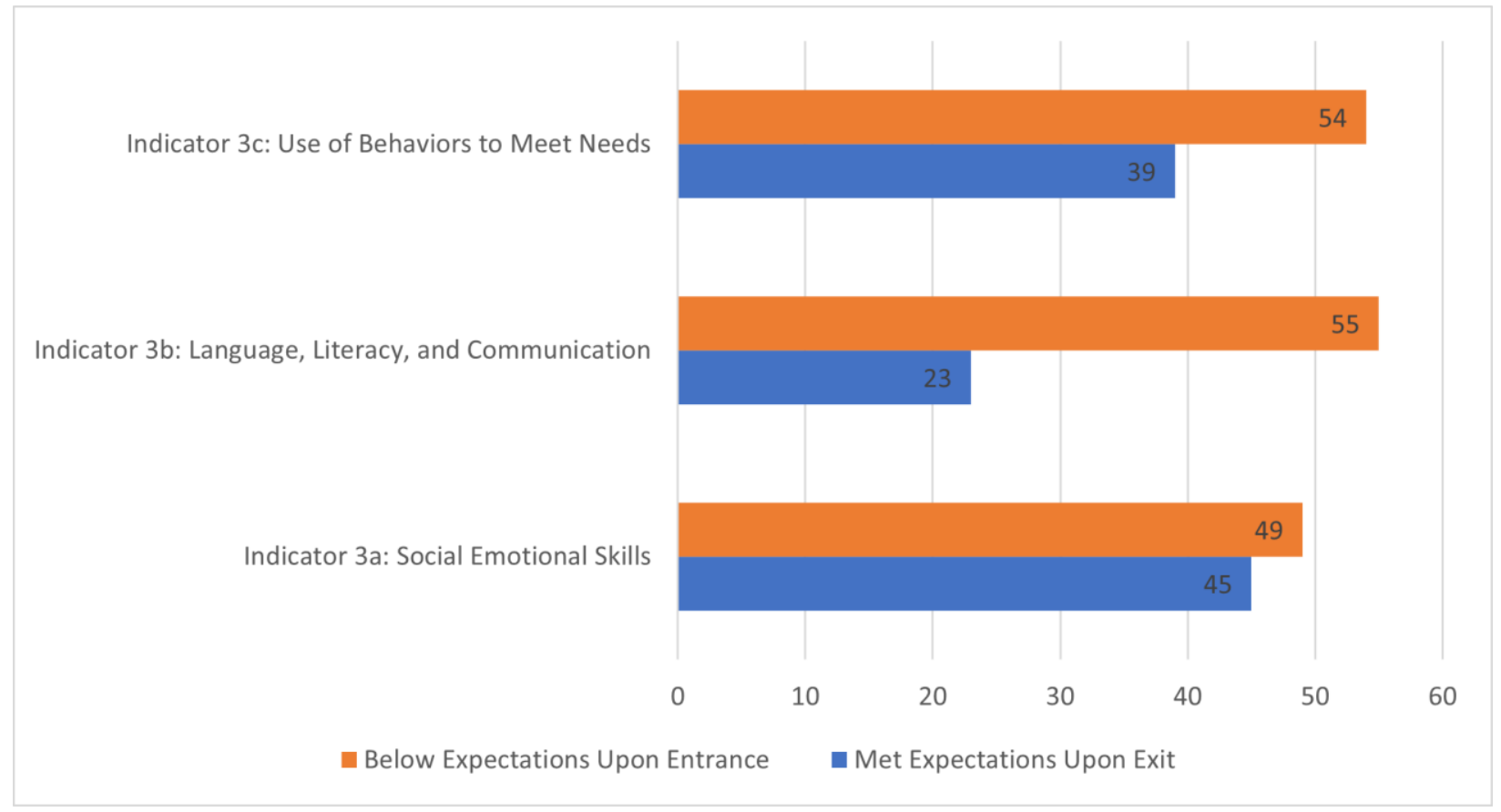

The above data from the 41st Annual Report to Congress on the Implementation of the Individuals with Disabilities Education Act is inclusive of all disabilities. When considering current trends in early intervention for infants and toddlers who are deaf and hard of hearing, the history of universal hearing screening mandates tells a compelling story. Since states 
implemented newborn hearing screenings in the early 2000 's, the average age of identification has dropped from $2 \frac{1}{1} 2$ to 3 years old to less than 6 months old (CDC, 2017b; Porter et al., 2018; Shulman et al., 2010). The National Center for Hearing Assessment and Management (NCHAM) provides technical assistance and support for states as they work to implement and improve Early Hearing Detection and Intervention mandates. One of NCHAM's primary goals is to ensure that children with hearing loss are screened by one month of age, diagnosed by three months of age, and begin receiving intervention services by six months of age, commonly known in the field as the 1-3-6 Goals (NCHAM, n.d; Subbiah et al., 2018). After screening, 6,537 babies were identified as deaf or hard of hearing in 2017 in the U.S. (CDC, 2017b). From there, approximately $90.8 \%$ of those babies were referred for early intervention services under Part C of Individuals with Disabilities Education Act and $65.1 \%$ of them were enrolled in local early intervention programs and receiving support services (CDC, 2017b). However, there is currently no publicly available national data that indicates parental satisfaction with early intervention outcomes specific to families with deaf and hard of hearing children.

\section{Current Practice in Early Intervention in Illinois}

In Illinois, early intervention for infants and toddlers with disabilities is overseen by the Illinois Department of Human Services (IDHS) and their mission statement is stated as follows: to assure that families who have infants and toddlers, birth to three, with diagnosed disabilities, developmental delays or substantial risk of significant delays receive resources and supports that assist them in maximizing their child's development, while respecting the diversity of families and communities. (IECAM, n.d.)

As seen in Figure 5, after a child is found to be eligible for early intervention services, families work with a service coordinator and team of appropriate professionals to develop their 
individualized family service plan (IFSP), and then begin receiving services based on the agreedupon plan (Fowler, 2011). Note that if a child is not found eligible for services, they may qualify for monitoring services.

\section{Figure 5}

Flowchart of Early Intervention Process in Illinois

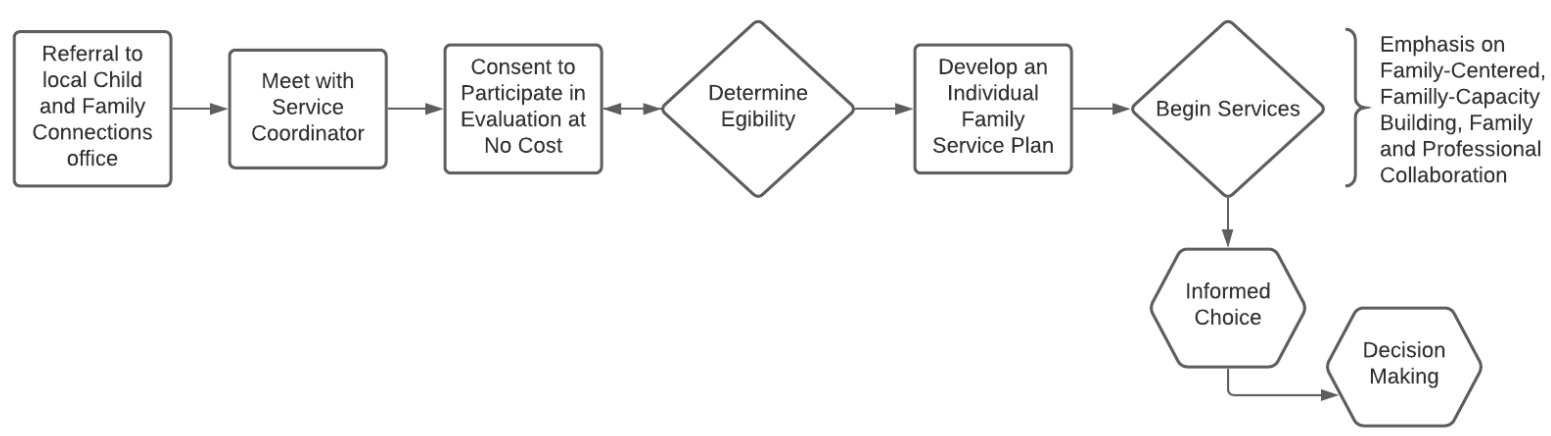

Note. Adapted from Fowler, 2011

In Illinois, the latest data shows that a total of 40,518 infants and toddlers are receiving early intervention services under Part $\mathrm{C}$ and less than $1 \%$ are identified as deaf or hard of hearing (CDC, 2017b; U.S. Department of Education, Special Education-Technical Assistance on State Data Collection- IDEA General Supervision Enhancement Grant, 2016). Out of the 312 infants and toddlers identified as deaf or hard of hearing, only 176 , or $56.4 \%$ are enrolled in early intervention services. In a search for parent satisfaction with early intervention, no information was found specific to Illinois. At this point in time, the federal government does not mandate that individual states report the rate of successfully achieved individual family service plan outcomes from early intervention. However, states are required to collect data on Part $\mathrm{C}$ families to determine parent satisfaction with early intervention services in these three areas: knowing their rights, effectively communicating their child's needs, and helping their children develop and 
learn (see Figure 3). In Illinois, the last available data (fiscal year 2015) indicated that families reported satisfaction rates of 74.14\%, 79.03\%, and 77.30\% respectively (IDHS Bureau of Early Intervention, 2016). This should be viewed with caution as this was based on an $8.27 \%$ return rate of the survey, sent to 20,981 families statewide. This is also across all disability areas, indicating that parent satisfaction rates are even lower for those with deaf and hard of hearing infants and toddlers as it is presumed to be a smaller subset of the total disability numbers. Regardless, the Illinois parent satisfaction rates are lower than the national satisfaction rates of 90\%, 91\%, and 92\% respectively (see Figure 6) (ECTA \& Center for IDEA Early Childhood Data Systems, 2020). In addition, the U.S. Department of Education collects implementation data to determine individual state compliance with Part $\mathrm{C}$ requirements across all disability areas. In the most recent report to Congress, Illinois has failed to meet all the requirements and has needed assistance in implementation of Part C mandates for two consecutive years (U.S. Department of Education, 2020). 


\section{Figure 6}

Parent Satisfaction with Early Intervention Outcomes: IL vs. National

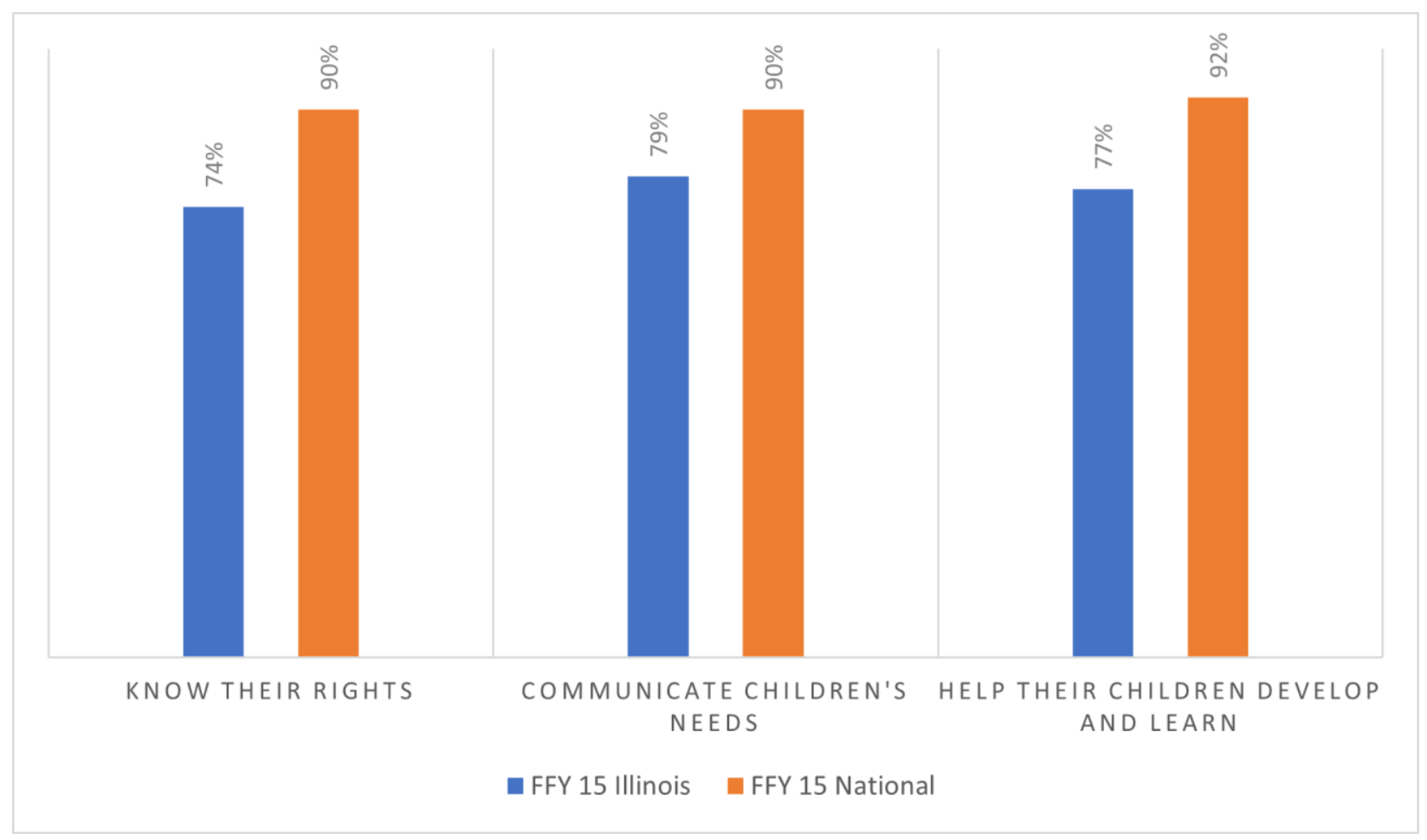

Current practices in Illinois related to professional development and credentialing requirements indicate that early intervention providers are trained to adhere to the Principles of Early Intervention (IDHS Division of Family and Community Services \& Bureau of Early Intervention, 2016, p. 1) for their service delivery, as listed in the Illinois Early Intervention Provider Handbook. Upon closer examination, it appears that these principles incorporate many of the DEC Recommended Practices (2014) as well as stipulations from IDEA Part C (2004) and recommendations from the National Association for the Education of Young Children (Schertz et al., 2011). Within these principles, there is a strong emphasis on collaborative relationships between parents and providers, family-centered intervention, and active participation by parents within interventions integrated into family routines and provided by qualified personnel. These 
Principles of Early Intervention have been adopted by the Illinois Interagency Council on Early Intervention and are also listed in The Illinois Early Intervention Program: A Guide for Families (Fowler, 2011), which is given to families upon entering the early intervention system. In addition, the Illinois Early Intervention Provider Handbook encourages early intervention providers adhere to the DEC Recommended Practices (2014) (IDHS Division of Family and Community Services \& Bureau of Early Intervention, 2016). Since a main component of familycentered practice revolves around information sharing and decision-making, the next step would be to investigate this process.

\section{Information Sharing and Decision-Making}

Providing families with information that is unbiased and comprehensive allows the family to make an informed choice based on their own unique circumstances as well as giving them ownership, thereby increasing the likelihood that they will follow through with their selection in a consistent manner (DesGeorges, 2018). Informed choice is defined as "one where all the available information...is weighed up and used to inform the final decision" (Marteau et al., 2001, p. 100). The resulting decision often aligns with existing values of the person making the decision (Marteau et al., 2001). A brief search through the literature indicates that informed choice is primarily considered within the medical field, such as diabetes care, vaccinations, cardiovascular health, and various medical screenings (Edwards \& Elwyn, 2009). Since parents of children with disabilities often have medical needs or interventions that require choices and decisions to be made, such as asthma management or chronic illness care (Adler et al., 2015), the concept of informed choice within the field of disabilities warrants a closer look.

In a systematic literature review on parents of deaf children and their decision-making, conducted by Porter and colleagues (2018), a number of studies mentioned the concept of 
informed choice, however, those studies did not explicitly define informed choice or explain what the process of informed choice looked like. In the international consensus statement on best practices in family-centered early intervention for deaf and hard of hearing children, providers are reminded that "informed choice is not synonymous with information that is neutral or functionally descriptive. Rather, evaluative information is essential in that it draws attention to the various risks, benefits, and uncertainties related to particular options" (Moeller et al., 2013, p. 434). It is important to remember that information does not equate understanding. While parents have the information, they may not understand the information and need some support in dissecting and applying it to their own individual situations (Porter et al., 2018; Young et al., 2006). As a result, the concept of providing comprehensive, inclusive information to parents is much more than the act of just physically giving it. Providers must be able to work with families to determine what their goals and priorities are, match them with relevant information, guide them in understanding it, and support them in this process. This requires providers to keep their own biases private. Consequently, it is essential that providers be aware of their own beliefs, attitudes, and actions, as they have the potential to strongly influence families. In fact, one study reported that $74 \%$ of families of deaf and hard of hearing children indicated that professional attitudes had a large positive influence on their involvement with parents reporting active listening, empathic behaviors, reflection, partnership, and shared decision-making as behaviors of high influence (Davis \& Gavidia-Payne, 2009; Jackson, 2009). However, some mentioned pressure from professionals to select specific strategies over others (Jackson, Traub, \& Turnbull, 2008).

The concept of complete and unbiased information is a component of the DEC (2014) Recommended Practice guidelines and reinforced in several Practice Guides available on the 
Early Childhood Technical Assistance (ECTA) website (ECTA, 2018). The Supporting Family Member Informed Decision-making Practice Guide highlights informed decision-making as a three-step process that requires "identifying (1) parent concerns and priorities, (2) the support and resources for addressing concerns and priorities, and (3) the sources of those supports and resources" (ECTA, 2018, p. 1). Following this three-step process can guide providers in providing objective and comprehensive information relevant to each family's unique situation. Making decisions is a flexible process, one that is affected by the situational needs of the child and family. An effective provider is able to support the family throughout that process (Moeller et al., 2013). Parents of children with disabilities are often required to gather information and make numerous decisions, decisions which sometimes shape the course of the child's path or identity (Mascia \& Mascia, 2019). Some parents have reported feeling pressured to make various decisions quickly while others felt a lack of support in the process (Decker \& Vallotton, 2016). As such, professionals should strive to share information in line with family-centered practices as they determine what kinds of information parents are seeking and consider how they will provide it.

Once the information is received, often the next step is to make a decision related to said information. The process of decision-making has been studied throughout the years, with some of the earlier research rooted in the concept of problem solving and human judgement (Payne, 1976). The process of making a decision can be described as either systematic (deliberate and intentional) or heuristic (automatic and instinctive) (Chaiken \& Ledgerwood, 2012; HerreraViedma et al., 2007; Payne, 1976; Porter et al., 2018). Systematic decision-making is described as a very analytical approach in which all of the information is thoroughly dissected in an attempt to fully understand the details and implications of the information whereas heuristic 
processing has a lighter cognitive load and is often more instinctive (Chaiken \& Ledgerwood, 2012; Payne, 1976). The method of processing information and then ultimately making a decision is directly related to the complexity of the task and there are differences in how individuals process the information given (Herrera-Viedma et al., 2007; Payne, 1976). The harder the task, the more difficult it is to process the resulting information and make a decision. Thusly, it is difficult to quantify and present a precise model of decision-making. To further complicate this process, in a group decision-making scenario, if the people involved do not have a full understanding of the problem to be solved, they may present a preference based on incomplete or missing information (Herrera-Viedma et al., 2007). However, there has been interest in developing models of shared decision-making that can be used in a clinical setting between practitioners and patients (Elwyn et al., 2012). Elwyn and colleagues (2012) lay out a process that can be used to foster a collaborative relationship between the provider and the patient which centers on a three-step model: Introducing Choice (being aware of available options), Describing Options (more detailed information about options) and Preference Exploration (discussing preferences and making decisions). This concept of shared decisionmaking is highlighted in the DEC (2014) Recommended Practices for working with families as part of the core component of family-centered practices, family and professional collaboration and is woven throughout the IDEA mandates for providing early intervention.

\section{Parent Information Needs Across All Disability Areas}

Much research has been done on the information needs of parents of children with disabilities and chronic health issues (Adler et al., 2015; Alsem et al., 2017; Davis \& GavidiaPayne, 2009; Jackson, Cheater, \& Reid, 2008). A systematic review of 149 studies focusing on parents making decisions regarding their child's health care needs uncovered the most prevalent 
theme: the need for information (Jackson, Traub et al., 2008). This theme was further categorized into four sub-themes related to information: content, mode of delivery, source, and timing. Specifically, parents expressed a desire to receive information on all available options in a balanced approach, in multiple formats, from a variety of sources, and in a timely manner with opportunities to process the information prior to making decisions (Jackson, Cheater et al., 2008). Often, parents relied heavily on early intervention service coordinators or case managers to provide this information to them (Hiebert-Murphy et al., 2011). In fact, a study of 64 families of children with developmental disabilities indicated that "professional support was found to be one of the strongest predictors of FQOL (family quality of life)" (Davis \& Gavida-Payne, 2009, p. 159).

Parents of children across all disability areas are seeking information and services (Douglas et al., 2017; Hiebert-Murphy et al., 2011; Resch et al., 2010). The most prevalent types of information that parents are seeking often include information about the condition/illness, types of support available, and treatment options, as well as the specific needs of their child (Adler et al., 2015; Decker \& Vallotton, 2016; Douglas et al., 2017). Families of children with intellectual disabilities primarily desired information about the disability, specific needs of their child, and supports and services available (Douglas et al., 2017). Parents of children with physical disabilities often sought out professional information (e.g. disability-specific information, available services, and supports) and experience-based knowledge (e.g. daily life experiences of living with the disability) (Alsem et al., 2017).

Unfortunately, while parents of children with disabilities desire information and seek out educational opportunities to learn more about supporting their child, many share stories of the struggles to actually obtain the information (Eleweke et al., 2008; Resch et al., 2010). Many 
parents report receiving contradictory information and go as far as to suggest that may be a reason for the varied outcomes within early intervention, specifically for families of deaf and hard of hearing children (Decker \& Vallotton, 2016). Others shared that the types of information provided by professionals appeared to be "haphazard" (Douglas et al., 2017, p. 2604), lacking in basic foundational information about the disability.

\section{Parent Information Needs for Children Who Are Deaf or Hard of Hearing.}

Similar to other disabilities, parents of children who are deaf and hard of hearing also desire information. It is important to identify what parents perceive to be needed and how that should be an integral part of services and supports available to them (DesGeorges, 2018; Fitzpatrick et al. 2008). Access to unbiased and accurate information is critical for parents of children who are deaf and hard of hearing as evidenced through one study of 419 families showing $84.2 \%$ ranked this as very important (Jackson, 2011).

A large number of researchers have completed cross-sectional surveys and structured interviews with a variety of families throughout the world, including the United States, Africa, and Canada (Fitzpatrick et al., 2008; Jackson, 2009; 2011; Zaidman-Zait, 2007). While there was a mixture of families in terms of socioeconomic status, marital status, ethnicity, and age of the child with the hearing loss across studies, many parents expressed a need for information about multiple issues: the identified hearing loss, impacts of the hearing loss, communication support, available resources, access to other families with similar experiences, and access to older deaf or hard of hearing children and adults (Fitzpatrick et al., 2008; Jackson, 2009; 2011; Zaidman-Zait, 2007). Out of 87 families of deaf and hard of hearing children, more than half of them desired access to informational resources across 16 different categories, including communication and language development as well as the impact of hearing loss (Jackson, 2009). 
For parents of deaf and hard of hearing children, most often the first decisions they make revolve around communication and technology, and these decisions can change over time (SassLehrer et al., 2016). Families have indicated that one of the most challenging and stressful decisions they make is that of a communication mode to use with their child (Sass-Lehrer, 2018). Several sources state that effective communication between parents and their child is a strong indicator of success in all areas of child development, therefore it is imperative that families receive accurate and unbiased information related to the communication and educational options in addition to the child's hearing status and prognosis (Eleweke et al., 2008; Knoors, 2015; Marschark, 2018; Sass-Lehrer et al., 2016). In addition to communication information, some parents expressed a desire in learning how to recognize signs of progress and success across all developmental areas in their child (Zaidman-Zait, 2007).

Very little effort has been spent on the types of information parents actually receive and who gives them that specific information (Decker \& Vallotton, 2016). While parents were largely satisfied with their early intervention experiences, many did express the desire for continuous, additional information, often specific to communication and hearing loss (Decker \& Vallotton, 2016; Jackson et al., 2010). One study of 17 families noted that there were strengths in receiving supports from audiology and therapy services but service coordination, information about resources and prognosis, and supports from other parents were lacking (Fitzpatrick et al., 2008). For many parents of deaf and hard of hearing children, the most common decisions that are made early are related to communication and language development, which is recognized by many in the field as a prime factor in early language acquisition (Decker et al., 2012; SassLehrer, 2018). However, there is a lack of information available on effective strategies for 
sharing information on specific communication modalities with families within the wide span of opinions regarding how deaf and hard of hearing children should communicate.

\section{Sources of Information: Formal and Informal}

Parents of children with disabilities seek information from a variety of sources, both formal and informal and use these various supports as a method of coping with stress (Poon \& Zaidman-Zait, 2014). Upon entering early intervention, and even prior, families encounter numerous professionals including early intervention providers, therapists, pediatricians, disability-related medical professionals, and various disability specialists. While parents of children with disabilities may seek out various sources, the desire for information is consistent. Many parents ranked professionals as their top source of support (Alsem et al., 2017; HiebertMurphy et al., 2011; Jackson, 2011; Porter et al., 2018).

Across all disability areas, parents often sought out their primary early intervention service coordinator and relied on them to provide information about next steps as well as available services (Hiebert-Murphy et al., 2011). Parents of children with physical disabilities generally looked to medical professionals, peers, and the internet for their information (Alsem et al., 2017). For parents with deaf and hard of hearing children, they typically relied on medical professionals for information about cochlear implants and hearing devices, whereas they look to early intervention providers, therapists, and other specialists for information about communication (Porter et al., 2018).

For parents of children who are deaf and hard of hearing, many reported relying on both professional and personal connections to cope with the diagnosis and obtaining an assortment of relevant information and services (Fitzpatrick et al., 2008; Jackson, 2009; 2011; Narr \& Kemmery, 2014; Zaidman-Zait, 2007). The top four sources of support for parents of deaf and 
hard of hearing children included teachers, spouses, therapists, and deaf adults (Dowling et al., 2011).

Many parents consider informal sources of information to be a great source of information as well, with a survey of 456 parents of deaf and hard of hearing children indicating that $63.6 \%$ highly preferred to receive information through interaction with other parents of deaf and hard of hearing children (Zaidman-Zait, 2007). Other preferred information sources included the internet, parent-friendly books, deaf adults, friends, grandparents/extended family, community members, other families of children with disabilities, and taking part in intervention services (DesGeorges, 2018; Henderson et al., 2016; Hiebert-Murphy et al., 2011; Jackson, 2011; Jackson et al., 2008; McNee \& Jackson, 2012; Porter et al., 2018; Zaidman-Zait, 2007).

Parents also reported that the access to a social support network, including other parents of children with disabilities, had an impact on their stress levels, with lack of access often resulting in increased stress (Bradham et al., 2011; Dirks et al., 2016; Jackson 2009; ZaidmanZait, 2007). Furthermore, this access to a social network also impacted the family's involvement in early intervention supports for their child, with increased access often leading to increased involvement in early intervention services (Jackson, 2009).

Several sources of literature shared how parents turned to the internet to seek information and find communities with others sharing similar experiences (Alsem et al., 2017; Douglas et al., 2017; Grant et al., 2016; Jackson, 2011). Interestingly, Alsem et al. (2017) indicated that while all 15 parents in their study used the internet to some degree, only a few actually sought advice from professionals regarding reliable website sources. Many reported the internet as a helpful source of information but overwhelming (Grant et al., 2016) and noted not all the information available was accurate and often difficult to find (Douglas et al., 2017). 
Other sources of information often used by parents included workshops and parent training sessions (Grant et al., 2016; Keen, 2007). While effective, some parents reported scheduling, transportation, and childcare to be a barrier to attending these types of support services outside of the home (Grant et al., 2016). Other parents reported reading books on their child's disability, written for either parents or professionals (Douglas et al., 2017; Jackson, 2011). And finally, a small number of parents also reported using information from brochures and pamphlets that were made available to them (Jackson, 2011).

\section{Best Practice Recommendations for Working with Families of Deaf and Hard of Hearing Children}

In addition to the DEC (2014) Recommended Practices in working with families of children with disabilities, there are best practice recommendations specifically for working with families of deaf and hard of hearing children. The Joint Committee on Infant Hearing (JCIH) Principles and the Best Practice Principles for Family-Centered Early Intervention (FCEI) are the two main sets of principles commonly referenced within the existing literature.

\section{Joint Committee on Infant Hearing (JCIH)}

In 1969, the Joint Committee on Infant Hearing (JCIH) was formed and comprised of professionals from the fields of audiology, otolaryngology, pediatrics, and nursing and were responsible for making recommendations related to screening and identification of infants at-risk for hearing loss (JCIH, n.d.). Over the years, JCIH produced several position statements. In 2000, JCIH proposed recommended guidelines for Early Hearing Detection and Intervention (EHDI) programs throughout the United States (Joint Committee on Infant Hearing, American Academy of Pediatrics, \& American Speech-Language-Hearing Association, 2000). The guidelines recommended all babies diagnosed as deaf and hard of hearing begin receiving early 
intervention supports by six months of age from professionals with a background in hearing loss. Emphasizing parent supports, JCIH (2000) strongly recommended that early intervention services be family-centered and include the concept of informed choice and decision-making by providing a large variety of information and resources for parents as well as the opportunity to meet deaf and hard of hearing adults and children. The guidelines encouraged providers to ensure that families have "access to general information on child development and specific information on hearing loss and language development" (JCIH, 2000, p. 798). The concept of family-centered practice is strongly emphasized throughout the eight principles, with several focusing on family-centered planning, informed choice, family rights, and decision-making (JCIH, 2000).

The JCIH 2000 Principles encouraged professionals to be partners with parents and approach early intervention as a team with families being vital members of that team and receiving "education, counseling, and guidance" (p. 800) from professionals (JCIH, 2000). The guidelines further clarify how each professional (pediatrician, audiologist, otolaryngologist, and early intervention professionals) could forge a partnership with the families and reminds early intervention providers that they should be addressing "environmental support and family involvement" (JCIH, 2000, p. 805) with the ultimate goal to "build family support and confidence in parenting the infant who is deaf or hard of hearing" (JCIH, 2000, p. 808). Specific benchmarks with quality indicators are included, with many specifically addressing family involvement, family-centered programming, informed choice, and respecting family rights to choose (JCIH, 2000).

In 2007, these guidelines were revised to update and expand each of the eight principles due, in part, to the dramatic increase in the percentage of infants screened annually in the U.S., 
from $38 \%$ to $95 \%$ (JCIH, 2007). The concepts of family-centered planning, informed choice, family rights, and decision-making remained integrated into the principles. Refer to Table 1 to see a side by side comparison of the JCIH 2000 and JCIH 2007 principles. While the specific wording and numbering of the principles were changed, the JCIH 2007 recommendations continued to stress a team approach with family involvement and address the partnership roles between the professionals and the families. The idea of family-centered planning remained and continued to be addressed throughout the guidelines, benchmarks, and quality indicators In 2013, a "Supplement to the JCIH 2007 Position Statement" was released (Muse et al., 2013). This supplement detailed recommended best practices for early intervention professionals working with children who are deaf and hard of hearing and their families with 12 familycentered goals, the rationale for each, and recommendations to meet each goal, as well as a listing of recommended core competencies of providers (Muse et al., 2013; Yoshinaga-Itano, 2013). Shortly thereafter, the American Academy of Pediatrics (AAP) released a Statement of Endorsement supporting the supplement to the JCIH 2007 position statement (AAP, 2013; Muse et al., 2013).

Recently, in 2019, the JCIH Principles were once again updated to reflect updated best practices and expert consensus reflected within the existing literature. Considerations for teletherapy, supporting infant and family mental health, perinatal risk factors, and ongoing hearing screening into the preschool years were included; however, the main goals for early intervention as presented in 2013 remain (JCIH, 2013, 2019). Family centered planning and collaboration continue to be heavily infused within the 2019 JCIH Principles, with continued emphasis of the concepts of informed choice and decision-making. Table 1 summarizes the current JCIH Guidelines for Early Intervention Programs (AAP, 2013). 


\section{Table 1}

Summary of JCIH Guidelines for Early Intervention Programs

\begin{tabular}{|c|c|}
\hline Number & Best Practice Guideline \\
\hline 1 & Access to Timely and Coordinated Entry into EI Programs \\
\hline 2 & $\begin{array}{l}\text { Timely Access to Service Coordinators Who Have Specialized Knowledge and } \\
\text { Skills }\end{array}$ \\
\hline 3 & $\begin{array}{l}\text { Access to EI Providers Who Have the Professional Qualifications and Core } \\
\text { Knowledge and Skills }\end{array}$ \\
\hline $3 a$ & $\begin{array}{l}\text { Intervention Services to Teach ASL Will Be Provided by Professionals Who Have } \\
\text { Native or Fluent Skills }\end{array}$ \\
\hline $3 b$ & $\begin{array}{l}\text { Intervention Services to Develop Listening and Spoken Language Will Be } \\
\text { Provided by Professionals Who Have Specialized Skills and Knowledge }\end{array}$ \\
\hline 4 & $\begin{array}{l}\text { All Children Who Are D/HH With Additional Disabilities and Their Families } \\
\text { Have Access to Specialists Who Have the Professional Qualifications and } \\
\text { Specialized Knowledge and Skills }\end{array}$ \\
\hline 5 & $\begin{array}{l}\text { All Children Who Are D/HH and Their Families From Culturally Diverse } \\
\text { Backgrounds and/or From Non-English-Speaking Homes Have Access to } \\
\text { Culturally Competent Services With Provision of the Same Quality and Quantity } \\
\text { of Information Given to Families From the Majority Culture }\end{array}$ \\
\hline 6 & Progress Monitored Every 6 Months From Birth to 36 Months of Age \\
\hline 7 & $\begin{array}{l}\text { Appropriate Monitoring and Immediate Follow-up Intervention Services Where } \\
\text { Appropriate (Hearing, Language, Communication) }\end{array}$ \\
\hline 8 & $\begin{array}{l}\text { Families Will Be Active Participants in the Development and Implementation of } \\
\text { EHDI Systems at the State/Territory and Local Levels }\end{array}$ \\
\hline 9 & Access to Other Families Who Have Children Who Are D/HH \\
\hline 10 & $\begin{array}{l}\text { Individuals Who Are D/HH Will Be Active Participants in the Development and } \\
\text { Implementation of EHDI Systems at the National, State/Territory, and Local } \\
\text { Levels }\end{array}$ \\
\hline
\end{tabular}

(Table Continues) 
Table 1, Continued

\begin{tabular}{ll}
\hline Number & \multicolumn{1}{c}{ Best Practice Guideline } \\
\hline 11 & Have Access to Support, Mentorship, and Guidance from Individuals Who Are \\
& D/HH \\
12 & Fidelity in the Implementation of the Intervention They Receive
\end{tabular}

Note. adapted from JCIH 2007 Supplement (AAP, 2013).

\section{Family Centered Early Intervention}

In 2012, a large panel of experts in the field of deafness, including "parents, deaf professionals, early intervention program leaders, early intervention specialists, and researchers" (p. 429) from around the world came together to discuss the concept of family-centered early intervention (FCEI) practices (Moeller et al., 2013). From this discussion, 10 principles emerged that were considered to be best practices in FCEI. The resulting publication included a description, a list of provider and program behaviors, and supporting evidence exemplifying each of the 10 principles. Refer to Table 2 for a list of the 10 Principles. Similar to the JCIH Principles (2000, 2007) several of the FCEI Principles incorporate family-centered planning, informed choice, family rights, and decision-making.

\section{Table 2}

Best Practice Principles for Family-Centered Early Intervention (FCEI)

\begin{tabular}{ll}
\hline \multicolumn{1}{c}{ Number } & \multicolumn{1}{c}{ Best Practice Principle } \\
\hline 1 & Early, Timely, \& Equitable Access to Services \\
2 & Family/Provider Partnerships \\
3 & Informed Choice and Decision-making \\
4 & Family Social \& Emotional Support \\
(Table Continues) &
\end{tabular}


Table 2, Continued

\begin{tabular}{|c|c|}
\hline Number & Best Practice Principle \\
\hline 5 & Family Infant Interaction \\
\hline 6 & Use of Assistive Technologies and Supporting Means of Communication \\
\hline 7 & Qualified Providers \\
\hline 8 & Collaborative Teamwork \\
\hline 9 & Progress Monitoring \\
\hline 10 & Program Monitoring \\
\hline
\end{tabular}

Note. Adapted from Moeller, M. P., Carr, G., Seaver, L., Stredler-Brown, A., \& Holzinger, D. (2013). Best practices in family centered early intervention for children who are deaf or hard of hearing: An international consensus statement. Journal of Deaf Studies and Deaf Education, 18, 429-445. doi:10.1093/deafed/ent03.

Each of these guidelines and recommended practices guidelines (AAP, 2013; DEC, 2014; JCIH 2000, 2007, 2019; Moeller et al., 2013) incorporate the concepts of informed choice, information sharing, and decision-making. See Table 3 for a visual highlighting of these concepts. Consideration and implementation of these recommended best practices when working with families of deaf and hard of hearing children will allow for systematic early intervention programming and allow for monitoring of service provision with increased fidelity. All these recommended principles should be guiding factors for early intervention providers as they consider how they will support families of deaf and hard of hearing children. 
Table 3

Comparison of Recommended Practices: Informed Choice, Decision-making and Sharing Information

DEC Recommended Practices (2014) JCIH 2007 Supplement (2013) JCEI (2013)

\begin{abstract}
L3. Leaders develop and implement policies, structures, and practices that promote shared decision-making with practitioners and families.
\end{abstract}

F2. Practitioners provide the family with up-to-date, comprehensive and unbiased information in a way that the family can understand and use to make informed choices and decisions.

F7. Practitioners work with the family to identify, access, and use formal and informal resources and supports to achieve family-identified outcomes or goals.

F8. Practitioners provide the family of a young child who has or is at risk for developmental delay/disability, and who is a dual language learner, with information about the benefits of learning in multiple languages for the child's growth and development.
Goal 1.2. Develop a mechanism that
ensures family access to all available resources and information that is accurate, well-balanced, comprehensive, and conveyed in an unbiased manner.
1.3. Families are offered comprehensive family support and early intervention programs in a timely manner following newborn hearing screening within a framework of informed choice.

Goal 2.2. Establish and implement professional development programs that include training in dissemination of information without bias.

Goal 3a.1. Ensure that families have complete and accurate information about ASL.

Goal 3b.1. Ensure that families have complete and accurate information about listening and spoken language development.

\subsection{Provide both informational and emotional support.}

\author{
3.1. Recognize that ultimately, decision \\ making authority rests with the family; \\ collaborate with families to support their \\ abilities to exercise this authority.
3.3. Share information and experiences from a variety of sources that are comprehensive, meaningful, relevant, and unbiased to enable informed decision making.

(Table Continues) 
DEC Recommended Practices (2014)

INS3. Practitioners gather and use data to inform decisions about individualized instruction.

TC2. Practitioners and families work together as a team to systematically and regularly

exchange expertise, knowledge, and information to build team capacity and jointly solve problems, plan, and implement interventions.

TC4. Team members assist each other to discover and access community-based services and other informal and formal resources to meet family-identified child or family needs.

(Table Continues)

JCIH 2007 Supplement (2013) FCEI (2013)

Goal 5.3. Develop a plan for ensuring access to information for families whose native language is not English that is comparable to information provided to native Englishspeaking families by providing resources in the family's home language or languages.

Goal 7.1. If the child does not qualify for state EI services, ensure that families are provided with access to information and counseling regarding their child's hearing loss and the potential impact of hearing loss on the child's daily life and communication development.

\section{Goal 7.12. Provide educational}

information to parents/family covering the following topics: .... language options including visual and spoken languages, benefits of multisensory input of language, and the need for ongoing comprehensive evaluation of communication.
3.4. Keep in mind that "informed choice" is not synonymous with information that is neutral or functionally descriptive.

Rather, evaluative information is essential in that it draws attention to the various risks, benefits, and uncertainties related to particular options.

3.5. Inform families about expectations for them that are inherent in implementing various approaches, as well as potential benefits and challenges.

3.6. Actively support the family in processes of decision making and self-determination. 
Goal 9.1. Develop and implement guidelines that address family-to-family support. These guidelines should outline the background and training necessary for family support providers to interact with families of infants/children newly identified as $\mathrm{D} / \mathrm{HH}$, including the importance of objective, unbiased information.
3.8. Support families to reach decisions in ways that reflect their individual strengths, resources, needs, and experiences.

3.10. Provide resources and support family members' decisions.

3.11. Recognize that informed choice is not a one-time decision but an ongoing process.

\subsection{Respect and support families'} decisions regarding communication methods.

8.4. Early intervention programs strive to provide access to international supports and promote international information sharing.

Note. DEC (2014) is across all disability areas whereas JCIH (2013) and FCEI (2013) is specific to families with deaf and hard of hearing children. 
Parent education programs for deaf and hard of hearing. While most studies focus on the needs of parents, few examine effective strategies for sharing that information, especially related to communication modality or approach (Decker \& Vallotton, 2016; Kingsley \& Mailloux, 2013). It is suggested that a combination of methods is needed for effective early intervention support, with parent training being a part of the overall process (Kingsley \& Mailloux, 2013). Parent training programs as a model for information sharing was quite common in the early years of early intervention but has tapered off in a shift towards more family-centered practices (Keen, 2007). Parents have reported receiving conflicting information from various professionals and feeling overwhelmed with information they seek on their own. Some families have reported wanting the professional to make the decision for them, as they feel overwhelmed or inadequate to make the decisions themselves (Young et al., 2006). Keeping in mind that the DEC (2014), JCIH (2000, 2007), and FCEI (Moeller et al., 2013) recommended guidelines and practices all include information sharing, we must consider how professionals are sharing information in an effort to provide uniform, unbiased information for families with deaf and hard of hearing children in a way that does not overwhelm or undermine the decision-making process.

Currently, there is a commercially available curriculum for training professionals that work with deaf and hard of hearing children and their families, called SKI-HI, which was created in 1972 (SKI-HI, n.d.). No information could be found to explain the meaning of the acronym. SKI-HI specifically trains professionals to become parent advisors and go into the homes of deaf and hard of hearing families to provide supports, information, and skills to facilitate their child's overall development (Barringer et al., 1998). The SKI-HI website describes their program as one that focuses on "communication and language with the child in ways that best match the child's needs" (SKI-HI, n.d.). In addition, the SKI-HI curriculum gives families choices, information, 
resources, and encouragement to consider all possibilities while aiming to enhance parent confidence in raising their child. As a result of their training, SKI-HI program coordinators were able to show, over a three-year period, that deaf and hard of hearing children and their families receiving support, information, and training from a SKI-HI parent advisor showed significant gains in both language and auditory development skills (Barringer et al., 1998; Strong \& Clark, 1990). While little research can be found on current use of SKI-HI in the United States, it is still available for purchase (last published in 2004) and advertised as a resource for providing familycentered programming using simple, topic-oriented sections. No other nationwide training program providing a comprehensive overview of deafness and communication similar to SKI-HI could be found. However, it is interesting to note that the SKI-HI Language Development Scale is an approved assessment tool for Illinois early intervention providers, which is published by the same company that created the SKI-HI curriculum.

\section{Information on Communication Approaches}

As shown earlier, parents desire information. Parents must make a lot of decisions, often based on the information that they have (Mascia \& Mascia, 2019). Further review of the literature shows that the top two types of decisions made relate to amplification and communication (Ching et al., 2018; Jackson et al., 2008; Scarinci et al., 2018) and to make decisions related to either topic, one must first have access to the relevant information. Informed decision-making is a complicated process influenced by a variety of factors, including the beliefs and values of both the families and professionals (Elwyn et al., 2012; Payne, 1976; Sass-Lehrer et al., 2016). The existing culture of the family tends to be a significant influence that shapes language and communication viewpoints for new family members (Borum, 2012). Within the existing culture of hearing families, some parents viewed deafness as 
something that needed to be fixed, therefore, they were more likely to be influenced by information related to spoken language (Decker et al., 2012). This is considered an audiological or medical view in contrast to a cultural view of deafness, which embraces sign language as the primary mode of communication. Parents with a cultural view of deafness were less likely to be influenced by information related to spoken language (Decker et al., 2012; Matthijs et al., 2017). Some parents did mention interactions with deaf adults as influential on their choice of communication as well (Crowe et al., 2014a; Crowe et al., 2014b; Matthijs et al., 2017). Due to the two main views of deafness, there are a variety of people that need to be involved to ensure comprehensive information sharing regarding communication approaches.

Choosing a method of communicating with their child while fielding many strong and diverse opinions from professionals is challenging for parents (Porter et al., 2018; Sass-Lehrer et al., 2016; Sass-Lehrer, 2018). Providing complete, unbiased information in a way that parents can understand and analyze for their own unique situations can be complicated for professionals. Standardized parent education on communication approaches could be one way to support the concept of informed choice and decision-making while alleviating the complexities of potentially biased and conflicting information. Porter et al. (2018) briefly discussed the use and guidelines of patient decision aids in the medical field as a way to reduce and minimize bias and enhance the understanding of information. Currently, the literature does not reflect any such patient decision aid model in the field of deafness. However, some similar references are obtainable. Beginnings, a non-profit for parents of children who are deaf and hard of hearing, has a reference chart available on their website that displays the communication possibilities commonly used by deaf and hard of hearing people. The reference chart lists the definition, primary goals of use, receptive and expressive language development goals, hearing status typically used with that 
communication mode, and family responsibilities/guidance when using that approach. This concept of a reference chart could be used to address each of the communication modes with parents of deaf and hard of hearing children as a source of comprehensive and unbiased information, which is in line with what parents are seeking. However, there is no data publicly available on the use and implementation of such a chart, nor is there training for professionals on how to do this.

Some parents have shared that access to communication approaches directed their information seeking. The availability of services in specific modalities influenced their choice, with several parents stating that where they lived influenced what services they got, which ultimately influenced what communication information they received and which approach was chosen (Jackson, Traub et al., 2008; Li et al., 2003; Steinberg et al., 2003). Currently, there is one correspondence course by the John Tracy Clinic available to families interested in learning more about spoken language (Rhoades, 2010). However, no publicly available data was found on parent perspective and benefits of this program.

\section{Conclusion}

Parenting a child with a disability, including a child who is deaf or hard of hearing, is a journey that requires parents to seek out new information to learn as well as make a multitude of decisions. Federal mandates have established early intervention programming to support families in this process. A primary goal of early intervention is to support optimal growth and development of infants and toddlers with disabilities by empowering parents with access to professionals and services to provide information, support, and guidance as they navigate the decision-making process. Recommended best practices and guidelines for professionals providing early intervention services have been developed over the years. These practices are 
family-centered and include guidelines that encourage empowering parents by sharing information and supporting informed choice and decision-making. The literature shows that parents desire information related to the disability and seek it from a variety of sources. However, there is currently no standardized form of sharing information in any disability area. In a field that is fraught with diverse and conflicting information regarding communication for deaf and hard of hearing children, it would be beneficial to further explore how professionals can meet best practices of informed choice within the context of familycentered early intervention. Communication is a foundational building block of language and is critical in supporting early language acquisition for deaf and hard of hearing children (Decker et al., 2012; Kushalnagar et al. 2010; Marschark, 2001; Sass-Lehrer, 2018). Part C of IDEA mandates that the Individual Family Service Plan include a statement of the family's priorities and the literature shows that families desire information specifically related to their child's hearing status, including information about communication. Recommended Practices from the DEC (2014), the JCIH 2007 Supplement (2013) and Family Centered Early Intervention consensus statement (Moeller et al., 2013) all include guidelines that address informed choice, decision-making, and sharing information (See Table 3). Thusly, providers working with families of deaf and hard of hearing children should ensure their service delivery practices incorporate informed choice, decision-making, and information sharing, including those related to communication approaches. It has already been established that parents of deaf and hard of hearing children desire and obtain information, specifically related to communication, from a variety of sources, but there currently is no tool or established method to support this process. Further research is needed to explore this information gathering process and resulting decision- 
making from the parental perspective and how providers can support the concepts of informed choice and decision-making. 


\section{CHAPTER II: LITERATURE REVIEW}

A large majority, upward to $96 \%$ of deaf and hard of hearing children are born into hearing families who often have very little knowledge of deafness (Humphries et al., 2012). When a deaf or hard of hearing child is born into a family with no experience with deafness, this sets families onto a multifaceted learning journey as they learn about deafness and how to communicate with their child. For many of these families, this is the beginning of a journey filled with information gathering and learning about deafness, as well as making decisions. Many of these decisions made revolve around amplification and communication (Ching et al., 2018; Jackson, Traub et al., 2008; Scarinci et al., 2018).

\section{Amplification and Communication}

In 2017, the Centers for Disease Control and Prevention (CDC) reported 98.3\% of babies born in the United States and its territories had their hearing screened prior to discharge from the hospital or birthing center, approximately 3.74 million babies (CDC, 2017b). Subsequently, $10.4 \%$, or 6,537 of those babies were diagnosed as deaf or hard of hearing, often before three months of age (CDC, 2017b). For a large majority of these babies, they are the first deaf or hard of hearing person their parents have ever met. From there, approximately $90.8 \%$ of those babies identified with a hearing loss were referred for early intervention services under Part $\mathrm{C}$ of Individuals with Disabilities Education Act (CDC, 2017b). Of the 5,937 babies referred, 65.1\% of them were enrolled in local early intervention programs and receiving support services (CDC, 2017b). The numbers from the CDC show many babies are now being identified and referred for services at a much earlier age, compared to decades ago when the average identification age was $2 \frac{1}{2}$ to 3 years old (Shulman et al., 2010). As a result, babies with diagnosed hearing loss and their families are entering the Early Hearing Detection and Intervention (EHDI) system and 
beginning services much sooner. Early identification and support have been shown to be instrumental to later language and developmental outcomes (Marschark, 2001; Subbiah et al., 2018).

When parents first discover the hearing status of their child, they are faced with a multitude of decisions they must make, often while they are simultaneously processing the unexpected absence or loss of their child's sense of hearing (Ching et al., 2018; Humphries et al., 2012). Being deaf or hard of hearing does not prevent communication or language development, however, it is critical that immersion and exposure to fluent language models begin early to ensure maximum impact on language outcomes, whether it is via audition or vision (Humphries et al., 2012; Marschark, 2001). The top two decisions parents report making quickly are often related to amplification and communication (Ching et al., 2018; Scarinci et al., 2018). While one may consider amplification and communication to be separate decisions, the existing literature shows that the two topics are often intertwined, and the decision-making process is far from simple. Amplification decisions concern the use of hearing aids or cochlear implants whereas communication decisions center around the use of spoken or visual languages or a combination of both. For parents to make decisions on either amplification or communication for their child, they must first have the information related to each topic.

\section{Informed Choice}

As previously discussed, current best practice recommendations for working with families of young children with disabilities revolve around family-centered practices with a core component focusing on informed choice, decision-making, and information sharing (DEC, 2014; Joint Committee on Infant Hearing, 2000, 2007; Moeller et al., 2013). While the DEC (2014) recommended practices are too detailed to list here, the Joint Committee on Infant Hearing 
(JCIH) $(2000,2007)$ and Moeller et al. (2013) practices are listed in Tables 1 and 2. A side by side comparison of the recommend best practices from all three sources that highlight informed choice, decision-making, and information sharing is shown in Table 3. In addition, it is recommend qualified personnel share information in an unbiased manner as a method to support families in the process of making informed decisions (Davis \& Gavidia-Payne, 2009; DEC, 2014; Dunst \& Espe-Sherwindt, 2016; Woods et al., 2011). However, the process of providing unbiased information is complex and bias is inherent in both the giver and receiver of information (Porter et al., 2018).

Currently, very little literature exists regarding informed choice and parents of deaf and hard of hearing children, however, informed choice is mentioned throughout the recommended best practices and guidelines (DEC, 2014; JCIH 2000, 2007; Moeller et al. 2013). Access to information that is unbiased and comprehensive allows the family navigate the decision-making process that takes into consideration their own unique circumstances. This increases ownership of the resulting decision, thereby increasing the likelihood that they will follow through and implement the decision in a consistent manner (DesGeorges, 2018). As stated earlier, informed choice is defined as "one where all the available information...is weighed up and used to inform the final decision" (Marteau et al., 2001, p. 100). Families often incorporate their existing values as a factor in their decision (Marteau et al., 2001). The concept of informed choice is currently more prevalent within the medical field, however, the journey of raising a child who is deaf or hard of hearing begins with a medical diagnosis. Therefore, the use and impact of informed choice in supporting families of children who are deaf or hard of hearing warrants a closer look. Informed choice was mentioned in a number of studies within a systematic literature review; however, those studies did not provide a definition of informed choice or illustrate what 
the process of informed choice looked like, nor did they highlight the resulting decision-making process (Porter et al., 2018). The international consensus statement on best practices in familycentered early intervention for deaf and hard of hearing children clearly states that "informed choice is not synonymous with information that is neutral or functionally descriptive. Rather, evaluative information is essential in that it draws attention to the various risks, benefits, and uncertainties related to particular options" (Moeller et al., 2013, p. 434). Therefore, information does not equate understanding. While parents may have the information, providers may need to be actively involved in the process of understanding, dissecting, and applying the information to each individual family (Elwyn et al., 2012; Porter et al., 2018; Young at al., 2006, 2007). As a result, the concept of providing comprehensive, inclusive information to parents is much more than the act of just giving it. Providers must be able to work with families in a shared decisionmaking process to determine what their goals and priorities are, match them with relevant information, guide them in understanding it, and provide support through this process, which requires them to keep their own bias in check. Existing literature shows that providers have the potential to strongly influence families, with a recent study indicating that $74 \%$ of families with deaf and hard of hearing children surveyed reported that professional attitudes had a large influence on their decision-making (Davis \& Gavidia-Payne, 2009; Jackson, 2009).

The concept of complete and unbiased information is woven throughout the DEC (2014) Recommended Practice guidelines and reinforced in several Practice Guides (ECTA, 2018). Specifically, the Supporting Family Member Informed Decision-making Practice Guide recommends a three-step process: identifying information needs, knowing what relevant information is available, and knowing the sources of that information (ECTA, 2018). This aligns with a proposed model provided by Elwyn and colleagues (2012) which also uses three steps to 
decision-making: inform, discuss, and apply. Using these processes can encourage objective decision-making while also ensuring individual needs and desires are accounted for. These steps also highlight that making decisions is a flexible process, one that is affected by the situational needs of the child and family, and an effective provider can support the family throughout that process (Moeller et al., 2013). Parents of children with disabilities are often required to gather information and make numerous decisions; decisions which sometimes shape the course of the child's path or identity and that of the family (Mascia \& Mascia, 2019). Some parents have reported feeling pressured to make various decisions quickly while others felt a lack of support in the process (Decker \& Vallotton, 2016). Conscious awareness of this information gathering and decision-making process can potentially alleviate some of this pressure while allowing providers to follow the recommended guidelines related to informed choice and decisionmaking.

The development of language requires early, frequent, consistent, and accessible communication, regardless whether it is visual or auditory (Kushalnagar et al., 2010; Marschark, 2001). For a child with access to sound, there is often no question of how communication will occur within the home as it is generally assumed they will be immersed in spoken language from the day they are born and use the language of the home to communicate. However, for a child who is deaf or hard of hearing, there is potentially a communication mismatch as parents must consider whether the auditory based language of the home will be accessible for their child. Since early communication exposure is critical for language development for deaf and hard of hearing children, it is one of the decisions that parents feel most concerned about (Porter et al., 2018). As a result, the initial information seeking process likely has strong implications on the 
resulting decisions made as parents consider how to provide communication access for their child.

\section{Methods}

To address the question of what kinds of information parents initially received about communication approaches for their child and how that influenced their decision-making process, a search of the existing literature was completed. The final literature review investigated a total of 15 studies focusing on parent perspectives, communication approaches for their deaf and hard of hearing children, and the factors that influenced their decisions.

With a focus on academic, peer-reviewed journal articles published from 2008 to 2018 using BOOLEAN terms AND and OR, the following search terms were targeted: parents of children, deaf, hard of hearing, communication, decision, choice, and selection. The search was conducted using the following databases through Illinois State University: ComDisDome, PubMed, and ERIC in EBSCO. Within ERIC in EBSCO, a combined database search was conducted including Academic Search Complete, CINAHL Plus with Full Text, Communication Source, ebook Collection (EBSCOhost), Education Full Text (H.W. Wilson), ERIC, Primary Search, Professional Development Collection, and PsycINFO. An additional search was conducted in Google Scholar. The same search parameters were used for each database search as follows: parents of children AND (deaf OR hearing*) AND communication AND (decision OR choice OR selection). Note that the askterisk was used to truncate the search to include any words connected with hearing such as hearing impaired/ment or hearing loss or deafness or hard of hearing or hearing aids. As indicated in Figure 7, each database was searched separately, for a total of four database searches (with the exception of the third database search, which was a combined search of nine databases). 


\section{Figure 7}

Flowchart of Literature Search

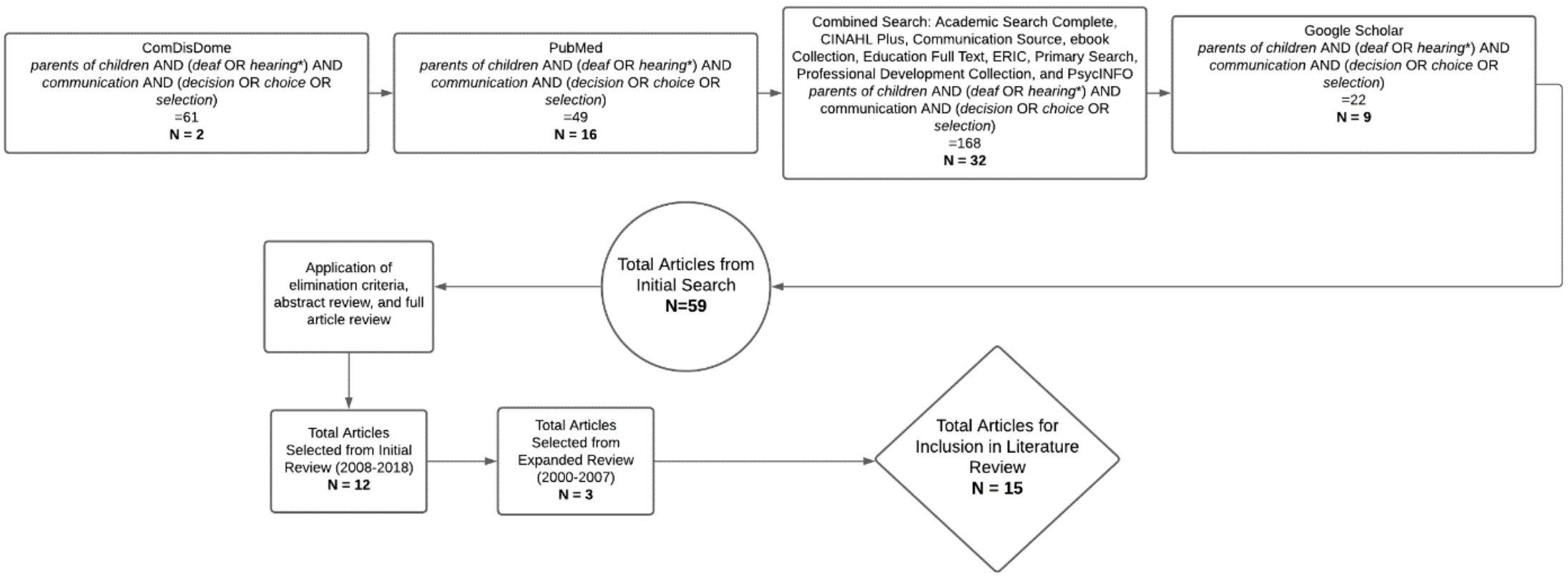


The initial search of the first three databases yielded a total of 278 potential articles. The additional search in Google Scholar (abstract search sorted by date) yielded an additional 22 potential articles for a final total of 300 potential articles, including duplicates. After duplicates were eliminated, an initial abstract review was conducted. Inclusion criteria included abstracts that focused on parents of deaf and hard of hearing children, information seeking, or communication choice. Articles that described a focus on deaf and hard of hearing parents or adults, effects or outcomes of a specific communication modality, decision-making related to cochlear implants, mode used during assessment, and intervention strategies were eliminated. As a result, a total of 59 potential articles remained. A full-text review of each of the 59 articles commenced, with a focus on articles that reported study results focusing on the process of information gathering related to communication decision-making. Based on this criteria, an additional 47 articles were eliminated, leaving 12 articles for inclusion in this literature review of studies focusing on factors influencing parent selection of communication modes and the decision-making process.

Since universal newborn hearing screening mandates began around 2000 (Porter et al., 2018), a secondary search was conducted with an expanded timeframe. This was done to see if there were any additional studies on factors influencing parent communication choice in the timeframe immediately following implementation of universal newborn hearing screening. Thus, an additional search was conducted, using the same search terms and procedures as outlined above, but expanding the search to include literature from 2000 to 2007. This resulted in an additional 108 potential articles. After an abstract review, application of exclusionary criteria, and full text review as previously described, an additional three articles were selected. A final 
total of 15 articles were chosen for inclusion in this literature review focusing on parents of deaf children, communication choice, and the decision-making process from 2000 to 2018.

\section{Results}

Table 4 has a brief overview of each of the selected studies, including the location, number of participants, method used to gather information, the research question or focus of the study, and a summary of the findings. Twelve of the 15 studies are from the recent 10 years. Their findings will be synthesized and then compared to the remaining three studies which are more than 10 years old. This will be done to determine if the themes related to communication choice and influence have remained consistent for the past 18 years. 


\section{Table 4}

Studies Focusing on Factors Influencing Parents' Choice of Communication

\begin{tabular}{|c|c|c|c|c|c|}
\hline Author & Location & Sample & Method & Research question/focus & Findings \\
\hline Borum (2012) & $\begin{array}{c}\text { USA (Washington } \\
\text { DC Metro area \& } \\
\text { PA) }\end{array}$ & $\begin{array}{c}14 \text { parents } \\
\text { (all hearing), } \\
14 \text { children }\end{array}$ & $\begin{array}{c}\text { Qualitative, } \\
\text { exploratory in-depth } \\
\text { semi structured } \\
\text { thematic interviews } \\
\text { with focus questions }\end{array}$ & $\begin{array}{c}\text { What are African } \\
\text { American parents' } \\
\text { perceptions of } \\
\text { communication choice } \\
\text { and usage with their } \\
\text { deaf and hard of hearing } \\
\text { children? }\end{array}$ & $\begin{array}{l}\text { Four themes: 1) access } \\
\text { to African oral } \\
\text { traditions via speech, } \\
\text { 2) access to DHH } \\
\text { community via sign \& } \\
\text { speech, 3) access to } \\
\text { English via reading \& } \\
\text { writing, and, 4) access } \\
\text { to racial, ethnic, and } \\
\text { cultural heritage }\end{array}$ \\
\hline $\begin{array}{l}\text { Bruin \& Nevøy } \\
\text { (2014) }\end{array}$ & Norway & $\begin{array}{l}27 \text { parents } \\
\text { (all hearing), } \\
28 \text { children }\end{array}$ & $\begin{array}{c}\text { Qualitative discourse } \\
\text { analysis based on } \\
\text { questionnaires }\end{array}$ & $\begin{array}{l}\text { How is the discourse on } \\
\text { communication } \\
\text { modality in follow-up } \\
\text { after pediatric CI } \\
\text { constructed, how does it } \\
\text { operate, and how does it } \\
\text { govern people's } \\
\text { thinking and acting? }\end{array}$ & $\begin{array}{l}\text { Three discourses: } 1 \text { ) } \\
\text { truth: right vs wrong \& } \\
\text { "tug of war" with } \\
\text { opposing opinions, } 2 \text { ) } \\
\text { norm: desire and ability } \\
\text { of normalization with } \\
\text { hearing society, and, 3) } \\
\text { subjugated knowledge: } \\
\text { caught in the conflict } \\
\text { and not being heard or } \\
\text { supported }\end{array}$ \\
\hline
\end{tabular}

(Table Continues) 
Table 4, Continued

\begin{tabular}{|c|c|c|c|c|c|}
\hline Author & Location & Sample & Method & Research question/focus & Findings \\
\hline $\begin{array}{l}\text { Ching et al. } \\
(2018)\end{array}$ & $\begin{array}{l}\text { Australia (Victoria, } \\
\text { South Wales, \& } \\
\text { Queensland) }\end{array}$ & $\begin{array}{l}14 \text { parents ( } 3 \\
\text { with hearing } \\
\text { loss), } 14 \\
\text { children }\end{array}$ & $\begin{array}{c}\text { Qualitative } \\
\text { descriptive analysis } \\
\text { of semi-structured } \\
\text { interviews with probe } \\
\text { questions }\end{array}$ & $\begin{array}{l}\text { To explore the factors } \\
\text { influencing parents' } \\
\text { choice of } \\
\text { communication mode } \\
\text { during early education }\end{array}$ & $\begin{array}{l}\text { Four themes: 1) draw } \\
\text { from variety of } \\
\text { information and } \\
\text { experiences, 2) } \\
\text { preferred outcomes } \\
\text { drive choices, 3) child } \\
\text { preference and } \\
\text { proficiency drive } \\
\text { choice, and, 4) fears } \\
\text { and worries influence } \\
\text { decisions }\end{array}$ \\
\hline $\begin{array}{l}\text { Crowe et al. } \\
(2014 a)\end{array}$ & $\begin{array}{l}\text { Australia (New } \\
\text { South Wales, } \\
\text { Queensland, \& } \\
\text { Victoria) }\end{array}$ & $\begin{array}{l}177 \text { parents, } \\
157 \text { children }\end{array}$ & $\begin{array}{l}\text { Qualitative analysis } \\
\text { of questionnaire } \\
\text { responses }\end{array}$ & $\begin{array}{l}\text { Influences on decision- } \\
\text { making about } \\
\text { communication }\end{array}$ & $\begin{array}{l}\text { Four themes: 1) } \\
\text { sources of information, } \\
\text { 2) practicalities of } \\
\text { communication, 3) } \\
\text { children as individuals, } \\
\text { and, 4) children's } \\
\text { future lives }\end{array}$ \\
\hline
\end{tabular}

(Table Continues) 
Table 4, Continued

\begin{tabular}{|c|c|c|c|c|c|}
\hline Author & Location & Sample & Method & Research question/focus & Findings \\
\hline $\begin{array}{l}\text { Crowe et al. } \\
(2014 b)\end{array}$ & $\begin{array}{l}\text { Australia (New South } \\
\text { Wales, Queensland, } \\
\text { \& Victoria) }\end{array}$ & $\begin{array}{l}177 \text { parents, } \\
157 \text { children }\end{array}$ & $\begin{array}{l}\text { Quantitative analysis } \\
\text { of Likert-type } \\
\text { questionnaire } \\
\text { responses } \\
\text { (proportional and } \\
\text { exploratory factor) }\end{array}$ & $\begin{array}{l}\text { The influence of a } \\
\text { comprehensive range of } \\
\text { factors on the decision- } \\
\text { making of caregivers of } \\
\text { children with hearing } \\
\text { loss regarding the use of } \\
\text { speech, the use of sign, } \\
\text { spoken language } \\
\text { multilingualism, and } \\
\text { spoken language choice }\end{array}$ & $\begin{array}{l}\text { Decisions influenced } \\
\text { by: 1) child } \\
\text { audiological and } \\
\text { intervention } \\
\text { characteristics, 2) } \\
\text { communication with } \\
\text { those around them, 3) } \\
\text { community } \\
\text { participation, 4) access } \\
\text { to intervention and } \\
\text { education services in } \\
\text { English, and, 5) } \\
\text { concerns about } \\
\text { children's future lives }\end{array}$ \\
\hline
\end{tabular}

(Table Continues) 
Table 4, Continued

\begin{tabular}{|c|c|c|c|c|c|}
\hline Author & Location & Sample & Method & Research question/focus & Findings \\
\hline $\begin{array}{l}\text { Decker et al. } \\
(2012)\end{array}$ & USA & $\begin{array}{l}36 \text { parents, } \\
35 \text { children }\end{array}$ & $\begin{array}{l}\text { Quantitative Online } \\
\text { survey }\end{array}$ & $\begin{array}{l}\text { 1. From whom did } \\
\text { parents receive } \\
\text { information about } \\
\text { communication } \\
\text { options? } \\
\text { 2. Who did parents feel } \\
\text { was most influential to } \\
\text { their decision? } \\
\text { 3. Are there differences } \\
\text { in sources of } \\
\text { information and } \\
\text { influence between those } \\
\text { that choose speech only } \\
\text { vs. including sign? } \\
\text { 4. Did parents' } \\
\text { knowledge and values } \\
\text { influence the method } \\
\text { chosen? }\end{array}$ & $\begin{array}{l}\text { 1. Parents received } \\
\text { information most often } \\
\text { from medical } \\
\text { professionals, } \\
\text { audiologists, and } \\
\text { speech pathologists. } \\
\text { 2. Most influential } \\
\text { sources were parents } \\
\text { own judgement and } \\
\text { other parent/partner. } \\
\text { 3. Speech only received } \\
\text { more information than } \\
\text { those including sign but } \\
\text { no significant different } \\
\text { in influence was found. } \\
\text { 4. No significant } \\
\text { different in knowledge } \\
\text { and influence, } \\
\text { however, only info } \\
\text { from AuD or SLP was } \\
\text { significantly related to } \\
\text { parent values. }\end{array}$ \\
\hline
\end{tabular}

(Table Continues) 
Table 4, Continued

\begin{tabular}{|c|c|c|c|c|c|}
\hline Author & Location & Sample & Method & Research question/focus & Findings \\
\hline $\begin{array}{l}\text { Eleweke \& } \\
\text { Rodda }(2000)\end{array}$ & England & $\begin{array}{l}2 \text { parents, } 3 \\
\text { children }\end{array}$ & $\begin{array}{l}\text { Qualitative Case } \\
\text { Study design } \\
\text { including semi } \\
\text { structured } \\
\text { questionnaire and } \\
\text { unstructured } \\
\text { interview }\end{array}$ & $\begin{array}{l}\text { To identify the various } \\
\text { factors that might } \\
\text { influence parents in } \\
\text { choosing a } \\
\text { communication mode } \\
\text { for their children }\end{array}$ & $\begin{array}{l}\text { Four themes: 1) } \\
\text { influence of } \\
\text { information provided to } \\
\text { parents, 2) parent } \\
\text { perceptions of assistive } \\
\text { technology, 3) attitudes } \\
\text { of professionals, and, } \\
\text { 4) quality and } \\
\text { availability of support } \\
\text { services }\end{array}$ \\
\hline $\begin{array}{l}\text { Guiberson } \\
\text { (2013) }\end{array}$ & Spain & $\begin{array}{l}71 \text { parents, } \\
71 \text { children }\end{array}$ & $\begin{array}{l}\text { Quantitative } \\
\text { descriptive, online } \\
\text { survey }\end{array}$ & $\begin{array}{l}\text { (a) to describe factors } \\
\text { and trends associated } \\
\text { with Spanish parents' } \\
\text { choice of } \\
\text { communication } \\
\text { modality and spoken } \\
\text { language bilingualism } \\
\text { and (b) to identify if } \\
\text { bilingual variables } \\
\text { predict children's } \\
\text { bilingual status in a } \\
\text { country where } \\
\text { bilingualism is common }\end{array}$ & $\begin{array}{l}\text { Most parents indicated } \\
\text { they believed being } \\
\text { bilingual was beneficial } \\
\text { and } 38 \% \text { chose oral } \\
\text { bilingualism. Parents' } \\
\text { own bilingual status } \\
\text { was significantly } \\
\text { associated with choice } \\
\text { to use oral bilingual } \\
\text { modes of } \\
\text { communication. }\end{array}$ \\
\hline
\end{tabular}

(Table Continues) 
Table 4, Continued

\begin{tabular}{|c|c|c|c|c|c|}
\hline Author & Location & Sample & Method & Research question/focus & Findings \\
\hline $\begin{array}{l}\text { Jackson et al. } \\
(2008)\end{array}$ & $\begin{array}{l}\text { USA (Northeast, } \\
\text { Midwest, Southwest, } \\
\text { Suburban, Urban, } \\
\text { and Rural) }\end{array}$ & $\begin{array}{l}9 \text { parents }(1 \\
\text { deaf }), 8 \\
\text { children }\end{array}$ & $\begin{array}{l}\text { Qualitative and } \\
\text { naturalistic inquiry } \\
\text { methods via semi } \\
\text { structured face to face } \\
\text { interviews, phone, } \\
\text { and email }\end{array}$ & $\begin{array}{l}\text { To explore the } \\
\text { perceptions of deafness } \\
\text { and the impact on } \\
\text { family life from parent } \\
\text { perspective }\end{array}$ & $\begin{array}{l}\text { Rationale for } \\
\text { communication } \\
\text { decisions often based } \\
\text { on trial and error. } \\
\text { Factors influencing } \\
\text { communication } \\
\text { decisions: desire to } \\
\text { maximize hearing } \\
\text { ability, sorting through } \\
\text { biased information, and } \\
\text { health/safety concerns. }\end{array}$ \\
\hline Li et al. (2003) & USA & $\begin{array}{l}83 \text { parents, } \\
82 \text { children }\end{array}$ & $\begin{array}{l}\text { Quantitative } \\
\text { descriptive survey }\end{array}$ & $\begin{array}{l}\text { To compare the relative } \\
\text { importance of the } \\
\text { child's hearing loss and } \\
\text { parental attitudes, } \\
\text { beliefs, values, and } \\
\text { aspirations in the } \\
\text { decision process. }\end{array}$ & $\begin{array}{l}\text { Degree of hearing loss } \\
\text { was the most influential } \\
\text { factor on selection of } \\
\text { communication mode. } \\
\text { Parental value placed } \\
\text { on speech ability } \\
\text { second most influential } \\
\text { factor. }\end{array}$ \\
\hline
\end{tabular}

(Table Continues) 
Table 4, Continued

\begin{tabular}{|c|c|c|c|c|c|}
\hline Author & Location & Sample & Method & Research question/focus & Findings \\
\hline $\begin{array}{l}\text { Matthijs et al. } \\
(2017)\end{array}$ & Belgium & $\begin{array}{l}3 \text { parents, } 3 \\
\text { children }\end{array}$ & $\begin{array}{l}\text { Qualitative interviews } \\
\text { Case study }\end{array}$ & $\begin{array}{l}\text { What can the } \\
\text { positioning process } \\
\text { reveal about (a) the } \\
\text { decision-making } \\
\text { regarding education and } \\
\text { (b) the way both } \\
\text { traditional grand } \\
\text { discourses were } \\
\text { presented in the } \\
\text { contemporary discursive } \\
\text { contexts these mothers } \\
\text { were confronted with? }\end{array}$ & $\begin{array}{l}\text { Mother's first } \\
\text { positioning was } \\
\text { dependent on the } \\
\text { information received } \\
\text { and it had a strong } \\
\text { connection with } \\
\text { personal experiences. } \\
\text { The language of advice } \\
\text { used by service } \\
\text { providers has a } \\
\text { substantial influence on } \\
\text { the parents' } \\
\text { construction of } \\
\text { deafness. }\end{array}$ \\
\hline $\begin{array}{l}\text { Scarinci et al. } \\
(2018)\end{array}$ & $\begin{array}{l}\text { Australia (New South } \\
\text { Wales \& Victoria) }\end{array}$ & $\begin{array}{l}7 \text { parents, } 7 \\
\text { children }\end{array}$ & $\begin{array}{l}\text { Qualitative } \\
\text { descriptive design, } \\
\text { semi structured in- } \\
\text { depth interviews }\end{array}$ & $\begin{array}{l}\text { Explore the factors that } \\
\text { influence caregiver } \\
\text { decision-making } \\
\text { process to change the } \\
\text { communication method } \\
\text { of their child }\end{array}$ & $\begin{array}{l}\text { Decisions to change } \\
\text { method of } \\
\text { communication } \\
\text { influenced by } \\
\text { characteristics, } \\
\text { strengths and beliefs of } \\
\text { family, access to } \\
\text { information, and } \\
\text { provision of family } \\
\text { centered services. }\end{array}$ \\
\hline
\end{tabular}

(Table Continues) 
Table 4, Continued

\begin{tabular}{|c|c|c|c|c|c|}
\hline Author & Location & Sample & Method & Research question/focus & Findings \\
\hline $\begin{array}{l}\text { Steinberg et al. } \\
(2003)\end{array}$ & $\begin{array}{l}\text { USA (Pennsylvania, } \\
\text { Texas, central } \\
\text { Florida, northern } \\
\text { California) }\end{array}$ & $\begin{array}{l}29 \text { parents, } \\
29 \text { children }\end{array}$ & $\begin{array}{l}\text { Mixed Methods, } \\
\text { questionnaire and } \\
\text { semi-structured } \\
\text { interviews }\end{array}$ & $\begin{array}{l}\text { What factors influence } \\
\text { decisions made after the } \\
\text { identification of } \\
\text { deafness for Hispanic } \\
\text { families? }\end{array}$ & $\begin{array}{l}\text { Decisions made } \\
\text { influenced by language } \\
\text { and cultural barriers, } \\
\text { and limited access to } \\
\text { information, resources, } \\
\text { and full range of } \\
\text { options. Professionals } \\
\text { were a big influence. }\end{array}$ \\
\hline $\begin{array}{l}\text { Tachtsis \& } \\
\text { Dettman } \\
(2018)\end{array}$ & Australia & $\begin{array}{l}155 \text { parents, } \\
162 \text { children }\end{array}$ & $\begin{array}{l}\text { Qualitative via } \\
\text { questionnaires, } \\
\text { retrospective }\end{array}$ & $\begin{array}{l}\text { What factors influence } \\
\text { caregiver decisions } \\
\text { regarding } \\
\text { communication of their } \\
\text { children using Cis and } \\
\text { examine their long-term } \\
\text { language outcomes }\end{array}$ & $\begin{array}{l}\text { Decisions driven by } \\
\text { multiple sources of } \\
\text { information, influenced } \\
\text { by parent values and } \\
\text { their interpretation of } \\
\text { child preference, but } \\
\text { unrelated to language } \\
\text { outcomes. }\end{array}$ \\
\hline $\begin{array}{l}\text { Wheeler et al. } \\
\text { (2009) }\end{array}$ & United Kingdom & $\begin{array}{l}12 \text { parents, } \\
12 \text { children }\end{array}$ & Qualitative interviews & $\begin{array}{l}\text { Comparing } \\
\text { communication choices } \\
\text { pre and post implant }\end{array}$ & $\begin{array}{l}\text { Pre-implant: most } \\
\text { effective } \\
\text { communication is goal, } \\
\text { utilizing oral and sign. } \\
\text { Post implant: increase } \\
\text { in oral use however, } \\
\text { once oral skills } \\
\text { established, increase } \\
\text { interest in use of sign }\end{array}$ \\
\hline
\end{tabular}


In the studies, parents often referenced three different communication approaches: spoken language, visual language, or a combination of both. Because these studies were conducted all over the world, with each country having its own native spoken and signed languages, the generic terms spoken language or sign language will be used to reference the native respective language of the families, rather than naming the specific language. The term visual language will be used to reference any manual mode, including signed languages, signed systems, and Cued Speech.

Twelve of the 15 studies were from the recent 10 years and the remaining three were more than 10 years old. Their findings appear to be fairly similar, indicating that information sources and factors influencing communication choice and decision-making have remained relatively consistent for the past 18 years. However, the recent recommendations for working with families from DEC (2014), JCIH (2000, 2007) and Moeller and colleagues (2013), open the door for a shift towards more of a partnership among families and professionals, with the emphasis on implementation of family-centered practice, something that appears to be continuously evolving (Rhoades, 2010). It will be important to continue to watch the trends in communication and decision-making among families of deaf and hard of hearing children to monitor the discourse and implementation changes over time so providers can continue to learn.

After a full review of all 15 articles related to factors influencing communication choice and decision-making for parents, several themes emerged. These themes include: Parent Values and Desires for Child's Future, Needs of the Child, Accessibility, and Sources of Information. Each of these themes is discussed in detail below. These themes were determined while reading each of these articles and charting common words and phrases that consistently appeared within 
the articles. A summary of the themes and the common words and ideas that appeared in each study is in Table 5.

Table 5

Literature Review Thematic Analysis

\begin{tabular}{|c|c|c|}
\hline Themes & Studies & Mentioned in Studies \\
\hline Parent Values and Desires for & Borum (2012) & I want... \\
\hline \multirow[t]{14}{*}{ Child's Future } & Bruin \& Nevøy (2014) & We had to... \\
\hline & Ching et al. (2018) & Access to both deaf/hearing \\
\hline & Crowe et al. (2014a) & worlds, communicate with \\
\hline & Crowe et al. (2014b) & everyone \\
\hline & Decker et al. (2012) & I wish... \\
\hline & Eleweke \& Rodda (2000) & Normal... \\
\hline & Guiberson (2013) & Bilingual, speak, sign, \\
\hline & Jackson et al. (2008) & $\mathrm{read} / \mathrm{write}$ \\
\hline & Li et al. (2003) & Fears and worries, hopes \\
\hline & Scarinci et al. (2018) & and dreams \\
\hline & Steinberg et al. (2003) & Children's future lives and \\
\hline & Tachtsis \& Dettman (2018) & opportunities \\
\hline & Wheeler et al. (2009) & Culture and religion \\
\hline & & $\begin{array}{c}\text { Family relationships and } \\
\text { experiences }\end{array}$ \\
\hline \multirow[t]{12}{*}{ Needs of the Child } & Bruin \& Nevøy (2014) & Best interests \\
\hline & Ching et al. (2018) & Child's initiative and \\
\hline & Crowe et al. (2014a) & preferences \\
\hline & Crowe et al. (2014b) & Child proficiency \\
\hline & Decker et al. (2012) & Current communication \\
\hline & Eleweke \& Rodda (2000) & skills/functioning \\
\hline & Jackson et al. (2008) & We need... \\
\hline & Li et al. (2003) & We don't need... \\
\hline & Scarinci et al. (2018) & Use hearing aid to hear, \\
\hline & Steinberg et al. (2003) & sign to communicate \\
\hline & Tachtsis \& Dettman (2018) & Amplification \\
\hline & Wheeler et al. (2009) & Hearing status \\
\hline
\end{tabular}

(Table Continues) 
Table 5 Continued

\begin{tabular}{|c|c|c|}
\hline Themes & Studies & Mentioned in Studies \\
\hline Accessibility & $\begin{array}{c}\text { Ching et al. (2018) } \\
\text { Crowe et al. (2014a) } \\
\text { Crowe et al. (2014b) } \\
\text { Eleweke \& Rodda (2000) } \\
\text { Guiberson (2013) } \\
\text { Jackson et al. (2008) } \\
\text { Scarinci et al. (2018) } \\
\text { Steinberg et al. (2003) } \\
\text { Wheeler et al. (2009) }\end{array}$ & $\begin{array}{c}\text { If you live here you access } \\
\text { this... } \\
\text { Location... } \\
\text { Access to services, } \\
\text { programs, schools, } \\
\text { therapies } \\
\text { Lack of.... }\end{array}$ \\
\hline Sources of Information & $\begin{array}{c}\text { Bruin \& Nevøy (2014) } \\
\text { Ching et al. (2018) } \\
\text { Crowe et al. (2014a) } \\
\text { Crowe et al. (2014b) } \\
\text { Decker et al. (2012) } \\
\text { Eleweke \& Rodda (2000) } \\
\text { Guiberson (2013) } \\
\text { Matthijs et al. (2017) } \\
\text { Scarinci et al. (2018) } \\
\text { Tachtsis \& Dettman (2018) } \\
\text { Wheeler et al. (2009) }\end{array}$ & $\begin{array}{l}\text { Hospital, professionals, } \\
\text { cochlear implant center, } \\
\text { early intervention, family, } \\
\text { friends, internet, service } \\
\text { providers, self research, } \\
\text { deaf services, deaf schools, } \\
\text { spouse/partner, teachers, } \\
\text { audiologist, speech } \\
\text { pathologist, other parents, } \\
\text { books/magazines, } \\
\text { community agencies, } \\
\text { caregivers } \\
\text { Conflicting information, } \\
\text { professional discourse, } \\
\text { satisfaction, family } \\
\text { centered }\end{array}$ \\
\hline
\end{tabular}

\section{Theme 1: Parent Values and Desires for Child's Future}

Throughout the studies, many parents admitted that their personal values and desires for how they wanted their child to function in the world and in their home had a strong influence on how they chose to communicate with their child. Several parents expressed the desire for their child to learn to speak because they themselves were hearing and the majority of the world communicated using spoken language (Borum, 2012; Bruin \& Nevøy, 2014; Ching et al., 2018; 
Crowe et al., 2014a; Jackson, 2008; Scarinci et al., 2018; Tachtsis \& Dettman, 2018; Wheeler, et al., 2009). Other parents expressed the desire for their children to be able to communicate with anyone (Ching et al., 2018; Matthijs et al., 2017) and did not "want to limit him to one type of people" (Borum, 2012, p. 11). Some parents shared that their desires drove the choice of communication, which then influenced the choice of amplification; meaning how parents wanted to communicate influenced them to select a modality first and then the related amplification option second (Ching, et al., 2018; Wheeler et al., 2009).

Literacy was another desire influencing communication choice, with parents wanting their child to have access to English so they could have strong reading and writing skills that were considered an essential life skill and related to academic success (Borum, 2012; Crowe et al., 2014a). The desire for their child to be seen as normal and accepted by society was mentioned in several studies as a consideration in choosing how to communicate (Ching et al., 2018; Crowe et al., 2014a; Jackson, 2008; Scarinci et al., 2018). In addition, many parents were thinking ahead to the future, envisioning what their child needed to function as an adult and cited that as an influencing factor, as well as a desire to make things easier for their child (Borum, 2012; Crowe, Fordham et al., 2014; Crowe, McLeod et al., 2014; Jackson, 2008; Li et al., 2003; Scarinci, 2018; Tachtsis \& Dettman, 2018; Wheeler et al., 2009).

The existing culture of the family tends to be a significant influence that shapes language and communication viewpoints for new family members (Borum, 2012). Within the existing culture of hearing families, in which language and communication are predominantly spoken, some parents viewed deafness as something that needed to be fixed, therefore, they were more likely to be influenced by information related to spoken language (Decker et al., 2012). This is considered an audiological view or medical model in contrast to a cultural view of deafness, 
which embraces sign language as the primary mode of communication and these parents were less likely to be influenced by information related to spoken language (Decker et al., 2012; Matthijs et al., 2017). Some parents did mention attempts to be involved within the deaf culture with mixed results, influencing their thoughts on communication approaches (Jackson, 2008).

In addition, several parents also expressed the desire to share their ethnic and cultural heritages with their children, stating they placed more value on the heritage than the hearing status, and wanted to ensure they would be able to communicate these stories with their children (Borum, 2012; Crowe, Fordham et al., 2014; Steinberg et al., 2003). Some families also expressed their desire for their child to be bilingual in spoken languages, which influenced their communication choice (Guiberson, 2013; Steinberg et al., 2003). Another factor that was thought to be influential was the general attitude toward bilingualism. If the attitude of the geographic area was open to spoken bilingualism, the parents would be more open to deaf and hard of hearing children becoming bilingual in spoken and signed languages; in contrast monolingualism views tended to gravitate toward spoken language only (Crowe, McLeod et al., 2014; Guiberson, 2013).

\section{Theme 2: Needs of the Child}

Many parents looked at the needs of their child to determine which communication opportunity would be the most appropriate fit. Hearing status and accessibility to amplification influenced communication choice and was often included in the decision to use spoken or visual languages or a combination of both (Crowe, McLeod, et al., 2014; Eleweke \& Rodda, 2003; Jackson, 2008; Li et al. 2003; Matthijs et al., 2017; Scarinci et al., 2018; Wheeler et al., 2009). Some parents talked about early access to adequate amplification leading to a decision to use spoken language whereas others were unsure about the potential to develop speech so they chose 
to use sign language (Crowe, Fordham et al., 2014; Scarinci et al., 2018). Others talked about additional disabilities and how that might impact their child's ability to use either spoken or visual languages (Crowe, Fordham et al., 2014).

Many of the studies attributed a change in communication modes over time to the hearing status and amplification; either the child's hearing status progressed to where amplification was no longer beneficial or the child chose to stop using the amplification, thus relying more on a signed or visual language (Borum, 2012; Scarinci et al., 2018). One such parent said, "We delayed signing to get her to talk, because she can hear some things you say. But as she got older and got away from the hearing aid; then we had to learn to sign" (Borum, 2012, p. 11). Other families made communication changes after receiving a cochlear implant, with more of an emphasis on spoken language (Bruin \& Nevøy, 2014; Jackson, 2008; Wheeler et al., 2009). Some families referenced trial and error and switching from one mode to another until they found a mode that their child responded to (Crowe, Fordham et al., 2014; Jackson, 2008), or selected one mode with the knowledge that other modes were available as a backup if needed (Ching et al., 2018). Several parents acknowledged their decision to use a combination of both spoken and signed languages when they noted their child responding well to both and saying this expanded the child's overall ability to interact with others as well as giving them the power to choose a preference in the future (Borum, 2012; Crowe, Fordham et al., 2014; Matthijs et al., 2017; Scarinci et al., 2018; Wheeler et al., 2009). Other parents talked about considering their child's progress, proficiency, and preferences over time as an influencing factor in changing or keeping the mode of communication (Ching et al., 2018; Crowe, Fordham et al., 2014; Jackson, 2008; Scarinci et al., 2018; Tachtsis \& Dettman, 2018; Wheeler et al., 2009). Some parents spoke about following the lead of their child, allowing them to use whichever mode they 
preferred at that time, as well as being willing to try anything that might work and using what seemed to be effective (Scarinci et al., 2018; Tachtsis \& Dettman, 2018; Wheeler et al., 2009). Some parents described communication as a journey that ebbed and flowed, based on a variety of factors, including child preferences, which they supported (Wheeler et al., 2009).

\section{Theme 3: Accessibility}

Accessibility to information was referenced by many parents as an area of influence. Some parents expressed the classic 'you don't know what you don't know' sentiment and felt that not all of the information regarding communication approaches was shared with them, therefore, they did not pursue that modality (Borum, 2012; Ching et al., 2018; Eleweke \& Rodda, 2000). Many parents relied on information received from professionals, yet others searched for further information on their own, from the internet and other parents because they felt the information was not readily accessible, which influenced their decision-making process (Ching et al., 2018; Jackson, 2008; Matthijs et al., 2017).

Accessibility to the communication approaches and opportunities to use and practice them were also stated as factors influencing decisions. One parent reported that they had the opportunity to join a pilot program focusing on spoken language and because that is what was available to them at the time, that is what they continued to focus on (Bruin \& Nevøy, 2014). However, the same parent said that if she had been offered the opportunity to use sign language with her child, she likely would have pursued that as well, expressing regret that she did not incorporate a combination of both, simply because it was not available to her (Bruin \& Nevøy, 2014), a sentiment expressed by other parents (Jackson, 2008; Matthijs et al., 2017). Some parents shared that the availability of services in specific modalities influenced their choice as well, with several alluding to the idea that where they live influenced what services they got, 
which ultimately influenced the communication mode used in the home (Ching et al., 2018;

Crowe, Fordham et al., 2014; Crowe, McLeod et al., 2014; Guiberson, 2013; Li et al., 2003;

Steinberg et al., 2003; Tachtsis \& Dettman, 2018; Wheeler et al., 2009). Others referenced the availability of time and confidence in their own skill levels in learning a new communication skill, such as sign language, as a factor in their decision (Scarinci et al., 2018; Tachtsis \& Dettman, 2018).

\section{Theme 4: Sources of Information}

Three main sources of information emerged: professionals, parent research, and others, including family members, friends, deaf adults and other parents of deaf and hard of hearing children.

Every study, with the exception of Borum (2012), mentioned a variety of professionals as a source and influence of information. These included medical professionals, such as doctors, surgeons, audiologists, and speech pathologists. Educational professionals were also mentioned, such as teachers of the deaf, early intervention specialists, and special education teachers. Parents shared that their communication decisions were influenced, both positively and negatively, by their educational or medical provider. The language used by the professionals to portray the successes and failures of communication approaches was influential and often reflected the values of the professional (Matthijs et al., 2017; Scarinci et al., 2018). One parent stated, "Sometimes they want you to try their approach because they think that's the best or that's what they've been using" (Borum, 2012, p. 12). Many parents reflected that they trusted the professionals because they viewed them as the expert, therefore they trust the information (Ching et al., 2018, Eleweke \& Rodda, 2000; Jackson, 2008; Scarinci et al., 2018). However, some parents were frustrated because they trusted the professional, only to find out later that not all of 
the information on both spoken and signed languages were given to them (Jackson, 2008). Positive connections with providers, feeling accepted, and establishing a sense of trust were all indicated as influences on communication modality choice (Ching et al., 2018; Tachtsis \& Dettman, 2018).

Some parents shared how they chose to go against recommendations and then those professionals reacted negatively toward them to the point the family considered moving to an entirely new location to feel more supported (Bruin \& Nevøy, 2014). One family talked about learning sign in secret, against the advice of the professional, and then eventually relocating to find more accessible services in alignment with their choice (Wheeler et al., 2009). Some felt that professionals did not understand or respect their reasons for choosing a different mode of communication because professionals did not take the time to understand the everyday needs of the family and how that impacted overall communication within the home (Bruin \& Nevøy, 2014).

Many parents took it upon themselves to do their own additional research and relied on that as a source of influencing information. Most often parents turned to the internet and books for additional information with the internet being more influential of the two (Crowe, Fordham et al., 2014; Decker et al., 2012). Because so few parents used existing books as a source of influence and information, Decker and colleagues (2012) did suggest further exploration to see if this is an issue of availability to the parents or accessibility of the content. Other sources of information included family members, friends, deaf adults and other parents of deaf and hard of hearing children (Bruin \& Nevøy, 2014; Crowe, Fordham et al., 2014; Crowe, McLeod et al. 2014; Decker et al., 2012; Guiberson, 2013; Steinberg et al., 2003). 
Interestingly, while the majority of the studies showed that the top sources of information were from professionals, it was the least influential for some (Bruin \& Nevøy, 2014; Decker et al., 2012). It appears that this was due, in part, to conflicting information or pressure, leading to feelings of frustration or distrust. Some families expressed frustration with deaf programs discouraging speaking in an effort to favor sign language, essentially separating the children from their families by not honoring the family's chosen mode of spoken language and supporting effective communication at home (Borum, 2012). Other parents stated that information was given to them as an absolute truth but was in direct conflict with information from another professional who declared their information as the absolute truth, feeling pressured to make the right choice, which made the experience stressful (Bruin \& Nevøy, 2014; Jackson, 2008;

Matthijs et al., 2017). The conflicting information received from professionals supporting different communication approaches was enough to make some parents distrustful of all of the information received, therefore, less influential (Bruin \& Nevøy, 2014). Some others shared that they felt the information they received was inadequate, unbalanced or favoring one modality over the other, leading to feelings of frustration and unrealistic expectations as they tried to apply the information to their own situations (Eleweke \& Rodda, 2000; Jackson, 2008; Matthijs et al., 2017).

\section{Discussion}

The literature shows that parents rely on a variety of sources of information, including both medical and educational professionals, their own research, and, to a lesser degree, deaf adults and other parents. There are a variety of influences guiding the decision-making process, with parent's desires for their child's future and family values appearing to be the most commonly reported influencing factor, along with accessibility to services supporting the 
selected mode (or modes) of communication as well as amplification characteristics and child preferences.

While keeping in mind the variety of factors influencing the selection of communication approaches, the various viewpoints on communication modes and the lack of evidence supporting any one modality over another further complicates matters (Bruin \& Nevøy, 2014; Spencer \& Marschark, 2010). Many parents described this process as challenging (Bruin \& Nevøy, 2014; Jackson, 2008), while others said the decision was simple to make (Bruin \& Nevøy, 2014, Ching et al., 2018; Scarinci et al., 2018). This is an indicator of the complexity of decision-making itself and how the differing attitudes, beliefs, and personalities of both the parents and professionals involved can influence the process. However, this author also wonders how much of the challenge within the decision-making process is actually imposed on the parents by the professional discourse and conflicting opinions surrounding the discussion of communication modes and what might happen if that discourse were somehow altered.

In early intervention, Individuals with Disabilities Education Act mandates that services are to be individualized to each child, perhaps leading to the discussion that it is not possible to provide standard information about communication approaches to families with deaf or hard of hearing children. The information sharing process must be individualized, which leads one to wonder how to ensure the information is still comprehensive and unbiased. Several parents mentioned that each child and family is different and felt frustrated with the pressure to make choices, but the right choice means different things to different people (Bruin \& Nevøy, 2014). In contrast, a recent report released by the National Center for Hearing Assessment and Management (NCHAM) stated that $80 \%$ of the 318 families surveyed across 10 states reported feeling little to no pressure to make decisions (NCHAM, 2017). Several of the studies ( $\mathrm{n}=5$ ) 
mentioned information from professionals was an influencing factor in the communication decision, with some reporting the experience as positive and others as negative. As such, professionals need to be aware of the discourse surrounding their information sharing practices of communication approaches, which can also be influenced by their own views of deafness from a medical or cultural perspective (Matthijs et al., 2017). When sharing information, professionals must remember that each child is unique and what worked for one family may not work for another. In addition, professionals must consider the possibility that what was working at one time may no longer be meeting the needs of the family due to various factors. With many families admitting to communication change over time, it appears they are aware when a communication choice is no longer the right fit, or a child is not progressing as desired, and they are open to making a change, whatever it may be. However, they did not always receive the professional support they desired during that change.

While the studies reflected mixed information related to adequate knowledge of communication approaches, with some saying they had enough and others saying they needed more, it is important to keep in mind that merely having all the information does not simplify the decision-making process. While evaluating an information guide provided by a local parent agency in focus groups, parents were asked to evaluate the comprehensiveness and neutrality of the information; however, the discussion turned to the concept of making decisions (Young et al., 2005). Many of those parents felt that even having comprehensive and unbiased information still presented a dilemma, stating, "the problem of how to make choices did not automatically go away" (Young et al., 2005, p. 67). This concept that is also addressed in the realm of informed choice. While providing information that is unbiased and all-inclusive fits the definition of informed choice, parents may not understand all the information or may not know how to move 
forward (Marteau et al., 2001). This opens the discussion to the next steps and how to support families in knowing what to do with the information and how to make the choice.

Due to the conflicting opinions parents often experienced, it is safe to assume that most professionals have a bias when it comes to communication modalities, even those who profess not to have one. Information provided on communication approaches is often framed as one of two discourses: a medical view (auditory and spoken) or cultural view (signed/visual) (Matthijs et al., 2017). It is important to remember that there is no one approach that works for all deaf and hard of hearing children (Bruin \& Nevøy, 2014; Spencer \& Marschark, 2010). In these studies, many of the factors influencing communication choice were external, from outside of the family: accessibility of information, access to services, and the opinion of professionals. However, parent desire for their child's future was a common influence and decisions are often made in alignment with personal values of the decision maker (DesGeorges, 2018; Marteau et al., 2001), which are internal, from within the family. So perhaps the role of professionals supporting the decision-making process now is two-fold: the provision of comprehensive information and a discussion on how to make choices while managing both external and internal influences. This would require a paradigm shift for many within the field.

Language development is dependent on communication (Kushalnagar et al. 2010; Marschark, 2001) and communication begins at birth in both verbal and nonverbal forms. Children who share a common language with their parents tend to have more linguistic rich experiences and progress along typical language and communication milestones (Marschark, 2001). In reading through each of these studies, I wonder if the parents, and perhaps the professionals themselves, have an understanding of how language and communication are intertwined for children who are deaf or hard of hearing and the development process of each 
one. Decker and colleagues (2012) does touch upon this concept in their study by incorporating a self-made "Knowledge of Communication Development Scale" (p. 335) into their survey. Their results showed no significant difference in knowledge of communication development and communication choice between those who chose spoken language and those who chose sign language. However, they caution that their sample (36 parents, 35 children) was relatively well educated and warranted further exploration to see if this would generalize to a diverse educational demographic (Decker et al., 2012). Further exploration of the understanding of language and communication would add another layer to the communication modality discussion for both parents and professionals as well as provide additional insight into the decision-making process.

The United States has an established and systematic hearing screening system in place, with $98.3 \%$ of babies being screened prior to discharge (CDC, 2017b). While the CDC shows that $65.1 \%$ of diagnosed deaf and hard of hearing babies are enrolled in early intervention, this literature review appears to show that there is nothing systematic about the information shared with families regarding communication approaches to ensure all parents receive consistent information. As the old saying goes, "You don't know what you don't know." Parents reported feeling overwhelmed at the amount of information to learn and the intense pressure to make decisions in a short time frame about what is often an unfamiliar topic that is sometimes framed as right vs. wrong (Bradham et al., 2011; Bruin \& Nevøy, 2014; DesGeorges, 2016).

While medical and educational professionals are a primary source of influence for many families, few studies mentioned connecting with and receiving information from deaf adults themselves (Crowe, Fordham et al., 2014; Crowe, McLeod et al., 2014; Matthijs et al., 2017), and other parents (Decker et al., 2012; Guiberson, 2013). Including deaf adults in the information 
sharing process is an area of need highlighted by NCHAM (2017) as needing improvement. This current gap presents a risk that parents may not be receiving comprehensive information due to the diverse opinions within the field, reliance on information from professionals, and limited contact with deaf adults and other parents. Connecting families with deaf adults and other parents are also included in the JCIH $(2000,2007)$ guidelines and Best Practices in Family Centered Early Intervention (Moeller et al., 2013) principles, stating that deaf and hard of hearing adults are a valuable source of information and support for families. Many studies brought up the idea of attitudes, values, and beliefs (Crowe, McLeod et al., 2014; Decker et al., 2012; Li et al., 2003) as an influencing factor in the communication decision, both from professionals and from those with personal experiences, such as deaf adults and other parents (Crowe, Fordham et al., 2014; Crowe, McLeod et al., 2014; Matthijs et al., 2017).

The Best Practices in Family Centered Early Intervention (Moeller et al., 2013) and JCIH $(2000,2007)$ guidelines recommend informed consent, family involvement, and dissemination of comprehensive information relating to communication approaches. Keeping in mind the concept of informed choice, this author would suggest that the current early intervention system needs to explore in depth the idea of informed choice and how it relates to communication modalities. Perhaps a systematic model of sharing information would remove some of the conflicting information and resulting pressure some parents feel. In addition to a systematic model of sharing information, it appears that parents might also need support in how to make decisions (Ching et al., 2018; Young et al., 2005), similar to patient decision aids sometimes used in the medical field as a way to reduce and minimize bias and enhance the understanding of information (Porter et al., 2018). 
Currently, the literature does not reflect any such patient decision aid model in the field of deafness, consequently, it is not widely used. At this point in time, to the best of my knowledge, there is no systematic information sharing model regarding communication approaches in place within the early intervention system at either the national level or within the state levels. There are some attempts, such as the SKI-HI program (Barringer et al., 1998), Beginnings for Parents of Children who are Deaf or Hard of Hearing (http://ncbegin.org), and NCHAM's Preparing to Teach, Committing to Learn: An Introduction to Educating Children Who Are Deaf/Hard of Hearing e-book with a chapter on Communication Options (GardinerWalsh \& Lenihan, 2017). SKI-HI specifically trains professionals to become parent advisors and go into the homes of deaf and hard of hearing families to provide supports, information, and skills to facilitate their child's overall development, and includes, but is not focused solely on, discussion of communication approaches (Barringer et al., 1998). Beginnings, a non-profit for parents of children who are deaf or hard of hearing, has a reference chart available on their website that displays the communication approaches, listing the definition, primary goals, receptive and expressive language development goals, hearing status typically associated with that communication mode, and family responsibilities/guidance when using that mode. The NCHAM e-book chapter on Communication Options provides definitions of each modality, prevalence, benefits and challenges, and sources for additional information. While these resources appear to be comprehensive and unbiased, no in-depth studies could be found in the literature review on the effectiveness or implementation of these models. One exception is a report on SKI-HI, showing that deaf and hard of hearing children and their families receiving support, information, and training from a SKI-HI parent advisor showed significant gains in both language and auditory development (Barringer et al., 1998). Further exploration into these, or 
similar models for systematic information sharing on communication approaches to support the concept of informed choice is necessary and determine if parents would consider this beneficial.

While there are several studies focusing on factors influencing communication choice, of those in this literature review, only five were conducted in the United States (Borum, 2012; Decker et al., 2012; Jackson, 2008; Li et al., 2003; Steinberg et al., 2003) and two of them focus on specific ethnic groups (Borum, 2012; Steinberg et al., 2003). With the emphasis on familycentered practices and informed choice within early intervention, much could be learned from continuing this line of study with families in the United States. A recent study conducted by NCHAM (2017) indicates that families are receiving quality information about communication approaches and identifies this as an area of strength. However, in looking at their data, many families still report receiving poor quality information (as compared to excellent, good, or fair) across four modalities: $14 \%$ listening and spoken language, $17 \%$ sign language, $21 \%$ total communication, and 32\% cued speech (NCHAM, 2017). Per the recommended early intervention guidelines (JCIH 2000, 2007; Moeller et al., 2013) all families should be receiving excellent quality information about all communication approaches.

Furthermore, there is very little information on the process of sharing communication approaches from the perspective of a professional or provider. Wheeler et al. (2009) did interview the providers of the participants and found that many acknowledge that the families and children should be making the communication decisions, with the child's preferences and progress needing to be closely monitored. However, these providers were not asked about the concept of sharing information. In a different study in the U.S., NCHAM (2017) briefly mentions that about half of the 185 early intervention providers surveyed report having an excellent to good knowledge of teaching children who are deaf or hard of hearing using sign language (54\%), 
spoken language (68\%), or total communication (61\%), but does not mention their self-efficacy of sharing information regarding communication choice with families. Continued research is needed in this area with a focus on the United States and how that information can guide professional practices in alignment with the recommended guidelines of early intervention. Perhaps this would uncover some insight into reducing the conflicting information as well as alter the discourse and pressure surrounding communication approaches that is felt by some parents. In addition, this kind of understanding could allow current early intervention professional practices to become more aligned with informed choice practices.

As a deaf individual and professional who is not the parent of a deaf child, this author fully recognizes the personal experiences of her own upbringing adds a potential bias to this discussion. This author also fully recognizes that birthing children who are hearing prevents a full understanding of the decision-making experience that parents of deaf and hard of hearing children encounter. However, being fluent in various forms of spoken and visual languages, including spoken English, American Sign Language, and Cued American English (i.e. Cued Speech) allows the author a unique perspective into the discussion of communication modalities for deaf and hard of hearing children. The author also has the power to choose a mode of communication to fit the situation, as referenced by some parents (Borum, 2012; Crowe, Fordham et al., 2014). As a result, the author might approach the concept of sharing information about communication approaches differently than another deaf individual fluent in only one communication mode, regardless of the successes or challenges with that mode.

\section{Conclusion}

Ultimately, it is evident in this literature review that there are a variety of factors influencing communication decisions made by parents of deaf and hard of hearing children. 
Parent values and desires for their children, needs of the child, accessibility of information and services, and various sources of information are all influencing factors. Parents are aware of the need for communication and consistently evaluate their choices in terms of what appears to be effective for their family, often taking into consideration their child's preferences, explicit or implicit. Many parents expressed that they felt equipped to make the necessary communication decisions but others expressed frustrations at the lack of information made available to them, prompting them to seek out more information. The diverse discourse surrounding the conversation of communication approaches leads to the possibility of the need for a systematic model of information sharing, but also opens up the necessity of support for the next step, which is applying the information and making the decision. However, the challenge then becomes using a systematic model while simultaneously keeping it individualized for each family. One must consider the feasibility of this. Also, keeping in mind the concept of informed choice, it is not enough to just have comprehensive and unbiased information, there is also a need to process and understand the information. Only then can one make the actual decision on communication usage within the family. 


\section{CHAPTER III: METHODOLOGY}

The purpose of this multiple methods study using a phenomenology focus was to identify the parental perception of the information gathering process as they learn about communication approaches to use with their deaf or hard of hearing child and how this factored into their decision-making. A better understanding of this experience as currently experienced by parents in Illinois will lead to discovery of ways to support them in the process, while keeping in line with current recommended best practices and the concept of informed choice. As indicated in the literature review, research has been done on factors that influence communication choices, with the vast majority of recent research conducted outside of the United States. Prior to this study, there has been no examination of this issue within Illinois.

\section{Problem Statement}

The development of language in a deaf or hard of hearing child is dependent upon early and effective communication access (Marschark, 2018; Marschark \& Hauser, 2012; Pittman et al., 2016; Scott \& Dostel, 2019; Scott \& Henner, 2020). Often, when a hearing child is born into a hearing family, communication occurs naturally because communication approaches and hearing status match. However, when a child's hearing status is different than the parent's (i.e. a deaf child is born into a hearing family), as is the case for a majority of deaf and hard of hearing children, communication becomes much more complicated and parents are faced with the decision of how they will communicate with their child (Pittman et al., 2016). There are a number of communication approaches available to deaf and hard of hearing children and research has shown all of them to be successful when appropriately matched with the child, taking into consideration their needs and abilities (Marschark, 2018; Stredler-Brown, 2012). It is important that parents understand the continuum of auditory and visual approaches to 
communication, ranging from solely relying on hearing and speaking to solely relying on sign, to a mixture of both and how they might benefit their child.

Upon entering early intervention, some parents have already been in contact with some professionals and have received some assortment of information related to communication approaches due to connecting with an audiologist to receive a diagnosis as well as some selfinitiated research. However, there is some concern regarding the comprehensiveness and accuracy of the information that is being provided (Eleweke et al., 2008; Matthijs et al., 2017; Meadow-Owens et al., 2003; Porter et al., 2018). To add to the confusion, there are a variety of terms used when describing communication with deaf and hard of hearing people. Pittman and colleagues (2016) summarize this confusion and their definition as follows:

Various terms are used to describe how deaf people communicate. These include options, methodologies, approaches, modalities, choices, and since 2011, communication opportunities. In this chapter, we will be using the term modality to represent a sensory modality (e.g. visual, auditory, or tactile) and communication approaches to describe the systems used to communicate (e.g. cued speech, MCE [Manually Coded English], simultaneous communication, listening, spoken language). We will focus on English and ASL [American Sign Language] to represent the two most common languages used in the education of children who are D/HH [Deaf/Hard of Hearing] in the United States (p. 150).

The modality represents the way the communication occurs (via vision, hearing, touch/movement) whereas the approach represents how that communication occurs. In the U.S., the language conveyed through the modality and approach is typically English and ASL. For the purpose of this paper, the same parameters will be used. Pittman and colleagues (2016) created a 
table summarizing the communication approaches with examples of each modality and language used, which is reprinted with permission in Table 6. It is important to note that the authors of the table did not mention their rationale for the presentation order of the Communication Approaches. Upon further examination, it appears that the approaches are listed in the order of visual access to language, as well as on a continuum starting with ASL and moving towards English. 


\section{Table 6}

Communication Approaches

\begin{tabular}{|c|c|c|c|}
\hline Approach & Description & $\begin{array}{c}\text { Languages } \\
\text { incorporated }\end{array}$ & Modalities incorporated \\
\hline $\begin{array}{l}\text { Bilingual-bimodal } \\
\text { (Bi-Bi) }\end{array}$ & $\begin{array}{l}\text { Incorporates the use of two languages, one visual and } \\
\text { one spoken. American Sign Language (ASL) is a full } \\
\text { and complete visual language with complete } \\
\text { grammatical structures that incorporate signs and } \\
\text { nonmanual markers expressed on the face and body. } \\
\text { ASL has no spoken or written form. ASL is used } \\
\text { separately but in the same environment as a true, full, } \\
\text { and complete spoken language. The two languages are } \\
\text { given equal value and equal representation. }\end{array}$ & $\begin{array}{l}\text { ASL or a native } \\
\text { sign language and } \\
\text { English or another } \\
\text { spoken language }\end{array}$ & $\begin{array}{l}\text { Listening/speaking } \\
\text { Print } \\
\text { Visual systems of signs or } \\
\text { cues that represent a } \\
\text { spoken language visually } \\
\text { Facial/body } \\
\text { expressions/gestures } \\
\text { Speechreading }\end{array}$ \\
\hline $\begin{array}{l}\text { Simultaneous } \\
\text { communication } \\
\text { (Sim-Com) }\end{array}$ & $\begin{array}{l}\text { A true spoken language is used with a system of signs } \\
\text { (not a true visual language) that borrow from ASL but } \\
\text { are put in English order and then said and signed } \\
\text { simultaneously. }\end{array}$ & $\begin{array}{l}\text { Spoken English or } \\
\text { another spoken } \\
\text { language }\end{array}$ & $\begin{array}{l}\text { Visual system of signs or } \\
\text { cues that represent a } \\
\text { spoken language visually } \\
\text { Facial/body } \\
\text { expressions/gestures } \\
\text { Speechreading }\end{array}$ \\
\hline Sign-supported speech & $\begin{array}{l}\text { Signs are used to clarify and support the use of spoken } \\
\text { language. Primarily used when children rely on mostly } \\
\text { audition and spoken language to communicate but may } \\
\text { need visual support to understand spoken language in } \\
\text { loud settings or for new information. }\end{array}$ & $\begin{array}{l}\text { Spoken English or } \\
\text { another spoken } \\
\text { language }\end{array}$ & $\begin{array}{l}\text { Listening/speaking } \\
\text { Visual system of signs that } \\
\text { represent a spoken } \\
\text { language visually } \\
\text { Facial/body } \\
\text { expressions/gestures } \\
\text { Speechreading }\end{array}$ \\
\hline
\end{tabular}

(Table Continues) 
Table 6, Continued

\begin{tabular}{|c|c|c|c|}
\hline Approach & Description & $\begin{array}{l}\text { Languages } \\
\text { incorporated }\end{array}$ & Modalities incorporated \\
\hline $\begin{array}{l}\text { Pidgin Signed English } \\
\text { (PSE) }\end{array}$ & $\begin{array}{l}\text { Used when native English speakers are learning ASL } \\
\text { and use ASL signs without using appropriate ASL } \\
\text { grammar and sign in an incomplete way. Used as a } \\
\text { bridge to link spoken and signed language and is not } \\
\text { seen as a true representation of either language. }\end{array}$ & $\begin{array}{l}\text { Parts of spoken } \\
\text { language and parts } \\
\text { of ASL or a signed } \\
\text { English system }\end{array}$ & $\begin{array}{l}\text { Listening/speaking } \\
\text { Signs (may be ASL signs } \\
\text { or signs from an English- } \\
\text { based sign system) } \\
\text { Facial/body } \\
\text { expressions/gestures } \\
\text { Speechreading }\end{array}$ \\
\hline Cued speech & $\begin{array}{l}\text { A system of eight arbitrary handshapes placed in one } \\
\text { of four positions near the face that visually presents a } \\
\text { phonemic representation of syllables used in spoken } \\
\text { English. Cued speech systems have been created to } \\
\text { represent sounds in } 48 \text { different languages to make } \\
\text { visual the phonemes that are spoken that cannot be } \\
\text { visually distinguished through lipreading. }\end{array}$ & $\begin{array}{l}\text { Spoken English or } \\
\text { another spoken } \\
\text { language }\end{array}$ & $\begin{array}{l}\text { Listening/speaking } \\
\text { Speechreading } \\
\text { System of cues that } \\
\text { phonetically represents a } \\
\text { spoken language } \\
\text { Facial/body } \\
\text { expressions/gestures }\end{array}$ \\
\hline $\begin{array}{l}\text { Auditory-oral } \\
(\mathrm{A}-\mathrm{O})\end{array}$ & $\begin{array}{l}\text { Using listening to understand speech along with } \\
\text { speechreading, facial expression, and gestures and } \\
\text { using spoken language to interact with others. }\end{array}$ & $\begin{array}{l}\text { Spoken English or } \\
\text { another spoken } \\
\text { language }\end{array}$ & $\begin{array}{l}\text { Listening/speaking } \\
\text { Speechreading } \\
\text { Facial/body } \\
\text { expression/gestures }\end{array}$ \\
\hline $\begin{array}{l}\text { Listening and spoken } \\
\text { language (previously } \\
\text { known as auditory- } \\
\text { verbal/AV) } \\
\text { (LSL) }\end{array}$ & $\begin{array}{l}\text { Using primarily listening and audition to understand } \\
\text { spoken language and using spoken language to interact } \\
\text { and communicate with others. }\end{array}$ & $\begin{array}{l}\text { Spoken English or } \\
\text { another spoken } \\
\text { language }\end{array}$ & $\begin{array}{l}\text { Listening } \\
\text { Speaking }\end{array}$ \\
\hline
\end{tabular}


Note. Reprinted with permission (Appendix B) from Pittman, P., Sass-Lehrer, M., \& Abrams, S. (2016). Sign language, sign systems, and other visual modalities. In M. P. Moeller, D. J. Ertmer, \& C. Stoel-Gammon (Eds.), Promoting language \& literacy in children who are deaf or hard of hearing (pp. 149-179). Baltimore, MD: Paul H. Brookes Publishing Co. 
Existing literature is available that explores information parents have received and how it factors into their decision-making, however, there is little recent literature actually describing the experience of parents making a decision based on that information (Crowe et al. 2014a, 2014b; Decker et al., 2012; Porter et al., 2018). The process of making a decision can be described as either heuristic (automatic and instinctive) or systematic (deliberate and intentional) (Chaiken \& Ledgerwood, 2012; Elwyn et al., 2012; Payne, 1976; Porter et al., 2018). Decisions related to communication approaches could also be described as either heuristic or systematic, or perhaps both. There is also literature discussing the concept of shared decision-making in the medical field, with providers and patients working together in a systemic way to explore the options, preferences, and ultimately make a decision (Elwyn et al., 2012; Payne, 1976; Young et al., 2006). While the concepts of a specific decision-making model could be applied to decisions related to communication approaches, the existing literature has not yet explored this.

As indicated in the studies throughout the literature review (see Table 4), to make a decision related to communication approaches, parents first sought out information. Unfortunately, there are still some serious discrepancies between the recommended guidelines for accessing information and the actual experiences as reported by parents (Fitzpatrick et al., 2008; Meadow-Owens et al., 2003; Scarinci et al., 2018). To complicate matters further, the discourse among professionals within the field of deafness is often conflicted between a medical view (spoken/auditory) or cultural view (signed/visual) (Matthijs et al., 2017), leaving some parents feeling overwhelmed and distrustful (Bruin \& Nevøy, 2014; Jackson, 2011; Matthijs et al., 2017). Some families are not receiving unbiased information about communication approaches in a timely manner (Eleweke et al., 2008; Porter et al., 2018; Scarinci et al., 2018), which is critical because the diagnosis of deafness impacts all areas of family life in a variety of 
ways, resulting in multifaceted needs for families (Jackson, Traub, \& Turnbull, 2008; Marschark, 2018). As a result, this phenomenon of receiving information related to communication approaches and the resulting decision-making process needs to be studied further in an attempt to learn how to better support families in this process.

Understanding what information parents are currently receiving about communication approaches for their deaf or hard of hearing child would ultimately enhance the early intervention service provider's delivery methods and provision of support to future families of deaf and hard of hearing children. The results of this study will be significant as the findings could guide early intervention providers to discover the gaps in supporting informed choice, decision-making, and information sharing as related to the guidelines recommended by Division for Early Childhood (DEC) (2014), Joint Committee on Infant Hearing (JCIH) (2000, 2007, 2019) and the supplement (AAP, 2013; Muse et al., 2013; Yoshinaga-Itano, 2013), and best practices put forth by Moeller and colleagues (2013), specifically in regards to disseminating information about the various communication approaches and supporting families during the decision-making process.

\section{Purpose of the Study}

The purpose of this study was to examine parental perspectives of information received about communication approaches for their child. In addition, the study will determine if the recommended guidelines related to informed choice, decision-making, and information sharing within the early intervention process were implemented with the study participants based on their reported experiences. Specifically, this study aimed to look at the information gathering and resulting decision-making process from the parent perspective. This study has two parts, beginning with the use of a survey (Appendix C) targeted towards parents or primary caregivers 
of deaf and hard of hearing children (aged 3-5) who have participated in the early intervention system in Illinois for at least one year. The survey asked questions related to the kinds of information parents/primary caregivers received regarding communication approaches, who they received it from, and how that information factored into their decision-making. Following the survey, participants had the option to participate in individual interviews with the researcher.

\section{Research Questions}

A multiple methods phenomenological research design will be used to help answer the following research questions: how did parents perceive the process of receiving information about communication approaches for their deaf or hard of hearing child? Specifically, (a) what information did parents of young deaf and hard of hearing children in Illinois receive regarding communication approaches?, (b) who or where did they receive information about communication approaches from?, (c) how did this information factor into their decision-making process in selecting communication approaches for their child?, and (d) how might future parents potentially benefit from the use of a reference chart or communication matrix when learning about, and ultimately selecting, communication approaches to use with their child?

\section{Theoretical Framework}

Upon identification of a child being deaf or hard of hearing, the family is referred to the local early intervention offices so that they can begin to explore available services and supports as they navigate the unknown reality of raising their child (see Figure 5). Often, these services and supports include information about communication approaches. Many studies have indicated that families rate access to unbiased information about communication approaches as important, as well as how to implement and support that approach with their child (Eleweke et al., 2008; 
Jackson, 2011; Porter et al., 2018). This is in line with the current recommendations by DEC (2014), JCIH (2007, 2013, 2019), Yoshinaga-Itano (2013), and Moeller et al. (2013).

The concept of informed choice and decision-making is complex, requiring both access to and analysis of the relevant information (Porter et al., 2018; Young et al., 2005, 2006). The current recommendations when working with families of young deaf and hard of hearing children include guidelines for supporting families through the concepts of informed choice, decision-making and sharing information (DEC, 2014; JCIH 2007, 2013, 2019; Moeller et al. 2013; Muse et al., 2013, Yoshinaga-Itano, 2013). Table 3 shows a side-by-side comparison of the specific recommendations that mention informed choice, decision-making and sharing information. Furthermore, the JCIH 2007 Supplement (Muse et al., 2013; Yoshinaga-Itano, 2013) specifically mentions that providers must have knowledge and skills to: "promote informed decision-making through provision of accurate and comprehensible information, resources, and support" (p. 168) as mentioned in three out of eight best practice documents. All of the best practice documents also encourage providers to "implement strategies for guiding and supporting families' decisions regarding communication approaches/opportunities" (p. 168). These consistent references to informed choice, decision-making, and sharing information highlight the importance of these actions when supporting families of deaf and hard of hearing children.

Informed choice is defined as "one where all the available information...is weighed up and used to inform the final decision" (Marteau et al., 2001, p. 100). To support families as they make an informed choice regarding communication approaches, providers should be providing families with information about all of the approaches, including those they may be unfamiliar with or do not use professionally or personally. In addition, providers should be guiding a 
balanced discussion of the potential implications, what each approach might look like for the individual child and their family, as well as discussing commitment and outcomes typically associated with each approach (Marschark, 2018; Moeller et al., 2013). Doing these things empowers the family to make informed choices based on their own unique circumstances, as well as increasing the likelihood that they will follow through with their choice (DesGeorges, 2018). However, a recent systematic literature review of 35 studies (Porter et al., 2018) looked at parental decision-making and discovered that while informed choice was mentioned within a number of those studies, it was not explicitly defined nor was the process of informed choice described in detail. Based on this information, this study will examine the perspectives of parents who have recently exited the Illinois early intervention system and determine what their experiences reveal related to learning about communication approaches for their child in an effort to further understand the process of informed choice and decision-making.

\section{Methods}

\section{Research Design}

A phenomenological approach was selected for this study, more specifically an explanatory sequential design by using both a survey and interviews. The use of an explanatory sequential design allows for descriptive data to be collected first via survey, with in-depth qualitative phenomenological data collected afterwards through individual interviews (Merriam \& Tisdell, 2016). Using a survey established current trends in information dissemination related to communication approaches within early intervention while the individual interviews allowed for a more in-depth examination of the parent experience regarding receiving information about communication approaches. Using multiple data collection methods also supports triangulation 
by comparing and contrasting the data derived from each method to allow more confidence in the resulting conclusions (Maxwell, 2013).

The descriptive data collected via survey allowed for a description of the representative sample population, specifically categorization data (i.e. age of diagnosis, hearing status, amplification, location of services, and other demographic information). It also allowed for a collection of data using Likert Type scales that analyzes the perception of information received related to communication approaches by this sample, ease of access to information, and perceived knowledge of particular providers. This data will create a snapshot of current trends as perceived by families during their time within early intervention in Illinois, which aligns well with the purpose of this study and using a survey design as part of the methodology. Limiting the time frame since exiting early intervention will ensure the information provided by the study participants is relatively recent and attempts to avoid the effects of history and maturation (Fraenkel et al., 2016).

The qualitative aspect of this research design utilizes the foundation of phenomenology as a guiding factor. Phenomenology is described as the study of human experiences and how humans perceive them, in which the researcher is tasked with uncovering the underlying core of the experience and then relaying that to others in an effort to truly understand the event (Merriam \& Tisdell, 2016). In addition, the interview questions are designed to access the episodic memory of the participants by asking parents to share and describe information about specific events (Maxwell, 2013). Since the research question focuses on the parent experiences of information dissemination regarding communication approaches with the hope of discovering ways to better support them. The use of phenomenology within the qualitative aspect of this research as well as episodic interviewing techniques aligns well with the purpose of this study. 


\section{Sample and Participants}

Participants for this study were identified using purposeful sampling. Parents or primary caregivers of deaf and hard of hearing children who exited the early intervention program in Illinois within the past two years were asked to complete a written survey online. Inclusion criteria indicated that their children would be between the ages of 3 and 5 years old, had been identified as deaf or hard of hearing between the ages of birth and 3 years of age, and received early intervention services for at least one year while residing in Illinois. Participants were recruited by eliciting the assistance of various parent support organizations throughout Illinois and their social media groups. Additional recruitment occurred through a snowball effect from social media posts shared via the Facebook pages of the above parent support organizations.

\section{Survey Population Sample Description}

A total of 33 surveys were attempted with 21 completed. Twenty completed surveys were filled out by mothers while one was completed by a father. Twenty-one children were the focus of the survey, with 11 males and 10 females. All the children were between the ages of 3 and 5 years old. Three of them had one or both parents who were deaf or hard of hearing, while the other 18 had hearing parents and there were no reported deaf or hard of hearing siblings. All 21 parents indicated they had some college education or more with six indicating annual household incomes of less than $\$ 50,000$ and 15 earning more than $\$ 50,000$. Geographically, the respondents primarily resided in the northern sector of Illinois while receiving early intervention services $(86 \%)$ while the others resided in central or southern Illinois. A summary of the respondent information can be seen in Table 7. Encouraged to select all that apply, the respondents reported their ethnicity/race as white (58\%); Hispanic, Latino, or Spanish Origin 
(23\%); Black or African American (11\%); American Indian or Alaska Native (4\%); and Asian (4\%) (see Figure 8).

\section{Table 7}

Survey Respondent Demographic Information

\begin{tabular}{|c|c|c|}
\hline Demographic information & Number (n) & $\%$ \\
\hline \multicolumn{3}{|l|}{ Relationship to the child } \\
\hline Mother & 20 & $95 \%$ \\
\hline Father & 1 & $5 \%$ \\
\hline \multicolumn{3}{|l|}{ Gender of child who is deaf or hard of hearing } \\
\hline Female & 10 & $48 \%$ \\
\hline Male & 11 & $52 \%$ \\
\hline \multicolumn{3}{|l|}{ Hearing status of parent and siblings } \\
\hline No deaf or hard of hearing parents & 18 & $86 \%$ \\
\hline One deaf or hard of hearing parent & 2 & $9 \%$ \\
\hline Two deaf or hard of hearing parents & 1 & $5 \%$ \\
\hline Reported deaf or hard of hearing siblings & 0 & $0 \%$ \\
\hline \multicolumn{3}{|l|}{ Highest education level } \\
\hline Some college or more & 21 & $100 \%$ \\
\hline \multicolumn{3}{|l|}{ Total income } \\
\hline Less than $\$ 50,000$ & 6 & $29 \%$ \\
\hline More than $\$ 50,000$ & 15 & $71 \%$ \\
\hline \multicolumn{3}{|l|}{ Geographical location when receiving EI } \\
\hline Northern Illinois & 18 & $86 \%$ \\
\hline Central and Southern Illinois & 3 & $14 \%$ \\
\hline
\end{tabular}




\section{Figure 8}

Self-Reported Ethnicity/Race of the Child

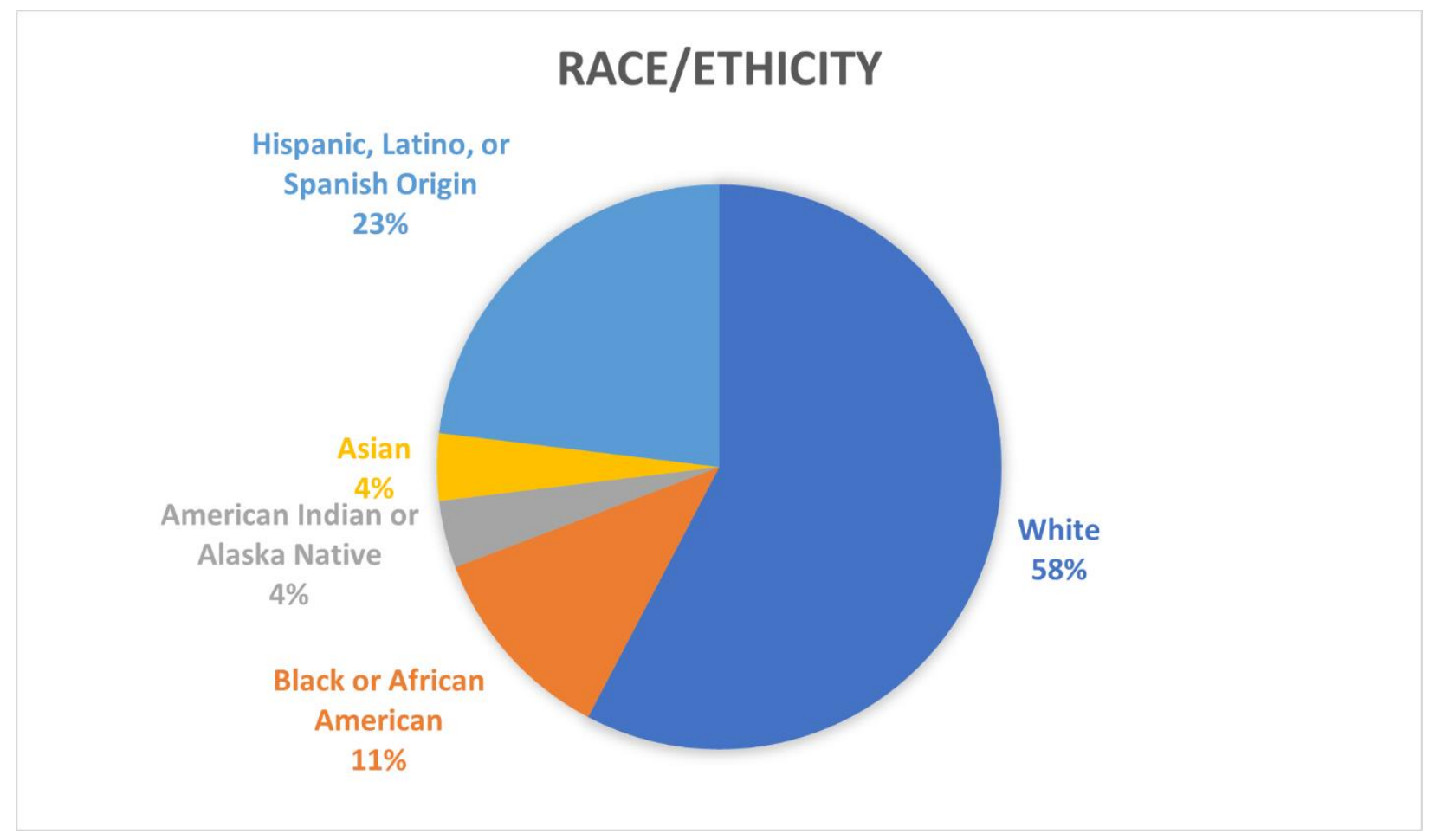

Note. Out of 21 surveys, 26 items were selected. Native Hawaiian or Pacific Islander, Other, and Prefer Not To Answer were not selected by any respondents.

Hearing Levels, Technology, and Additional Delays

Question \#3, 4, and 5 asked for information about the child's unaided hearing levels, current technology used, and the presence of additional delays. The children were reported to have varying hearing levels ranging from none to profound without the use of hearing technology. No parameters or definition were provided for each hearing level. See Figure 9 for a side-by-side comparison of reported hearing levels by ear. 


\section{Figure 9}

Reported Current Unaided Hearing Level of the Child, Right Ear and Left Ear

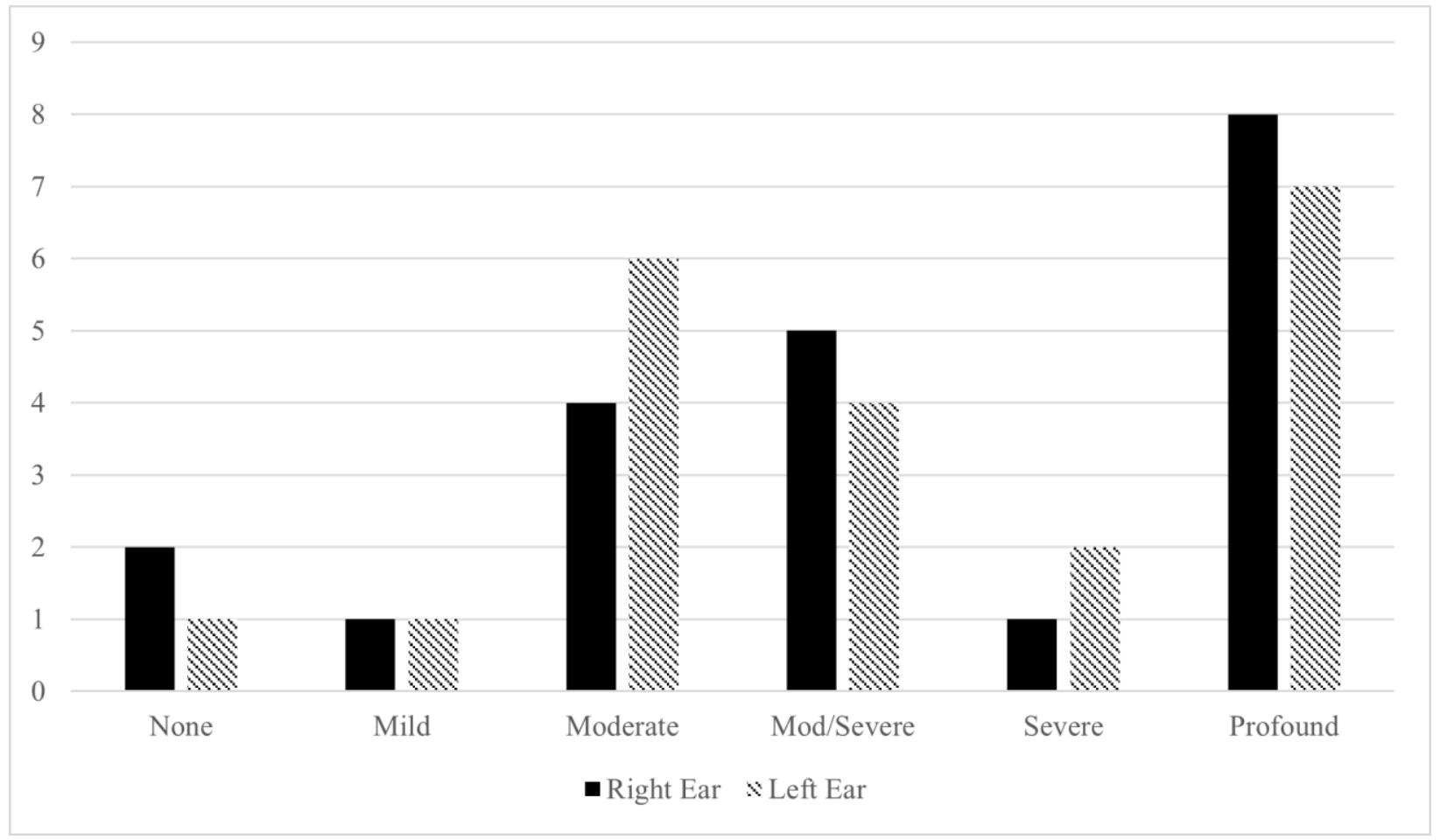

Parents were then asked to report what hearing technology was currently being used, again broken down by right ear and left ear. Figure 10 provides a side-by-side comparison of the hearing technology currently being used by ear. Note the total sample size for the right ear is higher than the left, however, the vast majority of the children have some sort of hearing technology. 


\section{Figure 10}

Reported Hearing Technology Currently Being Used by the Child, Right Ear and Left Ear

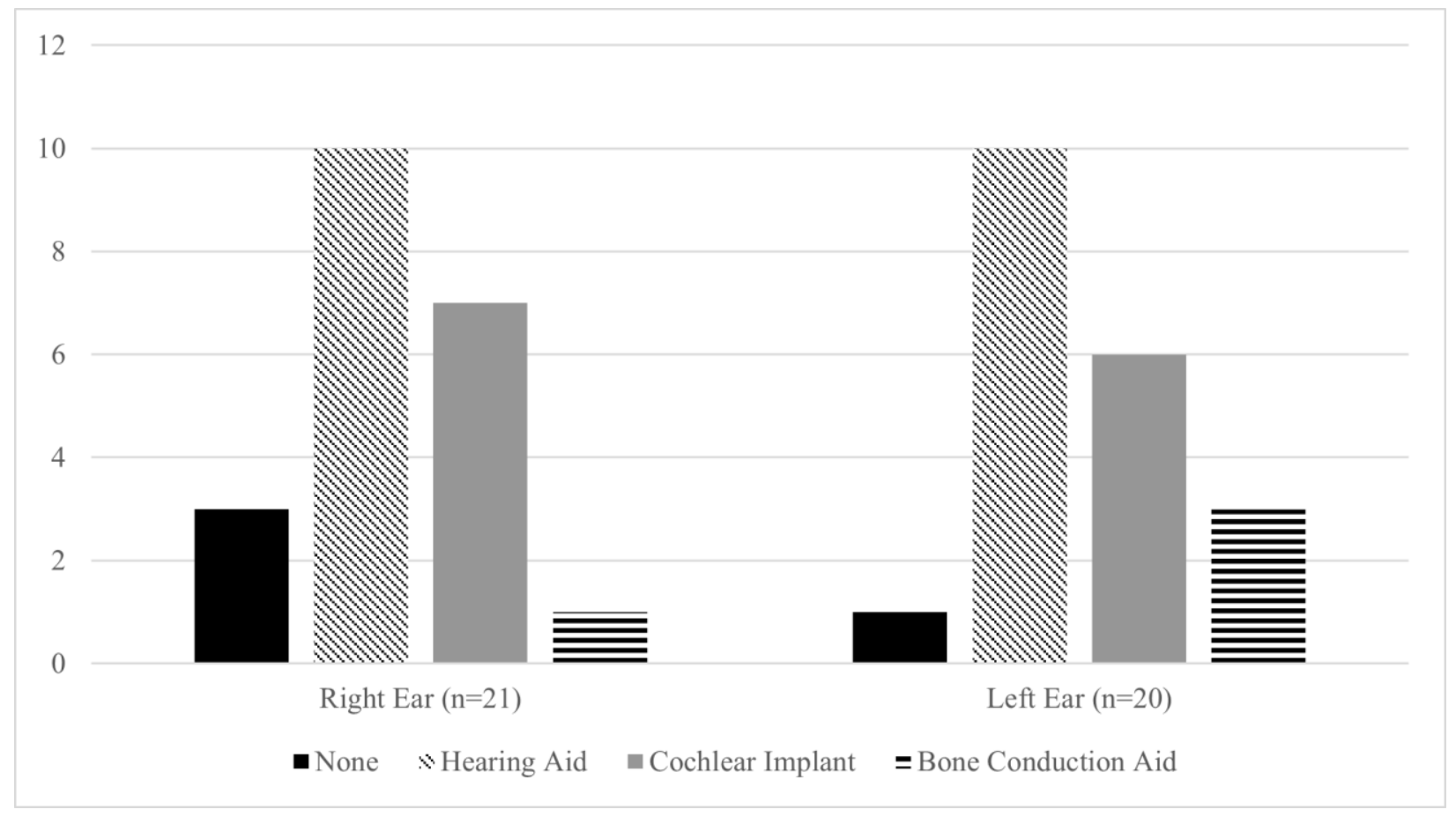

Note. The total reported $\mathrm{n}$ is higher for the right than for the left.

Survey respondents were also asked to report the existence of other delays and to categorize them as none, mild, moderate, severe, and unknown. No definition of the delays/categorization were provided nor was the word 'diagnosis' used in the question. See Figure 11 for a breakdown of each delay area plus level of severity chose. 


\section{Figure 11}

Additional Delays as Reported by Parents



\section{Interview Population Sample Description}

Four individual interviews were conducted and all four were mothers of deaf or hard of hearing children ages three to five years old. Three of the mothers were hearing and one was deaf, however two of the mothers indicated a family history of deafness during their interviews (for a total of two with family history of deafness and two without). Interviews ranged from 20 to 45 minutes long. Three of the interviews were conducted in spoken English with an interpreter present. One interview was conducted completely in ASL. All interviews were recorded for transcription and analysis purposes. All voice recorded interviews were transcribed by the Student Access and Accommodation Services office at Illinois State University, with the exception of the interview with the deaf mother, which the researcher transcribed from ASL into written English. This transcription was checked for accuracy by a second member of the research team who is also fluent in ASL. 


\section{Recruitment}

Participants were recruited through an email, approved by Illinois State University IRB, sent to various parent support organizations in Illinois that specialize in deafness with a request to distribute via their email lists and social media sites (Appendix G). The following parent support organizations were sent the recruitment email: Illinois Hands and Voices, Illinois Guide By Your Side, CHOICES for Parents/Chicago Hearing Society, and the Illinois School for the Deaf Outreach program. Written permission was obtained from each of these organizations to assist in the recruitment process (Appendix H). The recruitment email included a short introduction, request for participation in this survey, and a list of potential risks and benefits of their participation. The email also included a flyer with a link to the survey as well as a QR code linked to the survey (see Appendix G).

The survey was designed with logic to ensure participants met the inclusion listed as the first three questions. If all three questions were answered yes, then the participant could continue to the rest of the survey. If any one of the three answers were no, then the participant was automatically exited from the survey. The criteria to participate was as follows: parents with a child aged three to five years old identified as deaf or hard of hearing residing in Illinois while receiving early intervention (birth to three) supports and services for at least one year. Consent to participate in the survey (Appendix F) was also embedded within the first question of the survey.

\section{Data Collection Techniques}

Surveys and individual interviews were used to collect the data. The survey collected demographic data including current age of the child, zip code of residence, hearing level diagnosis, age of diagnosis, current amplification, current communication status, and additional diagnosis (if any). The individual interviews took place via video conferencing and were 
recorded. All recordings were stored on a password-protected cloud site provided through the primary researcher's university. The interviews ranged from 20 to 40 minutes each. The questions asked during the interviews (see Appendix D) were as follows: a) what information did you receive regarding communication approaches to use with your deaf/hard of hearing child?, b) who gave you this information or where did you get this information?, c) how did this information factor into your decision-making process in selecting communication approaches to use with your child?, d) What kind of pressures did you feel as you went through the decisionmaking process?, and e) Looking at this reference chart or communication matrix and based on your experience, how might future parents potentially benefit from using this when learning about, and ultimately selecting, communication approaches to use with their child? Written permission was obtained from the Executive Director of Beginnings to use the reference chart available on their website as part of this study (see Appendices A and $\mathrm{H}$ ). This reference chart was used during discussion of the fourth research question and shared on the video screen with each of the interviewees. Table 8 shows how each survey question (see Appendix C) and interview question (see Appendix D) corresponds to the research questions.

\section{Table 8}

Crosswalk of Research, Survey, and Interview Questions

\begin{tabular}{lcc}
\hline \multicolumn{1}{c}{ Research Question } & Survey Question & Interview Question \\
\hline $\begin{array}{l}\text { What information did parents } \\
\text { of young deaf and hard of }\end{array}$ & $6,9,10,11,12,13,14,15$ & 1 \\
hearing children in Illinois & & \\
receive regarding & & \\
communication approaches? & & \\
(Table Continues) & &
\end{tabular}


Table 8 Continued

\begin{tabular}{|c|c|c|}
\hline Research Question & Survey Question & Interview Question \\
\hline $\begin{array}{l}\text { Who or where did parents } \\
\text { receive information about } \\
\text { communication approaches } \\
\text { from? }\end{array}$ & $7,9,11,12,13,14,15$ & 2 \\
\hline $\begin{array}{l}\text { How did this information } \\
\text { factor into their decision- } \\
\text { making process in selecting } \\
\text { communication approaches } \\
\text { for their child? }\end{array}$ & $8,9,11,12,13,14,15$ & 3,4 \\
\hline $\begin{array}{l}\text { Would parents find a } \\
\text { reference chart or } \\
\text { communication matrix } \\
\text { influential when learning } \\
\text { about, and ultimately } \\
\text { selecting, communication } \\
\text { approaches to use with their } \\
\text { child? }\end{array}$ & $9,11,12,13,14,15$ & 5 \\
\hline $\begin{array}{l}\text { Demographic/descriptive data } \\
\text { about the population } \\
\text { participating in this study } \\
\text { (characteristics) }\end{array}$ & $\begin{array}{c}1,2,3,4,5,16,17,18,19,20 \\
21,22,23\end{array}$ & \\
\hline
\end{tabular}

\section{Survey Design}

Each of the questions was derived after careful examination of existing literature and current recommended guidelines (AAP, 2013; Jackson, 2011; Jackson et al., 2008; JCIH 2000, 2007, 2019; Moeller et al., 2013; Muse et al., 2013; Yoshinaga-Itano, 2013). In addition, questions from the National Center for Hearing Assessment and Management (NCHAM) survey tool (NCHAM, 2017) were used as a guide in developing questions for the survey. A copy of the NCHAM survey is available on their website at http://www.infanthearing.org/ei-snapshot/. The study survey consisted of both closed and open-ended questions. The closed ended questions included yes/no and multiple-choice options, Likert Scales, and alternative (opt-out options such 
as don't know, N/A, other, or prefer not to answer) options. In addition to the open-ended questions, there were options for respondents to provide additional comments. The final survey had a total of 23 questions with 11 multiple choice, three Likert style, six open-ended, and three short answer questions (month/year of birth, month/year of identification, and zip code of residence while receiving early intervention services). A copy of the survey is available in Appendix C and was administered through Qualtrics (Qualtrics, 2019) for the initial phase of the study.

\section{Individual Interviews}

The final question of the survey (question \#23) explained the option of continuing to participate in the study by sharing stories in individual interviews with the researcher. If the participant selected yes to this option, they were directed to a separate link within Qualtrics to provide their contact information. Those who consented to participate in the individual interviews were contacted separately by the researcher with participation details. Out of 21 survey respondents, four participants opted to provide contact information for follow up through individual interviews. These interviews were conducted via video conferencing through Zoom® at a mutually agreed upon time. Prior to the interviews, each participant was emailed a copy of the consent to participate in the interviews (see Appendix E) and instructed to reply "yes" to indicate consent to move forward with the individual interview.

The interviews questions (Appendix D) were derived from the research questions. The interviews were recorded and each participant could opt to show or hide their faces by turning on or off their video camera to protect confidentiality. Prior to recording, each participant was verbally reminded of their agreement to consent to recording via email and asked if there were any questions or concerns. At the end of one interview, the participant did ask for more 
clarification regarding redaction of names of people and locations mentioned within the interview. The researcher clarified that all personal identifying information would be replaced with a pseudonym or adjusted to generically represent the program or organization (i.e. a signing program instead of naming the specific school). The participant expressed satisfaction with that answer and allowed for the recording to remain on record.

\section{Survey Dissemination}

A link to the survey via Qualtrics as well as researcher contact information was included in the recruitment email if anyone wished to reach out directly to the researcher. One person did contact the primary researcher via email to clarify residency requirements for participants. Once the participant clicked on the link, the consent form to participate in the survey appeared (see Appendix C) and the participant chose either yes or no to consent to participate in the remainder of the survey. The participant was then directed to answer the three criteria questions to determine if they qualified for the study. All survey participants received an automated message thanking them for their participation as well as researcher contact information. The full survey link remained open for three months (March - May 2020). The final survey sample resulted in 21 participants (out of 33 attempted participants) who met the established criteria and completed the survey in its entirety.

\section{Data Analysis}

Survey data analysis primarily focused on establishing a description of the population described within the survey with the purpose of demonstrating whether a representative sample of the target population was indeed achieved as compared to publicly available data. Next, the percentage of respondents choosing each option for each question was analyzed and reported, presenting an overall picture of the sample in terms of communication information, supports, and 
services offered and participated in. All items using the Likert Scales were translated into stacked bar graphs to demonstrate comparison of each response to the whole. This information provided a demonstration of the average information and supports related to communication approaches offered in Illinois along with the average participation rates as represented by this survey sample.

Both the open-ended survey responses and interviews were prepared and analyzed using the same process. Upon completion of the individual interviews, the recordings were preserved and transcribed by the primary researcher's university disability supports office. In addition, captions were added to the video recordings. To prepare for the data coding, the primary researcher transferred each interview transcription into a spreadsheet of six columns. The columns were titled Statement, PI Code, Coder 2, Coder 3, New Codes??, and Notes. The dialogue from the interviewee was entered into the Statements column, separated into rows by each statement for a line by line analysis (Campbell et al., 2013; O'Connor \& Joffe, 2020; Syed \& Nelson, 2015). Survey comments were also included in the spreadsheet, each in its own row in the Statements column. The raw data was edited for clarity (i.e. removed statements such as you know, uh, um; identifying information redacted for privacy; clarification added in brackets) (Roulston, 2013).

\section{Codebook Development Process}

Since the research revolves around the experience of information gathering and the resulting decision-making process, a small set of a priori (or deductive) codes was established, based on the process of making a decision, described as either heuristic (automatic and instinctive) or systematic (deliberate and intentional) (Chaiken \& Ledgerwood, 2012; Payne, 1976; Porter et al., 2018). In addition, additional a priori codes were derived from the literature 
review conducted prior to this study. These codes included source of information, type of information, factors in making the decision, and future implications. An option to develop additional codes inductively was allowed in alignment with phenomenological research methodology (DeCuir-Gunby et al., 2011; Roberts et al., 2019). In addition, the codes can be structural, based on research questions (DeCuir-Gunby et al., 2011). See Table 9 for the initial codebook developed prior to full analysis of the raw data. 


\section{Table 9}

\section{Codebook for Training and Coding}

\begin{tabular}{|c|c|c|c|c|}
\hline Research Question & Structural Codes & Deductive (a priori) Codes & Inclusion Criteria & Exclusion Criteria \\
\hline $\begin{array}{l}\text { What information was } \\
\text { received regarding } \\
\text { communication } \\
\text { approaches? (Information, } \\
\text { QQ\#1) } \\
\text { DEFINED: } \\
\text { what information specific } \\
\text { to ways of communicating } \\
\text { with deaf was } \\
\text { given/received (i.e. sign, } \\
\text { talk, cue, oral, } \\
\text { lipread/speech read, } \\
\text { nothing, all, etc.) }\end{array}$ & $\begin{array}{l}\text {-Information Given } \\
\text {-Information Not Given }\end{array}$ & $\begin{array}{l}\text { Informed Choice and } \\
\text { Decision-making } \\
\text { A choice based on } \\
\text { relevant knowledge } \\
\text { (Marteau et al., 2001; } \\
\text { O'Connor et al., 1989) } \\
\text {-information related to } \\
\text { communication } \\
\text { approaches used with Deaf } \\
\text { and Hard of Hearing } \\
\text { children (i.e. sign, ASL, } \\
\text { bi-bi, speaking, oral, } \\
\text { cueing, etc.) }\end{array}$ & $\begin{array}{l}\text { - Names a specific way of } \\
\text { communication or "all" } \\
\text { - Specifies program: } \\
\text { communication, deaf, total } \\
\text { communication, cued } \\
\text { speech, oral, speech } \\
\text { - language, mode, option, } \\
\text { communication } \\
\text { - Technology (hearing aid, } \\
\text { cochlear implant) } \\
\text { - I got, I received, I did } \\
\text { not get, I did not receive, } \\
\text { etc. about a } \\
\text { communication approach } \\
\text { - Information received } \\
\text { through an evaluation } \\
\text { - Content of material } \\
\text { given, how much/little } \\
\text { given/found } \\
\text { - } \\
\text {-Express desire to learn } \\
\text { more }\end{array}$ & $\begin{array}{l}\text { - Reference to type of } \\
\text { material (specifies from a } \\
\text { person or other source, i.e. } \\
\text { organization, book, } \\
\text { brochure, etc.) (this goes } \\
\text { under QQ\#2) } \\
\text { - If related to decision- } \\
\text { making process or stated } \\
\text { as a factor ("I decided } \\
\text { ABC because of } \\
\text { information from/about } \\
\text { XYZ") (this goes under } \\
Q Q \# 3.1 \text { ) }\end{array}$ \\
\hline
\end{tabular}


Table 9, Continued

\begin{tabular}{|c|c|c|c|c|}
\hline Research Question & Structural Codes & Deductive (a priori) Codes & Inclusion Criteria & Exclusion Criteria \\
\hline $\begin{array}{l}\text { Who or where did the } \\
\text { information come from? } \\
\text { (Source, } Q Q \# 2 \text { ) } \\
\text { DEFINED: where that } \\
\text { information came from } \\
\text { (i.e. person, item such as } \\
\text { book, paper, organization, } \\
\text { website, etc.) }\end{array}$ & $\begin{array}{l}\text {-EI professionals (i.e. } \\
\text { Developmental Therapist- } \\
\text { Hearing, Case worker/case } \\
\text { manager, Speech } \\
\text { Pathologist) } \\
\text {-Medical (i.e. Doctor, } \\
\text { Audiologist, Speech } \\
\text { Pathologist) } \\
\text {-Cultural (i.e. Deaf } \\
\text { Adults/Mentor) } \\
\text {-Self } \\
\text {-Books } \\
\text {-Internet } \\
\text {-Organization/Program }\end{array}$ & $\begin{array}{l}\text { Lit Review- } \\
\text { Medical view (doctors, } \\
\text { audiologists, SLPs) } \\
\text { Cultural view (deaf } \\
\text { community, deaf led } \\
\text { organizations) } \\
\text { Resources (books, } \\
\text { brochures, internet, } \\
\text { organizations, } \\
\text { conferences, other parents) } \\
\text { Self (self-initiated } \\
\text { research, prior experience) }\end{array}$ & $\begin{array}{l}\text { - Names a specific person } \\
\text { (doctor, therapist, etc.) } \\
\text { - Identifies a location, } \\
\text { type, source (internet, } \\
\text { organization, book, paper, } \\
\text { etc.) } \\
\text { - Mention of previous } \\
\text { knowledge, or previous } \\
\text { experience, existing } \\
\text { knowledge }\end{array}$ & $\begin{array}{l}\text { - Mentions lack of } \\
\text { information (did not get, } \\
\text { could not find, etc.) (this } \\
\text { goes under QQ\#1) } \\
\text { - Specifies information } \\
\text { about the communication } \\
\text { approach (this goes under } \\
Q Q \# 1)\end{array}$ \\
\hline
\end{tabular}

(Table Continues) 
Table 9, Continued

\begin{tabular}{|c|c|c|c|c|}
\hline Research Question & Structural Codes & Deductive (a priori) Codes & Inclusion Criteria & Exclusion Criteria \\
\hline $\begin{array}{l}\text { How did this information } \\
\text { influence your decision- } \\
\text { making in selecting a } \\
\text { communication } \\
\text { approach(es) to use? } \\
\text { (Factors. QQ\#3.1) } \\
\text { DEFINED: how they } \\
\text { decided to communicate } \\
\text { the way they did? Why? } \\
\text { What information was } \\
\text { used to make decision? }\end{array}$ & $\begin{array}{l}\text {-Input from multiple } \\
\text { sources } \\
\text {-Type of input } \\
\text {-Amount of input } \\
\text {-Familiarity with and } \\
\text { understanding of } \\
\text { information received } \\
\text { - } \\
\text { Satisfaction/dissatisfaction } \\
\text { with information received }\end{array}$ & $\begin{array}{l}\text {-desires for the child and } \\
\text { family values } \\
\text { Lit Review- } \\
\text {-Accessibility to } \\
\text { information and } \\
\text { opportunities } \\
\text {-Additional disabilities } \\
\text {-Hearing levels } \\
\text {-Pressure from self and } \\
\text { others } \\
\text {-Self-desires, values } \\
\text {-Previous choices/change }\end{array}$ & $\begin{array}{l}\text { - Describes process of } \\
\text { decision (what they did, } \\
\text { why, hard/easy, etc.) } \\
\text { - How information was } \\
\text { used/applied } \\
\text { - Previous } \\
\text { exposure/experience with } \\
\text { deafness } \\
\text { - Desires/ regrets (i.e. "I } \\
\text { want(ed), I wish(ed)" } \\
\text { - Motivation/ motivating } \\
\text { factors to do something } \\
\text { - Rationale (i.e. "I did } \\
\text { ABC because XYZ”) } \\
\text { - Barriers, available } \\
\text { resources } \\
\text { - Conflicting information } \\
\text { and impact } \\
\text { - How information was } \\
\text { - describes feeling } \\
\text { supported or not }\end{array}$ & $\begin{array}{l}\text { - Describes/ details the } \\
\text { different and/or conflicting } \\
\text { information between } \\
\text { specific people/places (this } \\
\text { goes under QQ\#3.2) } \\
\text { - Advice for new families } \\
\text { or potential/hypothetical } \\
\text { situations (this is excluded } \\
\text { from analysis as it does } \\
\text { not relate to research } \\
\text { question) } \\
\text { - Sources of information } \\
\text { (this goes under QQ\#2) }\end{array}$ \\
\hline
\end{tabular}


Table 9, Continued

\begin{tabular}{|c|c|c|c|c|}
\hline Research Question & Structural Codes & Deductive (a priori) Codes & Inclusion Criteria & Exclusion Criteria \\
\hline $\begin{array}{l}\text { What kind of pressures did } \\
\text { you feel as you went } \\
\text { through the decision- } \\
\text { making process? (Factors, } \\
\text { QQ\#3.2) } \\
\text { DEFINED: did they feel } \\
\text { pushed in one way or } \\
\text { another? Did they feel } \\
\text { rushed? Did they feel } \\
\text { supported? Where was } \\
\text { that pressure from? What } \\
\text { was the specific pressure } \\
\text { being felt? Did they feel } \\
\text { confused/overwhelmed? }\end{array}$ & $\begin{array}{l}\text {-Satisfaction or } \\
\text { Dissatisfaction with } \\
\text { information and/or process } \\
\text { (abundance, type, } \\
\text { similar/different, ease of } \\
\text { decision) } \\
\text {-Expected timelines } \\
\text { (Window of Opportunity, } \\
\text { Language Development) }\end{array}$ & $\begin{array}{l}\text { Lit Review- } \\
\text { amplification/technology } \\
\text { use and communication } \\
\text { choice } \\
\text {-conflicting information }\end{array}$ & $\begin{array}{l}\text { - Mention of conflict } \\
\text { (information, people, or } \\
\text { self)- mentions } \\
\text { assumptions } \\
\text { - describes presence or } \\
\text { lack of feeling } \\
\text { pushed/pressured } \\
\text { - discusses } \\
\text { amplification/technology } \\
\text { use/choice (i.e. hearing } \\
\text { aid, cochlear implant, FM } \\
\text { system, alert/signal } \\
\text { systems, closed captions, } \\
\text { etc.) } \\
\text { - describes } \\
\text { satisfaction/dissatisfaction } \\
\text { with information gathering } \\
\text { process }\end{array}$ & $\begin{array}{l}\text { - Type/description of } \\
\text { information (this goes } \\
\text { under QQ\#1)- Source of } \\
\text { information (this goes } \\
\text { under QQ\#2) } \\
\text { - Desires for transition } \\
\text { support/support outside of } \\
\text { EI (this is excluded from } \\
\text { analysis as it does not } \\
\text { relate to research } \\
\text { questions) } \\
\text { - Length of time in EI } \\
\text { (excluded) } \\
\text { - Current experiences in } \\
\text { preschool (excluded) }\end{array}$ \\
\hline
\end{tabular}

(Table Continues) 
Table 9, Continued

\begin{tabular}{|c|c|c|c|c|}
\hline Research Question & Structural Codes & Deductive (a priori) Codes & Inclusion Criteria & Exclusion Criteria \\
\hline $\begin{array}{l}\text { Benefits of a reference } \\
\text { chart or communication } \\
\text { matrix? (Future } \\
\text { Implications, QQ\#4) } \\
\text { DEFINED: seeking } \\
\text { feedback on use of chart } \\
\text { (for themselves in } \\
\text { hindsight or future } \\
\text { families). Benefits? } \\
\text { Drawbacks? }\end{array}$ & $\begin{array}{l}\text {-Perceived benefits or } \\
\text { drawbacks to chart }\end{array}$ & $\begin{array}{l}\text { Informed Choice: } \\
\text { Understanding risks and } \\
\text { benefits (Young, et al. } \\
\text { 2006) } \\
\text {-what does that approach } \\
\text { possibly look like for that } \\
\text { child } \\
\text {-Access to information } \\
\text { about communication } \\
\text {-Early access }\end{array}$ & $\begin{array}{l}\text { - Specific response to the } \\
\text { question (interview) } \\
\text { - Discusses } \\
\text { benefits/drawbacks of said } \\
\text { chart } \\
\text { - Discusses concept of } \\
\text { central resource } \\
\text { - Discusses concept of all } \\
\text { options/information } \\
\text { available at } \\
\text { diagnosis/early } \\
\text { - Discusses comparison of } \\
\text { options } \\
\text { - Hypothetical (if I had, I } \\
\text { would have...) }\end{array}$ & $\begin{array}{l}\text { - Advice to/from others } \\
\text { (excluded) } \\
\text { - Comments related to } \\
\text { specific information } \\
\text { already received (this goes } \\
\text { under } Q Q \# 1 \text { ) }\end{array}$ \\
\hline
\end{tabular}




\section{Coder Training}

To increase confidence in the coding process for this study, a total of three coders were used. The master coder was the primary researcher, and two additional researchers were used as reliability coders (Campbell et al., 2013; Syed \& Nelson, 2015). Each of the additional coders are doctoral level colleagues with experience in sensory disabilities and qualitative research who also understand the communication needs of the primary researcher, who is deaf. Both coders have completed ethics training for human subject research. As shown in Figure 12, coder training followed three basic steps: discussion of the initial codebook, practice with pilot data, and revision of codebook as needed (Roberts, et al., 2019; Syed \& Nelson, 2015). Prior to releasing the pilot data, a copy of the codebook was given to all coders. The primary researcher read through the codebook and discussed the codes by explaining the definitions and providing specific examples of the inclusion and exclusion criteria. This phase of the training session did not produce any questions or adjustments to the initial codebook. 


\section{Figure 12}

\section{Coder Training Process}

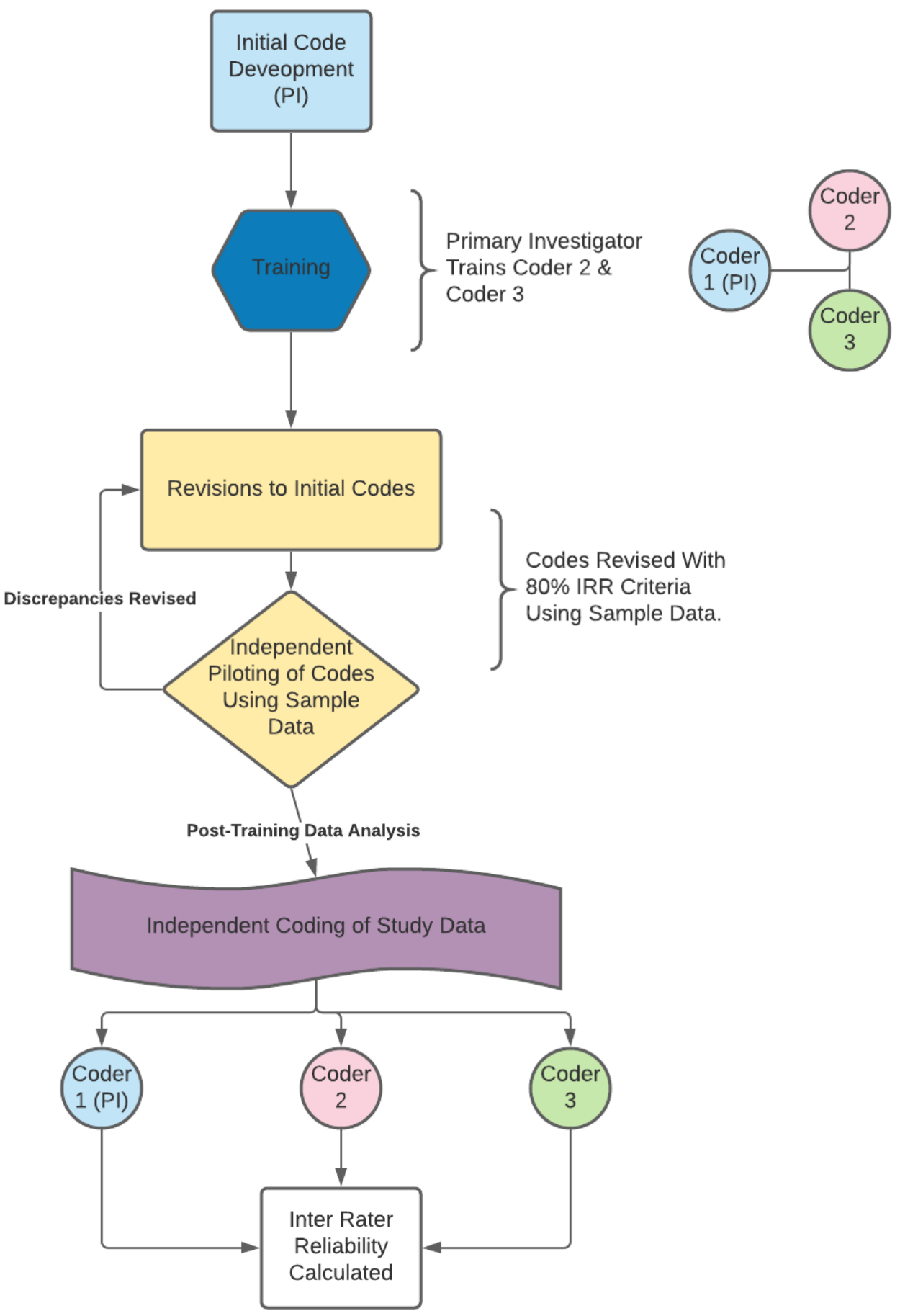


The codebook was organized by research question to assist in training of definitions, inclusion, and exclusion criteria. To assist in the ease of coding, the codes were placed into a spreadsheet and assigned a number for a total of 18 codes as shown in Table 10. Those numbers were used to perform a line by line analysis of each statement on three sets of pilot data. 
Table 10

Codebook Code Numbers and Revisions

\begin{tabular}{|c|c|c|c|c|}
\hline Number & Original Code & Revised Code & Rationale & Occurrence \\
\hline 1 & $\begin{array}{l}\text { Type: Information } \\
\text { Given }\end{array}$ & & & \\
\hline 2 & $\begin{array}{l}\text { Type: Information } \\
\text { Not Given }\end{array}$ & & $\begin{array}{l}\text { Discussion of } \\
\text { assumption of need } \\
\text { for/lack of } \\
\text { information due to } \\
\text { actively seeking out } \\
\text { information (led to } \\
\text { inclusion criteria } \\
\text { clarification only) }\end{array}$ & Sample Set \#2 \\
\hline 3 & $\begin{array}{l}\text { Source: Medical } \\
\text { Professional }\end{array}$ & & & \\
\hline 4 & $\begin{array}{l}\text { Source: Cultural } \\
\text { Professional }\end{array}$ & & & \\
\hline 5 & $\begin{array}{l}\text { Source: Early } \\
\text { Intervention } \\
\text { Professional }\end{array}$ & & & \\
\hline
\end{tabular}

(Table Continues) 
Table 10, Continued

\begin{tabular}{|c|c|c|c|c|}
\hline Number & Original Code & Revised Code & Rationale & Occurrence \\
\hline 6 & $\begin{array}{l}\text { Source: Self } \\
\text { (Research/Prior } \\
\text { Experience) }\end{array}$ & & & \\
\hline 7 & $\begin{array}{l}\text { Source: Reference } \\
\text { Item }\end{array}$ & & & \\
\hline 8 & $\begin{array}{l}\text { Source: Reference } \\
\text { Place } \\
\text { (organization, } \\
\text { website, etc.) }\end{array}$ & $\begin{array}{l}\text { Source: Reference Place } \\
\text { (organization, website, } \\
\text { conference, etc.) }\end{array}$ & $\begin{array}{l}\text { Clarification that an } \\
\text { event being } \\
\text { referenced to was an } \\
\text { annual conference in } \\
\text { Illinois }\end{array}$ & Sample Set \#1 \\
\hline 9 & $\begin{array}{l}\text { Influence: Type and } \\
\text { Level of } \\
\text { Hearing Status }\end{array}$ & & & \\
\hline
\end{tabular}

(Table Continues) 
Table 10, Continued

\begin{tabular}{|c|c|c|c|c|}
\hline Number & Original Code & Revised Code & Rationale & Occurrence \\
\hline 10 & $\begin{array}{l}\text { Influence: } \\
\text { Amplification Usage }\end{array}$ & $\begin{array}{l}\text { Influence: Amplification and } \\
\text { Technology Usage }\end{array}$ & $\begin{array}{l}\text { Clarification of } \\
\text { "technology for daily } \\
\text { living" could mean } \\
\text { hearing assistive } \\
\text { technology (i.e. } \\
\text { hearing aid, cochlear } \\
\text { implant, FM system) } \\
\text { or assistive } \\
\text { technology (i.e. } \\
\text { alert/signal systems, } \\
\text { closed captions, etc.) } \\
\text { (led to inclusion } \\
\text { criteria clarification) }\end{array}$ & Sample Set \#1 \\
\hline 11 & $\begin{array}{l}\text { Influence: Additional } \\
\text { Disabilities }\end{array}$ & & & \\
\hline 12 & $\begin{array}{l}\text { Influence: Opinions } \\
\text { from Others } \\
\text { (professionals, } \\
\text { family, friends, etc.) }\end{array}$ & $\begin{array}{l}\text { Influence: Input from Others } \\
\text { (professionals, family, friends, } \\
\text { etc.) }\end{array}$ & $\begin{array}{l}\text { The term "opinions" } \\
\text { is negatively implied } \\
\text { and does not reflect a } \\
\text { statement of "no } \\
\text { pressure" (also led to } \\
\text { inclusion criteria } \\
\text { clarification) }\end{array}$ & Sample Set \#2 \\
\hline
\end{tabular}

(Table Continues) 
Table 10 Continued

\begin{tabular}{|c|c|c|c|c|}
\hline Number & Original Code & Revised Code & Rationale & Occurrence \\
\hline 13 & $\begin{array}{l}\text { Influence: Wishes, } \\
\text { Self-Desires, Values }\end{array}$ & $\begin{array}{l}\text { Influence: Wishes, Self-Desires, } \\
\text { Values, Previous Decisions }\end{array}$ & $\begin{array}{l}\text { Reflects the idea that } \\
\text { previous decisions } \\
\text { may have already } \\
\text { been made and new } \\
\text { information affects a } \\
\text { new desire } \\
\text { (reaffirmed existing } \\
\text { inclusion criteria) }\end{array}$ & Sample Set \#1 \\
\hline 14 & $\begin{array}{l}\text { Influence: Access to } \\
\text { Opportunities to } \\
\text { learn/use }\end{array}$ & $\begin{array}{l}\text { Influence to Opportunities to } \\
\text { Learn/Use (person or experience } \\
\text { to use/practice with) }\end{array}$ & $\begin{array}{l}\text { Clarification of what } \\
\text { access meant } \\
\text { (reaffirmed existing } \\
\text { inclusion criteria) }\end{array}$ & Sample Set \#1 \\
\hline 15 & $\begin{array}{l}\text { Influence: Conflicting } \\
\text { Information }\end{array}$ & $\begin{array}{l}\text { Influence: } \\
\text { Satisfaction/Dissatisfaction with } \\
\text { Information (self or other) }\end{array}$ & $\begin{array}{l}\text { The term "conflicting } \\
\text { information" is } \\
\text { negatively implied, } \\
\text { replaced with neutral } \\
\text { term; additional } \\
\text { clarification that the } \\
\text { information can be } \\
\text { internal or external } \\
\text { (led to inclusion } \\
\text { criteria clarification) }\end{array}$ & $\begin{array}{l}\text { Sample Set \#1, } \\
\text { further refined with } \\
\text { Sample Set \#2 }\end{array}$ \\
\hline
\end{tabular}

(Table Continues) 
Table 10, Continued

\begin{tabular}{|c|c|c|c|c|}
\hline Number & Original Code & Revised Code & Rationale & Occurrence \\
\hline 16 & $\begin{array}{l}\text { Influence: Sense of } \\
\text { Urgency }\end{array}$ & $\begin{array}{l}\text { Influence: Expected Timeline } \\
\text { (Window of Opportunity) }\end{array}$ & $\begin{array}{l}\text { The term "sense of } \\
\text { urgency" is } \\
\text { negatively implied, } \\
\text { replaced with neutral } \\
\text { term }\end{array}$ & Sample Set \#3 \\
\hline 17 & Matrix Use: Benefits & & & \\
\hline 18 & $\begin{array}{l}\text { Matrix Use: } \\
\text { Drawbacks }\end{array}$ & & & \\
\hline
\end{tabular}


The codebook was adjusted as needed following negotiated agreement among all three coders. Negotiated agreement was accomplished by providing supporting rationale from the codebook, existing literature, or from the sample data. During the pilot process, a total of eight adjustments were made to the codes. Table 10 also shows the adjustments, the rationale, and when it occurred.

\section{Inter-Rater Reliability}

The following formula was used to determine IRR in both the pilot and the study data: for each statement, the number of code agreements was divided by the total number of agreements and disagreements with a target agreement of $80 \%$ or better (Miles \& Huberman, 1994). This formula was used to calculate IRR for each statement in the data. If one statement resulted in multiple codes, those codes were treated as a group and one IRR was calculated for that statement. The same procedure was used if only one code was found in a single statement. This process is clarified in Table 11 with two examples from the survey data and two examples from the interview data. If the resulting IRR agreement was $79 \%$ or less, the three coders addressed it using negotiated agreement and providing supporting rationale from the codebook, existing literature, or directly from the data. Those statements with IRR of $79 \%$ were then recoded to redetermine IRR. Table 12 shows the number of agreements and disagreements among coders by code, which was completed after IRR of $80 \%$ or better per statement was achieved. 


\section{Table 11}

Inter-Rater Reliability Coding by Statement

\begin{tabular}{|c|c|c|c|c|c|c|c|}
\hline Statement & Coder 1 & Coder 2 & Coder 3 & Agree & Disagree & First IRR & Recoded IRR \\
\hline \multirow{4}{*}{ \#6 (Survey) } & Code 5 & 5 & 5 & \multirow{4}{*}{10} & \multirow{4}{*}{2} & & \multirow{4}{*}{ N/A } \\
\hline & Code 10 & 10 & 10 & & & & \\
\hline & Code 15 & -- & -- & & & $.05(100)=$ & \\
\hline & Code 16 & 16 & 16 & & & 0570 & \\
\hline \multirow{3}{*}{ \#23 (Survey) } & -- & 13 & -- & \multirow{3}{*}{7} & \multirow{3}{*}{2} & $7 / 9=$ & $9 / 9=$ \\
\hline & Code 3 & 3 & 3 & & & $.78(100)=$ & $1(100)=$ \\
\hline & Code 15 & 15 & 15 & & & $78 \%$ & $100 \%$ \\
\hline \multirow{4}{*}{ \#12 (Interview \#1) } & Code 1 & 1 & 1 & \multirow{4}{*}{11} & \multirow{4}{*}{1} & & \multirow{4}{*}{ N/A } \\
\hline & Code 6 & 6 & 6 & & & & \\
\hline & Code 12 & 12 & 12 & & & $.92(100)=$ & \\
\hline & Code 15 & 15 & -- & & & $92 \%$ & \\
\hline \multirow{4}{*}{ \#17 (Interview \#4) } & Code 4 & 4 & -- & \multirow{4}{*}{9} & \multirow{4}{*}{3} & & \multirow{4}{*}{$\begin{array}{c}12 / 12= \\
1(100)= \\
100 \%\end{array}$} \\
\hline & Code 6 & 6 & 6 & & & & \\
\hline & Code 8 & 8 & 8 & & & $.15(100)=$ & \\
\hline & Code 14 & -- & -- & & & $15 \%$ & \\
\hline
\end{tabular}

Note. Code 1=Type: Information Given; Code 3=Source: Medical Professional; Code 4= Source: Cultural Professional; Code

5=Source: Early Intervention Professional; Code 6=Source: Self (Research/Prior Experience); Code 7= Source: Reference Item; Code 
8= Source: Reference Place; Code 10=Influence: Amplification and Technology Usage; Code 12=Influence: Input from Others; Code 13=Influence: Wishes, Self-Desires, Values, Previous Decisions; Code 15=Influence: Satisfaction/Dissatisfaction with Information; Code 16=Influence: Expected Timeline 
Table 12

Percent of Agreements and Disagreements Among Coders

\begin{tabular}{|c|c|c|}
\hline Code & $\%$ of Agreements & $\%$ of Disagreements \\
\hline 1: Information Given & $82 \%$ & $18 \%$ \\
\hline 2: Information Not Given & $79 \%$ & $21 \%$ \\
\hline 3: Medical Professional & $89 \%$ & $11 \%$ \\
\hline 4: Cultural Professional & $86 \%$ & $14 \%$ \\
\hline $\begin{array}{l}\text { 5: Early Intervention } \\
\text { Professional }\end{array}$ & $95 \%$ & $5 \%$ \\
\hline $\begin{array}{l}\text { 6: Self (research, previous } \\
\text { experience) }\end{array}$ & $86 \%$ & $14 \%$ \\
\hline 7: Reference Item & $100 \%$ & $0 \%$ \\
\hline 8: Reference Place & $73 \%$ & $27 \%$ \\
\hline $\begin{array}{l}\text { 9: Type and Level of Hearing } \\
\text { Status }\end{array}$ & $83 \%$ & $17 \%$ \\
\hline $\begin{array}{l}\text { 10: Amplification and } \\
\text { Technology Usage }\end{array}$ & $85 \%$ & $15 \%$ \\
\hline 11: Additional Disabilities & $87 \%$ & $13 \%$ \\
\hline 12: Input from Others & $82 \%$ & $18 \%$ \\
\hline $\begin{array}{l}\text { 13: Wishes, Self-Desires, } \\
\text { Values, Previous Decisions }\end{array}$ & $86 \%$ & $14 \%$ \\
\hline 14: Access to Opportunities & $93 \%$ & $7 \%$ \\
\hline $\begin{array}{l}\text { 15: Satisfaction, } \\
\text { Dissatisfaction }\end{array}$ & $94 \%$ & $6 \%$ \\
\hline 16: Expected Timelines & $80 \%$ & $20 \%$ \\
\hline 17: Matrix Benefits & $96 \%$ & $4 \%$ \\
\hline 18: Matrix Drawbacks & $100 \%$ & $0 \%$ \\
\hline
\end{tabular}

Note. Survey and interviews had 441 statements altogether. 


\section{Pilot Inter-Rater Reliability}

After full training and agreement on the codebook, a pilot coding was conducted using a data set that was not a part of the original study data. The pilot data set was collected from three participants familiar with the primary researcher who expressed interest in participating in the study but did not meet the criteria. Each family provided a written response to the interview questions as listed in Appendix C. Similar to the original raw data from the study, the responses were transferred into a spreadsheet, with one sentence per row, resulting in three sample data sets. Table 13 shows how many statements each sample data set contained. After the codebook training, each researcher independently coded the first sample data set and then reconvened to calculate inter-rater reliability (IRR), address questions, provide clarifications as needed, as well as the addition of any possible new codes that were inductively drawn from the raw data (DeCuir-Gunby et al., 2011). Detailed notes of the outcomes were taken, along with deference information (Campbell et al., 2013; Syed \& Nelson, 2015). Once all coders agreed, the researchers then recoded to ensure acceptable IRR levels of $80 \%$ or better (Miles et al., 2014). The process was then repeated for each sample data set until all three sample data sets were completed and final line by line coder IRR scores for the pilot were obtained, which is listed in Table 13. The recoding process only occurred twice, for Samples 1 and 2. In addition, all coders achieved $100 \%$ agreement on statements to be fully excluded from the study as they did not relate to any of the research questions. Figure 13 provides a flowchart of this process. 


\section{Table 13}

Inter-Rater Reliability from Pilot Coding

$\begin{array}{lll}\text { Sample } 1 & \text { Sample 2 } & \text { Sample } 3\end{array}$

\begin{tabular}{lccc}
\hline Number of Statements & 21 & 10 & 25 \\
$1^{\text {st }}$ Code Session IRR Range & $67-100 \%$ & $66.7-100 \%$ & $83.3-100 \%$ \\
$2^{\text {nd }}$ Code Session IRR Range & $86.7-100 \%$ & $83.3-100 \%$ & NA \\
\hline
\end{tabular}

Figure 13

Inter-Rater Reliability Flowchart

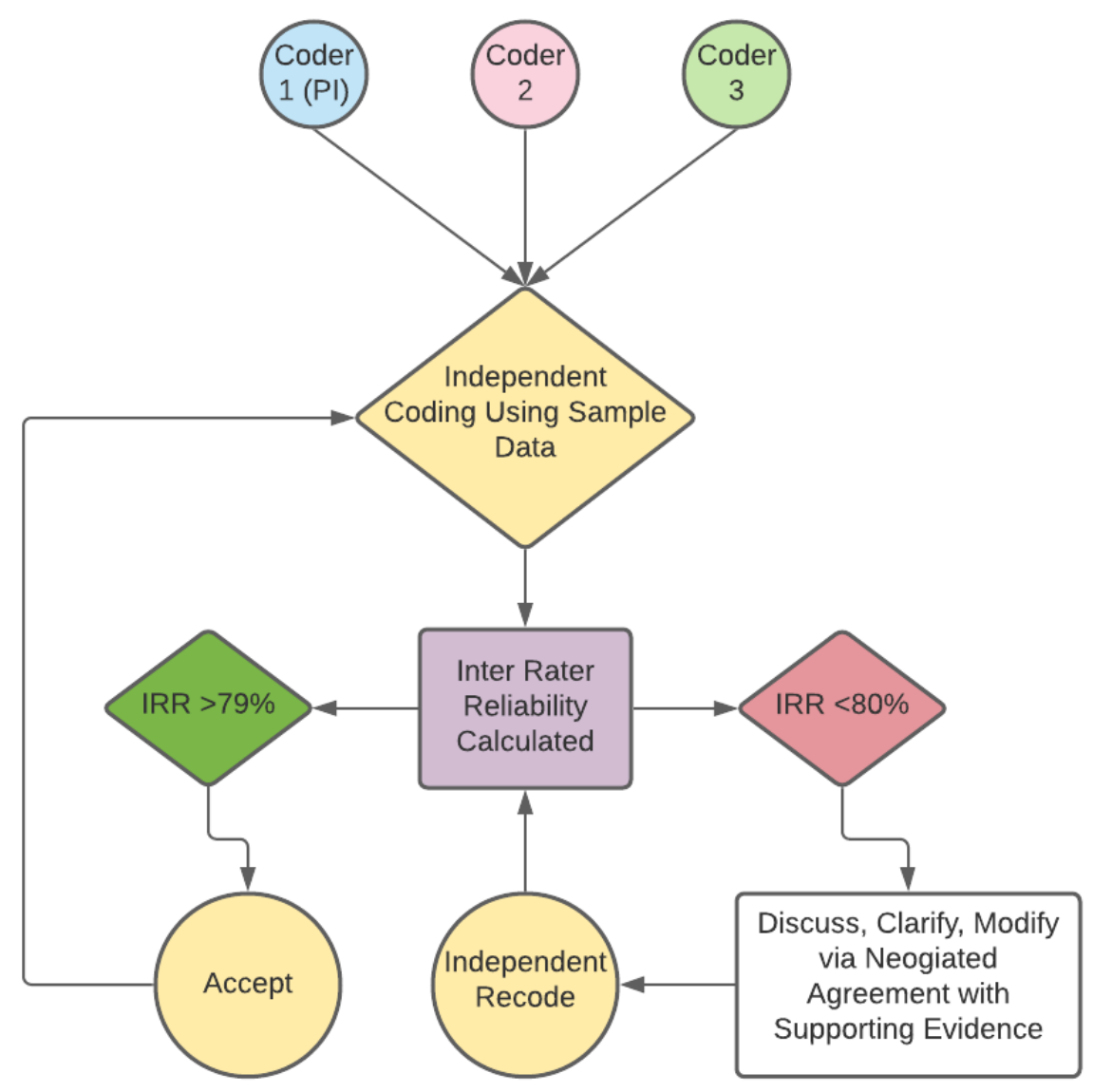


Figure 14 shows a histogram indicating the distribution of codes by node for the pilot coding. The top three most frequent codes were: Type: Information Given $(n=47)$, Influence: Opinions from Others (professionals, family, friends, etc.) $(n=42)$ and Source: Reference Place (organization, website, etc.) $(\mathrm{n}=35)$ respectively. Influence: Additional Disabilities $(\mathrm{n}=6)$, Influence: Sense of Urgency $(n=6)$, and Matrix Use: Drawbacks $(n=6)$ tied for the least frequent code. After IRR was established using the sample data, the primary researcher then proceeded to code the raw data from the study, which included both the interview and open-ended survey responses. No potential new codes were indicated during the pilot coding process.

\section{Figure 14}

Histogram of Code Frequencies in Pilot

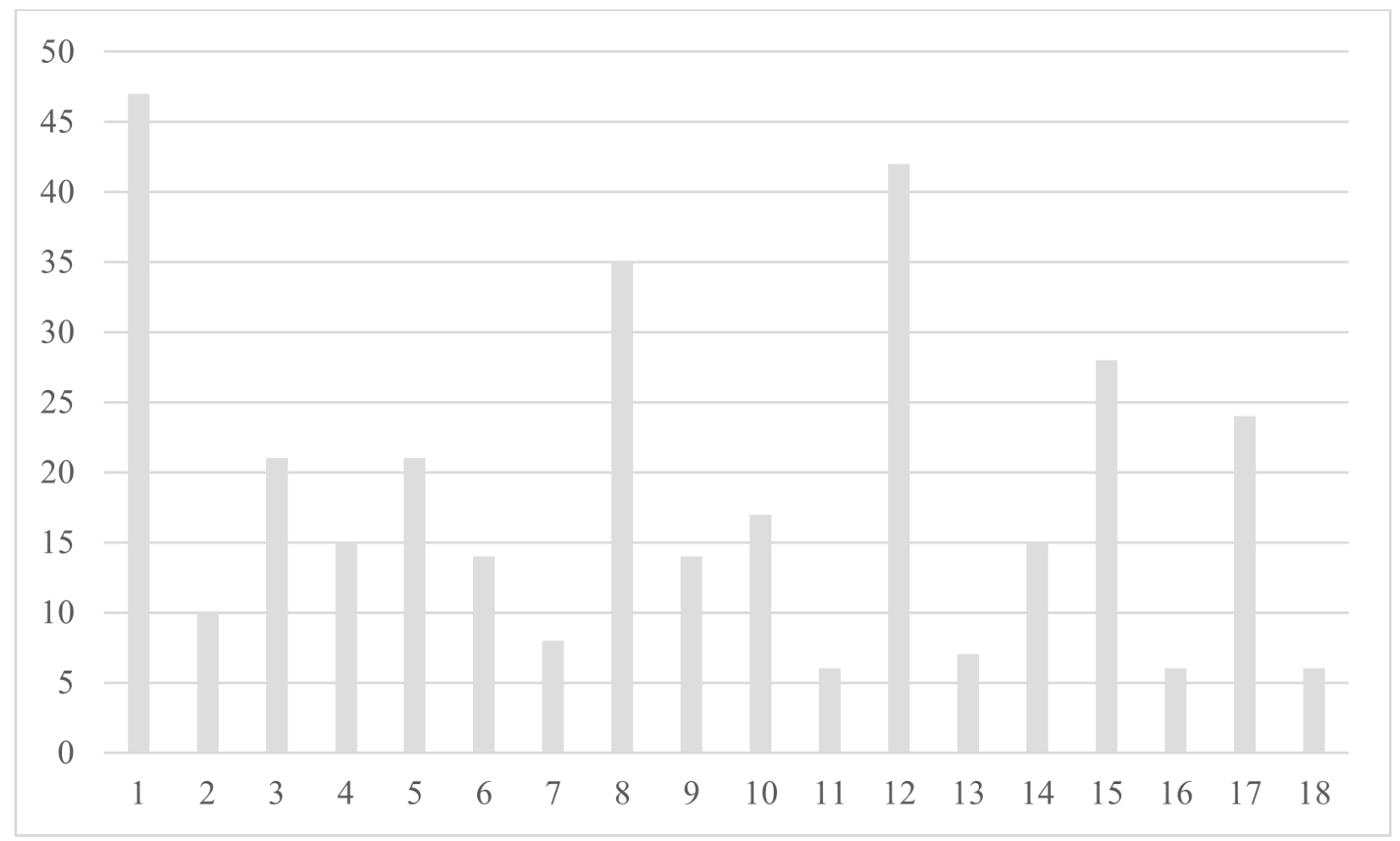




\section{Study Inter-Rater Reliability}

Inter-rater reliability was calculated for the study data as well, following the same procedures as the pilot study. Prior to the coding session, all three coders reviewed the codebook definitions and the coding numbers to ensure there were no questions or clarifications needed. As in the pilot session, all study data was imported into a spreadsheet to allow for a line by line analysis of each statement. This resulted in five data sets, one from the survey open-ended comments and one from each of the four interviews. Recoding was needed in four of the five data sets due to IRR calculated at lower than $80 \%$. However, it is important to note that out of a total of 441 statements, there were only 19 statements that were calculated as less than $80 \%$. Table 14 shows the IRR results for the open-ended survey comments and each interview participant.

\section{Table 14}

Inter-Rater Reliability of Study Coding

\begin{tabular}{|c|c|c|c|c|c|}
\hline & $\begin{array}{c}\text { Survey Open- } \\
\text { ended } \\
\text { Comments } \\
\end{array}$ & $\begin{array}{c}\text { Interview } \\
\text { Participant } 1\end{array}$ & $\begin{array}{c}\text { Interview } \\
\text { Participant } 2\end{array}$ & $\begin{array}{c}\text { Interview } \\
\text { Participant } 3\end{array}$ & $\begin{array}{c}\text { Interview } \\
\text { Participant } 4\end{array}$ \\
\hline $\begin{array}{l}\text { Number of } \\
\text { Statements }\end{array}$ & 70 & 76 & 182 & 50 & 63 \\
\hline $\begin{array}{l}1^{\text {st }} \text { Code } \\
\text { Session IRR } \\
\text { Range }\end{array}$ & $67-100 \%$ & $67-100 \%$ & $75-100 \%$ & $83-100 \%$ & $75-100 \%$ \\
\hline $\begin{array}{l}2^{\text {nd }} \text { Code } \\
\text { Session IRR } \\
\text { Range }\end{array}$ & $83-100 \%$ & $89-100 \%$ & $83-100 \%$ & NA & $89-100 \%$ \\
\hline
\end{tabular}

As with the pilot coding, detailed notes of the outcomes and deference information was recorded.

Discussion and recoding were needed in four of the five coding sessions. No new codes were developed but clarification was needed on the following issues: 
- classification of speech and language pathologist as a medical or early intervention professional,

- definition of self-research also includes information not given,

- clarification of the term DTH (developmental therapist hearing) as an early intervention professional or as a cultural professional based on how the parent framed it,

- the addition of other parents as a source of information,

- noting that comments regarding the desire of wanting all information at one time or in one spot should be coded with either the Matrix: Benefits, Matrix Drawbacks and with Wishes, Self-Desires, Values, Previous Decision

- Previous Decisions was clarified to include new information influencing (or not influencing) a change of a previous decision (i.e. to explore another communication approach while continuing to use current communication approach)

\section{Thematic Analysis}

Upon completion of coding, the primary researcher then moved into the thematic analysis stage (see Figure 15), which was conducted manually due to the small size of the data set (Johnson et al., 2020). Following the concepts of categorizing and connecting strategies in analyzing interview responses (Constas,1992; Maxwell, 2013), the data and resulting codes collected from both the open ended questions and interview responses were analyzed and categorized to determine common themes. The initial step of this analysis included several readings of each of the survey comments and interview transcripts as well as multiple viewings of the recordings. During these readings and viewings, notes were added into the additional comments section of the coding spreadsheet regarding tentative themes, emerging patterns, or categorizations of the raw data and codes (Constas, 1992; Saldaña, 2013). The resulting categories were further analyzed, interpreted, and then grouped into possible themes. The nature 
of the structured interview allowed for an analysis of each statement to identify which research question it addressed (Maxwell, 2013). After grouping each statement under its relevant research question, those comments were further analyzed and like statements were grouped together to develop substantive categories. Substantive categories are descriptive and closely related to the actual statements made by the survey and interview participants (Maxwell, 2013). Table 15 summarizes this process and identifies the origination of the category, the verification grounds, the nomination source, and the temporal designation. The resulting themes were then compared with those discovered during the literature review in preparation for this study to allow for triangulation of the data by previous research. The process and resulting codes were discussed with a second researcher to allow for investigator triangulation of the data. The three main themes that emerged in this study were:

Theme \#1: Information about communication is valued.

Theme \#2: Information from people is valued as a source.

Theme \#3: Access to opportunities to see, use, experience communication is valued as an influence. 


\section{Figure 15}

Flowchart of Thematic Analysis Process

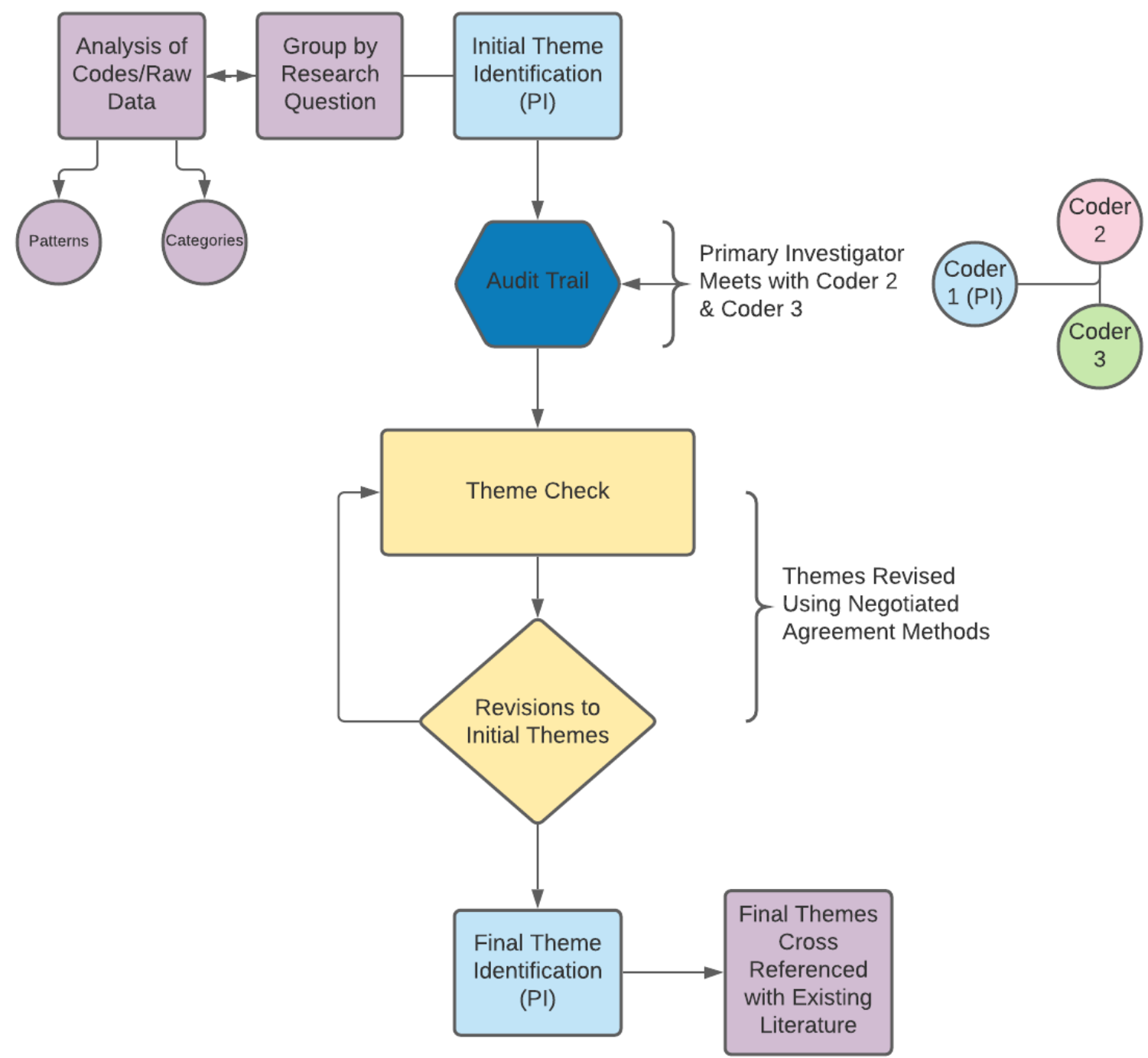




\section{Table 15}

Thematic Analysis Categorization

\begin{tabular}{|c|c|c|c|c|c|c|}
\hline $\begin{array}{l}\text { Research } \\
\text { question }\end{array}$ & Categories & Theme(s) & $\begin{array}{l}\text { Origination- } \\
\text { where does the } \\
\text { authority for } \\
\text { creating } \\
\text { categories } \\
\text { reside? }\end{array}$ & $\begin{array}{l}\text { Verification-on } \\
\text { what grounds } \\
\text { can one justify a } \\
\text { given category? }\end{array}$ & $\begin{array}{l}\text { Nomination- } \\
\text { What is the } \\
\text { source of the } \\
\text { name used to } \\
\text { describe a } \\
\text { category }\end{array}$ & $\begin{array}{c}\text { Temporal } \\
\text { designation }\end{array}$ \\
\hline $\begin{array}{l}\text { What } \\
\text { information was } \\
\text { received } \\
\text { regarding } \\
\text { communication } \\
\text { approaches }\end{array}$ & $\begin{array}{c}\text { sign/ASL } \\
\text { talk/oral } \\
\text { lipread/speech } \\
\text { read } \\
\text { cueing } \\
\text { nothing } \\
\text { everything/all }\end{array}$ & $\begin{array}{c}\text { Information: } \\
\text { Given and Not } \\
\text { Given }\end{array}$ & $\begin{array}{c}\text { Participants } \\
\text { Investigative } \\
\text { Literature }\end{array}$ & $\begin{array}{c}\text { External (audit) } \\
\text { Rational } \\
\text { Referential } \\
\text { Technical }\end{array}$ & $\begin{array}{c}\text { Participants } \\
\text { Investigative } \\
\text { Literature }\end{array}$ & $\begin{array}{l}\text { A priori } \\
\text { Iterative }\end{array}$ \\
\hline
\end{tabular}

(Table Continues) 
Table 15, Continued

\begin{tabular}{|c|c|c|c|c|c|c|}
\hline $\begin{array}{l}\text { Research } \\
\text { question }\end{array}$ & Categories & Theme(s) & $\begin{array}{l}\text { Origination- } \\
\text { where does the } \\
\text { authority for } \\
\text { creating } \\
\text { categories } \\
\text { reside? }\end{array}$ & $\begin{array}{l}\text { Verification-on } \\
\text { what grounds } \\
\text { can one justify a } \\
\text { given category? }\end{array}$ & $\begin{array}{l}\text { Nomination- } \\
\text { What is the } \\
\text { source of the } \\
\text { name used to } \\
\text { describe a } \\
\text { category }\end{array}$ & $\begin{array}{c}\text { Temporal } \\
\text { designation }\end{array}$ \\
\hline $\begin{array}{l}\text { Who or where } \\
\text { did the } \\
\text { information } \\
\text { come from? }\end{array}$ & $\begin{array}{l}\text {-EI professionals } \\
\text { (Developmental } \\
\text { Therapist- } \\
\text { Hearing, Case } \\
\text { manager, } \\
\text { Speech } \\
\text { Pathologist) } \\
\text {-Medical } \\
\text { (Doctor, } \\
\text { Audiologist, } \\
\text { Speech) } \\
\text {-Cultural (Deaf } \\
\text { Adults/Mentor) } \\
\text {-Self } \\
\text {-Other parents } \\
\text {-Books } \\
\text {-Internet } \\
\text {-Organization or } \\
\text { Program }\end{array}$ & $\begin{array}{l}\text { People } \\
\text { Places } \\
\text { Items }\end{array}$ & $\begin{array}{l}\text { Participants } \\
\text { Investigative } \\
\text { Literature }\end{array}$ & $\begin{array}{c}\text { External (audit) } \\
\text { Rational } \\
\text { Referential } \\
\text { Technical }\end{array}$ & $\begin{array}{l}\text { Participants } \\
\text { Investigative } \\
\text { Literature }\end{array}$ & A priori \\
\hline
\end{tabular}

(Table Continues) 
Table 15, Continued

\begin{tabular}{|c|c|c|c|c|c|c|}
\hline $\begin{array}{l}\text { Research } \\
\text { question }\end{array}$ & Categories & Theme(s) & $\begin{array}{l}\text { Origination- } \\
\text { where does the } \\
\text { authority for } \\
\text { creating } \\
\text { categories } \\
\text { reside? }\end{array}$ & $\begin{array}{c}\text { Verification-on } \\
\text { what grounds } \\
\text { can one justify a } \\
\text { given category? }\end{array}$ & $\begin{array}{l}\text { Nomination- } \\
\text { What is the } \\
\text { source of the } \\
\text { name used to } \\
\text { describe a } \\
\text { category }\end{array}$ & $\begin{array}{c}\text { Temporal } \\
\text { designation }\end{array}$ \\
\hline $\begin{array}{l}\text { How did this } \\
\text { information } \\
\text { influence your } \\
\text { decision-making } \\
\text { in selecting a } \\
\text { communication } \\
\text { approach(es) to } \\
\text { use? }\end{array}$ & $\begin{array}{c}\text {-Input: multiple } \\
\text { sources, types, } \\
\text { amounts } \\
\text {-Familiarity, } \\
\text { understanding } \\
\text { - } \\
\text { Satisfaction/diss } \\
\text { atisfaction with } \\
\text { information, } \\
\text { process } \\
\text { (abundance, } \\
\text { type, } \\
\text { similar/different, } \\
\text { ease of decision) } \\
\text {-Timelines } \\
\text { (Window of } \\
\text { Opportunity, } \\
\text { Language Dev) }\end{array}$ & $\begin{array}{c}\text { Access (or lack } \\
\text { of) to } \\
\text { information } \\
\text { Access to } \\
\text { opportunities } \\
\text { and experiences } \\
\text { (exposure) } \\
\text { Satisfaction/diss } \\
\text { atisfaction } \\
\text { Additional } \\
\text { disabilities } \\
\text { Current Needs } \\
\text { (hearing levels, } \\
\text { amplification, } \\
\text { communication) } \\
\text { Current desires } \\
\text { or wants for } \\
\text { child }\end{array}$ & $\begin{array}{c}\text { Participants } \\
\text { Investigative } \\
\text { Literature }\end{array}$ & $\begin{array}{c}\text { External (audit) } \\
\text { Rational } \\
\text { Referential } \\
\text { Technical }\end{array}$ & $\begin{array}{c}\text { Participants } \\
\text { Investigative } \\
\text { Literature }\end{array}$ & $\begin{array}{c}\text { A priori } \\
\text { A posteriori } \\
\text { Iterative }\end{array}$ \\
\hline
\end{tabular}

(Table Continues) 
Table 15, Continued

\begin{tabular}{|c|c|c|c|c|c|c|}
\hline $\begin{array}{l}\text { Research } \\
\text { question }\end{array}$ & Categories & Theme(s) & $\begin{array}{l}\text { Origination- } \\
\text { where does the } \\
\text { authority for } \\
\text { creating } \\
\text { categories } \\
\text { reside? }\end{array}$ & $\begin{array}{l}\text { Verification-on } \\
\text { what grounds } \\
\text { can one justify a } \\
\text { given category? }\end{array}$ & $\begin{array}{l}\text { Nomination- } \\
\text { What is the } \\
\text { source of the } \\
\text { name used to } \\
\text { describe a } \\
\text { category }\end{array}$ & $\begin{array}{c}\text { Temporal } \\
\text { designation }\end{array}$ \\
\hline $\begin{array}{l}\text { Benefits of a } \\
\text { reference chart } \\
\text { or } \\
\text { communication } \\
\text { matrix? }\end{array}$ & $\begin{array}{c}\text {-benefits or } \\
\text { drawbacks to } \\
\text { chart }\end{array}$ & $\begin{array}{l}\text { Access to all } \\
\text { information, } \\
\text { early } \\
\text { Comprehensive, } \\
\text { overwhelming }\end{array}$ & $\begin{array}{l}\text { Participants } \\
\text { Investigative }\end{array}$ & $\begin{array}{c}\text { External (audit) } \\
\text { Rational } \\
\text { Referential } \\
\text { Technical }\end{array}$ & $\begin{array}{c}\text { Participants } \\
\text { Investigative } \\
\text { Literature }\end{array}$ & $\begin{array}{l}\text { A priori } \\
\text { Iterative }\end{array}$ \\
\hline
\end{tabular}


To determine inclusion in the final themes, all comments were analyzed for the following: relation to communication, information gathering process, or the decision-making process. For the interview comments, they were required to specifically answer one of the four research questions, or they were not included in the analysis. Comments related to transition out of early intervention, length of time in early intervention, services received in preschool, and Individual Education Plans were eliminated from the final themes as they did not relate to the original research questions.

\section{Ethical Issues}

To ensure that study participants were protected, each of them gave their informed consent prior to participation in this study. The informed consent listed expectations of both the researcher and the parent and allowed the researcher to record and collect data using the survey and individual interviews via video. The informed consent also specified the rights of the participants to withdraw at any time or opt out of any questions. A copy of the informed consent letters (one for the survey and one for the individual interviews) can be found in Appendices $\mathrm{F}$ and $E$ respectively. The survey consent was embedded within the survey, with participants selecting "yes" to indicate consent. This was required prior to proceeding and if the participant declined to give consent, they were automatically exited from the survey. Efforts to protect against breaches of confidentiality were addressed within the consents and stated that all recordings, transcriptions, and data would be kept confidential by all reasonable efforts. It was stressed that participation in any part of the study was voluntary and participants could choose to withdraw at any time or opt out of specific questions. At the conclusion of the study, all recordings and transcriptions will be properly disposed of and deleted within three years from the completion of the study, as specified in the consent forms. Providing names in the survey and 
interviews was optional and all identifying information in both the surveys and interviews were redacted during data analysis. Zip codes were requested in the survey for the purpose of collecting geographical data only. All participation was voluntary and there was no compensation given to any of the parents for completion of the survey or participation in the interviews.

\section{Ensuring Validity and Reliability}

\section{Validity}

To assess content-related evidence of validity, the survey and interview questions were examined to ensure they included a representative sample of areas related to communication, information gathering, and decision-making. For example, survey and interview questions were examined to ensure that each of the communication approaches as identified by Pittman and colleagues (2016) and shown in Table 6 were included in the survey and addressed in the interviews. It was further ensured that each of the commonly identified sources of information, such as members of the early intervention team and others mentioned in various guidelines were included in both the survey and interviews. To further address the credibility of the questions developed to elicit responses in the survey and interview, the researcher looked at other similar surveys, existing literature, and current recommended guidelines to ensure content validity.

One common threat to validity in qualitative research is researcher bias (Maxwell, 2013). As a deaf individual and professional, it is entirely plausible that personal history, upbringing, and background in the field will affect how this study is approached and the resulting data is analyzed and interpreted. In addition, fluency in and personal experiences with each of the communication approaches allows for a unique perspective and potential bias in the analysis and interpretation of the results. This could also affect and ultimately determine the types of follow 
up questions that are asked within an interview. In addition, not having personal experience in the process of decision-making related to communication for a deaf or hard of hearing child prevents a full understanding and interpretation of that experience. All these factors will be considered throughout the entire process of this study and acknowledged during analysis of themes.

Another common threat to validity in qualitative research is reactivity (Maxwell, 2013). In an interview, there is a very real chance that the interviewee will alter or change their responses based on the reactions from the interviewer. In addition, there is a possibility that the interviewee may conform their responses or behaviors to fit a predetermined expectation of the interviewer, such as only focusing on certain aspects of their experiences and neglecting to share others. Keeping these in mind, the interviewer took caution to avoid leading by focusing on open-ended questions, remained aware of visual information conveyed through facial expressions and body language, and confirmed understanding throughout the interview. This was taken into account during the data collection, analysis, and reporting process. Some of effects of reactivity may be reduced by following up with the interviewees to ensure the resulting interpretations are correct. Member checking was conducted throughout the interview process by using clarifying statements such as, "I heard you say....is that correct?" These clarification statements were all affirmed, with the exception of one statement by the deaf mother, which was actually the result of an ASL translation (misunderstanding) issue rather than an analysis interpretation issue.

\section{Reliability}

Triangulation was used to address reliability among coders, participants, and existing literature. Prior to coding of the raw data, a pilot coding was conducted with three coders to 
calculate inter-rater reliability (see Table 13). Inter-rater reliability for the study data was also calculated (see Table 14). To address reliability of the resulting codes and themes, triangulation among participants was used to analyze agreement among resulting codes and themes. This included charting responses to see if responses to the questions contained any consistent information among the participants. Resulting similarities among both the interviewee and survey responses also strengthened the reliability of the questions asked. Upon the conclusion of the thematic analysis of open-ended survey questions and the interviews, the resulting themes were compared with previous themes uncovered by the literature review as an additional triangulation measure.

Additional reliability measures included a peer review and audit trail of the data analysis process and resulting themes, which were discussed with a second researcher (Johnson et al., 2020). In addition, during the interviews, member checking of interview responses, using active listening and clarifying statements such as, "I heard you say...is that correct?" was used to verify accuracy of the resulting interpretations as an additional reliability measure. This was consistently applied throughout all four interviews but could not be applied to the survey responses to the open-ended questions.

In addition, the themes were compared with the recommended practices and guidelines (AAP, 2013; JCIH, 2000, 2007; Moeller et al., 2013; Muse et al., 2013; Yoshinaga-Itano, 2013) to strengthen and validate the findings uncovered in this study, as well as determine if recommended practices and guidelines were indeed followed for the participants in this study. 


\section{CHAPTER IV: STUDY RESULTS}

This study was designed to examine the parental perspective of information gathering and decision-making process related to communication approaches for their deaf or hard of hearing child while in early intervention. Examination of this information will determine existing trends in Illinois and how the process ties into the existing recommended practices and guidelines (AAP, 2013; JCIH, 2000, 2007; Moeller et al., 2013; Muse et al., 2013; Yoshinaga-Itano, 2013) as related to informed choice, decision-making, and information sharing during the early intervention years.

To discover how parents perceived the process of receiving information and making decisions about communication approaches for their deaf or hard of hearing child within early intervention, the following research questions were addressed: (a) what information did parents of young deaf and hard of hearing children in Illinois receive regarding communication approaches?, (b) who or where did they receive information about communication approaches from?, (c) how did this information factor into their decision-making process in selecting communication approaches for their child?, and (d) how future parents might potentially benefit from the use of a reference chart or communication matrix when learning about, and ultimately selecting, communication approaches to use with their child? Research questions were addressed using both survey and interview questions. Table 8 provides a crosswalk of which survey and interview questions address which research question.

The survey contained 16 closed set questions along with six open-ended questions on the survey that participants were asked to consider and respond. These were: 1) Please share any additional comments regarding your experience in obtaining information on communication approaches, 2) Please share any comments regarding barriers you experienced in receiving 
information on communication approaches, 3) Please share any comments regarding supports you experienced in receiving information, 4) Knowing what you know now, what would you have done differently in obtaining information and making decisions related to communication approaches?, 5) Is there anything you would have found helpful in obtaining information and making decisions related to communication approaches? and, 6) What is the most important advice you would give a parent whose child has been recently identified as deaf or hard of hearing related to communication information and approaches? Each of the open-ended responses were coded and analyzed to uncover themes.

In the interviews, the following questions were asked: 1) What information did you receive regarding communication approaches to use with your deaf/hard of hearing child?, 2) Who gave you this information or where did you get this information from?, 3) How did this information factor into your decision-making process in selecting communication approaches to use with your child?, 4) What kind of pressures did you feel as you went through the decisionmaking process? and, 5) Looking at this reference chart or communication matrix and based on your experience, how might future parents potentially benefit from using this when learning about, and ultimately selecting, communication approaches to use with their child? In the interviews, follow up and clarifying questions were asked as needed. All of the interview responses were coded and analyzed to uncover themes.

The frequency of codes within the survey and interview results are listed in Table 16. The top five codes were: Information Given, Satisfaction/Dissatisfaction with Information, Early Intervention Professionals, Input from Others, and Access to Opportunities. The coding results are presented below, organized by research question. 


\section{Table 16}

Frequency of Codes within Survey and Interview Responses

\begin{tabular}{|c|c|c|c|c|c|}
\hline Category & Code & Name & Survey & Interview & Total \\
\hline \multirow[t]{2}{*}{ Information } & 1 & Information Given & 22 & 71 & 93 \\
\hline & 2 & Information Not Given & 15 & 21 & 36 \\
\hline \multirow{4}{*}{$\begin{array}{l}\text { Source: } \\
\text { People }\end{array}$} & 3 & Medical Professional & 16 & 20 & 36 \\
\hline & 4 & Cultural Professional & 7 & 5 & 12 \\
\hline & 5 & $\begin{array}{l}\text { Early Intervention } \\
\text { Professional }\end{array}$ & 19 & 58 & 77 \\
\hline & 6 & Self & 9 & 38 & 47 \\
\hline \multirow{2}{*}{$\begin{array}{l}\text { Source: } \\
\text { Item/Place }\end{array}$} & 7 & Reference Item & 2 & 9 & 11 \\
\hline & 8 & Reference Place & 5 & 21 & 26 \\
\hline \multirow[t]{8}{*}{ Influence } & 9 & $\begin{array}{l}\text { Type and Level of Hearing } \\
\text { Status }\end{array}$ & 4 & 2 & 6 \\
\hline & 10 & $\begin{array}{l}\text { Amplification and } \\
\text { Technology }\end{array}$ & 5 & 16 & 21 \\
\hline & 11 & Additional Disabilities & 2 & 11 & 13 \\
\hline & 12 & Input from Others & 8 & 61 & 69 \\
\hline & 13 & $\begin{array}{l}\text { Wishes, Self-Desires, } \\
\text { Values, Previous } \\
\text { Decisions }\end{array}$ & 17 & 37 & 54 \\
\hline & 14 & Access to Opportunities & 15 & 46 & 61 \\
\hline & 15 & Satisfaction/Dissatisfaction & 30 & 62 & 92 \\
\hline & 16 & Expected Timeline & 4 & 9 & 13 \\
\hline \multirow[t]{2}{*}{ Matrix Use } & 17 & Matrix: Benefits & 4 & 21 & 22 \\
\hline & 18 & Matrix: Drawbacks & 0 & 3 & 3 \\
\hline
\end{tabular}




\section{Information Received Regarding Communication Approaches}

The first research question looked at the information parents of young deaf and hard of hearing children in Illinois received regarding communication approaches. This was defined as listing or describing information specific to ways of communicating with deaf and hearing of hearing, including the terms referenced in Table 6.

\section{Rating of Information Received}

Survey participants were asked to rate the information received each communication approach when their child was first identified as deaf or hard of hearing. They were asked to select from excellent, good, poor, or none in their response and the raw data results are displayed in Table 15. The selection rate for each ranking across all approaches is as follows: excellent (14\%), good $(34.5 \%)$, poor (17\%), and none (34.5\%). A further look at each communication approach shows that respondents rated information received about Listening \& Spoken Language (38\%), closely followed by Auditory Oral (29\%) as excellent. Information rated as good was fairly evenly spread across each of the communication approaches (ranging from $38 \%$ to $43 \%$ ), with only $19 \%$ ranking information about Cued Speech as good and $15 \%$ ranking information about Pidgin Signed English as good. Information about Sign Supported Speech was the top ranked as poor at $38 \%$, with information about Bilingual-Bimodal following closely at $33 \%$. And finally, the results indicate that $80 \%$ of parents received no information about Pidgin Signed English, 57\% received no information about Cued Speech, and 50\% received no information about Simultaneous Communication. Note that Bilingual-Bimodal, Sign Supported Speech, Cued Speech, Auditory Oral, and Listening \& Spoken Language all had sample sizes of 21 whereas Simultaneous Communication and Pidgin Signed English had sample sizes of 20. 
Table 17

Ranking of Information Received

\begin{tabular}{lccccc}
\hline & $\begin{array}{c}\text { Excellent } \\
(\mathrm{n}=)\end{array}$ & $\begin{array}{c}\text { Good } \\
(\mathrm{n}=)\end{array}$ & $\begin{array}{c}\text { Poor } \\
(\mathrm{n}=)\end{array}$ & $\begin{array}{c}\text { None } \\
(\mathrm{n}=)\end{array}$ & $\begin{array}{c}\text { Total } \\
(\mathrm{n}=)\end{array}$ \\
\hline Bi-Bi & 3 & 9 & 7 & 2 & 21 \\
Sim-Com & 0 & 8 & 2 & 10 & 20 \\
$\begin{array}{l}\text { Sign Supported } \\
\text { Speech }\end{array}$ & 1 & 9 & 8 & 3 & 21 \\
PSE & 0 & 3 & 1 & 16 & 20 \\
Cued Speech & 3 & 4 & 2 & 12 & 21 \\
Auditory Oral & 6 & 9 & 1 & 5 & 21 \\
LSL & 8 & 8 & 3 & 2 & 21 \\
Total & 21 & 50 & 24 & 50 & 145 \\
\hline
\end{tabular}

\section{Ease of Information Seeking}

Survey participants were asked to rank the ease of receiving information about using communication approaches, supporting communication, and the process of language development before their child turned three years old. Given seven different statements related to using ASL or using signs with spoken language; developing spoken language, listening skills, and language; cued speech; and supporting communication they were asked to choose from the following: didn't need/want, needed and received easily, needed and had difficulty receiving, or needed and never received. Overall, 'needed and received easily' was the most selected rating (66\%) across all statements. Within this category (needed and received easily), information about Language Development was ranked the highest at $20 \%$, followed closely by Developing Listening Skills at 19\%, with Supporting Communication and Developing Spoken Language both tied at $18 \%$. The ranking of didn't need/want was selected $26 \%$ of the time, with $44 \%$ 
applying this to Cued Speech, 28\% applying this to Using ASL, and 20\% applying this to Using Signs with Spoken Language. Using ASL was rated as the highest area of 'needed and had difficulty receiving', with $29 \%$ of respondents selecting this. Needed and never received was the least selected option, with only one person selecting this in relation to Cued Speech. All of the raw data can be seen in Table 18.

\section{Table 18}

Ease of Receiving Information

\begin{tabular}{lccccc}
\hline & $\begin{array}{c}\text { Didn't } \\
\text { Need/Want }\end{array}$ & $\begin{array}{c}\text { Needed \& } \\
\text { Received } \\
\text { Easily }\end{array}$ & $\begin{array}{c}\text { Needed \& } \\
\text { Had } \\
\text { Difficulty } \\
\text { Receiving } \\
(\mathrm{n}=)\end{array}$ & $\begin{array}{c}\text { Needed \& } \\
\text { Never } \\
\text { Received }\end{array}$ & Total \\
& 7 & $(\mathrm{n}=)$ & 0 & 21 \\
\hline Using ASL & 5 & 7 & 4 & 1 & 20 \\
$\begin{array}{l}\text { Signs with } \\
\text { Speech }\end{array}$ & 2 & 10 & 2 & 0 & 21 \\
$\begin{array}{l}\text { Spoken Language } \\
\text { Listening Skills }\end{array}$ & 0 & 17 & 3 & 0 & 21 \\
Cued Speech & 11 & 7 & 3 & 0 & 21 \\
Communication & 0 & 17 & 3 & 0 & 20 \\
Language & 0 & 19 & 2 & 0 & 21 \\
Total & 24 & 95 & 24 & 145 \\
\hline
\end{tabular}

Analysis of both the survey and interview responses were categorized under two codes related to the first research question: Information Given and Information Not Given. To be included within these codes, responses named specific communication approaches or programs that are known to use specific approaches, or using words in reference to communication, language, mode, or options. 


\section{Information Given}

Although the concept of receiving information was coded 22 times (12\%) within the survey, very few survey responses mentioned a specific approach. For example, two responses included, "The only approach discussed in depth was spoken English" and "Our family chose listening and spoken language based on our needs however the only other immediate option discussed was ASL." Another participant shared that the only information received was about auditory verbal communication. Other responses referenced general information that was given related to communication, rather than mentioning a specific approach. For example, "we were provided information and education on communication styles and hearing loss" does not specify which communication approaches were discussed. Other general statements referenced “all communication," “all forms of communication," "communication options," and "different modes of communication."

Within the interviews, the idea of information given was coded 71 times, or $14 \%$ of the overall comments. All forms of communication approaches as stated in Table 6 by Pittman and colleagues (2016) were described as information given by participants. The exact terms used differed, but the descriptions given during the narratives matched those in the table. Terms specifically used by the parents included:

- American Sign Language (ASL) (Participants 1, 3, 4)

- Sign language, (Participant 1)

- $\quad$ Cued Speech, (Participants 3, 4)

- $\quad$ Speaking, (Participants 2, 4)

- $\quad$ Signed Exact English, (Participant 4)

- Oral communication, (Participants 2, 4) 
- Signing and talking, (Participant 3)

- Learn(ing) to listen, (Participant 4)

- Auditory oral, (Participants 2,4)

- Total communication. (Participant 4)

During the interviews, parents freely shared that they received information about ASL and signing as well as listening and speaking. However, only one of them shared that they were given information about Cued Speech. When directly asked if they were given this information, two of the remaining three said no. The third interviewee did recall “yes, it was brought up. But we were just so, oh, total communication, signing and talking. I don't think that if the information was given to me, I don't think that I really looked into it. I was just kind of like, oh, we're fine."

\section{Information Not Given or Lacking}

Information not given was coded 15 times (8\%) within the survey comments. Several comments within the survey that indicated a lack of information regarding communication approaches, such as, "I didn't even know about cued speech as an option until he was 2 years old and I was at a conference. I wish I would have known about it earlier." Another parent specifically mentioned not knowing about pidgin languages. Several of the comments within the survey were general comments supporting a lack of information such as, "It would have been helpful if right off the diagnosis of hearing loss, we were provided with our communication choices." Another respondent wrote "I also have never received statistics on communication modes and outcomes." One parent did state that "Nobody went through each option," while another mentioned, "The [deaf-led organization] was my first big break in getting the help and information I was missing." 
Within the interviews, there were also several comments that indicated parents either did not receive the information or they found the information received as lacking. Several of the comments indicated that only one or two of the communication approaches were discussed. For example, "I did not receive information about anything other than oral communication and using hearing devices to speak," "They just told me more or less that oral communication would be the best form of communicating for her. And no other real options were given to me." "The other ones were glossed over like "why would you choose those, they're too hard and you have enough to deal with." Another comment was “Our family chose listening and spoken language based on our needs however the only other immediate option discussed was ASL." The mother who was deaf shared, "Do they feel they have to limit what they say to me because we're already deaf so we already know from our own experience? So yeah, there's that." When a parent was specifically asked if she received information about Bilingual-Bimodal, she asked for clarification as to what that meant and responded that no, she did not get information about that.

\section{Source of Information}

The second research question looked at the source of information, namely from whom or where parents received information about communication approaches. This was defined as a person, item, or place. In the survey, participants were asked to indicate who provided them with information about each communication approach.

\section{Who Provided the Information}

Survey participants were asked to select who gave them information about each communication approach. The options included early intervention provider, speech therapist, pediatrician, audiologist, ear/nose/throat doctor, early intervention service coordinator, teacher of the deaf, deaf/hard of hearing adult, other parent of deaf or hard of hearing child, other family 
member, or myself. For each approach, the respondent was allowed to pick one person. Note that pediatrician, deaf and hard of hearing adult, other parent of deaf or hard of hearing child, and other family member were listed as options but were not selected for any approach. Therefore, they are not listed in the table. In addition, no definitions were provided for any source. The sample size for each approach ranged from 21 to 11 respondents. As shown in Table 19, the top source of information across all communication approaches was the early intervention provider at $55 \%$, followed by the respondent's own research (myself) at $17 \%$ and the speech language pathologist (SLP) at 10\%. The lowest sources of information were the Ear, Nose, Throat Specialist (ENT) and the Teacher of the Deaf (TOD). To clarify, the sources were expanded in full on the survey but abbreviated in the table (i.e. written as Ear, Nose, Throat Specialist in the survey but listed as ENT in the table).

\section{Table 19}

Information Received from Whom

\begin{tabular}{|c|c|c|c|c|c|c|c|c|}
\hline & $\begin{array}{c}\text { EI } \\
\text { Provider } \\
(n=)\end{array}$ & $\begin{array}{l}\text { SLP } \\
(\mathrm{n}=)\end{array}$ & $\begin{array}{l}\mathrm{AuD} \\
(\mathrm{n}=)\end{array}$ & $\begin{array}{l}\text { ENT } \\
(n=)\end{array}$ & $\begin{array}{c}\text { EI } \\
\text { Coordinator } \\
(n=)\end{array}$ & $\begin{array}{l}\text { TOD } \\
(n=)\end{array}$ & $\begin{array}{c}\text { Myself } \\
(n=)\end{array}$ & $\begin{array}{l}\text { Total } \\
(\mathrm{n}=)\end{array}$ \\
\hline $\mathrm{Bi}-\mathrm{Bi}$ & 14 & 1 & 1 & 0 & 2 & 0 & 3 & 21 \\
\hline Sim-Com & 8 & 1 & 1 & 0 & 2 & 1 & 4 & 17 \\
\hline $\begin{array}{l}\text { Sign } \\
\text { Supported } \\
\text { English }\end{array}$ & 14 & 2 & 0 & 0 & 0 & 0 & 2 & 18 \\
\hline PSE & 6 & 0 & 0 & 0 & 0 & 1 & 4 & 11 \\
\hline $\begin{array}{l}\text { Cued } \\
\text { Speech }\end{array}$ & 8 & 3 & 0 & 0 & 0 & 2 & 5 & 18 \\
\hline
\end{tabular}


Table 19, Continued

\begin{tabular}{|c|c|c|c|c|c|c|c|c|}
\hline & $\begin{array}{c}\text { EI } \\
\text { Provider } \\
(\mathrm{n}=)\end{array}$ & $\begin{array}{l}\text { SLP } \\
(\mathrm{n}=)\end{array}$ & $\begin{array}{l}\mathrm{AuD} \\
(\mathrm{n}=)\end{array}$ & $\begin{array}{l}\text { ENT } \\
(n=)\end{array}$ & $\begin{array}{c}\text { EI } \\
\text { Coordinator } \\
(\mathrm{n}=)\end{array}$ & $\begin{array}{l}\text { TOD } \\
(\mathrm{n}=)\end{array}$ & $\begin{array}{c}\text { Myself } \\
(\mathrm{n}=)\end{array}$ & $\begin{array}{l}\text { Total } \\
(\mathrm{n}=) \\
\end{array}$ \\
\hline $\begin{array}{l}\text { Auditory } \\
\text { Oral }\end{array}$ & 8 & 3 & 1 & 1 & 2 & 1 & 2 & 18 \\
\hline LSL & 10 & 2 & 6 & 0 & 1 & 0 & 1 & 20 \\
\hline Total & 68 & 12 & 9 & 1 & 7 & 5 & 21 & 123 \\
\hline
\end{tabular}

Note. EI=Early Intervention, SLP=Speech Language Pathologist, AuD=Audiologist, ENT=Ear,

Nose, Throat Specialist, TOD=Teacher of the Deaf

\section{Sources of Information: People and Resources}

Analysis of both the survey and interview responses were coded into two broad categories People and Resources as sources of information. People included Medical, Cultural, Early Intervention Professionals, and Self (Parents/Prior Knowledge). Resources included Reference Items and Places.

People Source: Medical, Cultural, and Early Intervention Professionals

Medical professionals were defined those who had a clinical background, including audiologists, doctors, and speech pathologists. Medical professionals appeared in the survey coding 16 times (9\%). Cultural professionals were defined as deaf adults or deaf mentors and appeared in the survey coding 7 times (4\%). Early intervention professionals were those who provide early intervention services in Illinois, including developmental therapists-hearing (DTH) and early intervention provider. These sources appeared in the survey coding 19 times (10\%).

\section{Medical Professionals.}

There were several comments identifying medical professionals as sources of information, or lack of, within the survey. One parent stated, "We were provided little to no information regarding communication styles by audiology when diagnosed." In contrast, another 
parent stated, "The only information that our pediatrician and audiologists provided was for auditory verbal communication." Another parent shared that she actually received a 20-minute lecture from her child's ENT on the use of listening and spoken language and "had evidence to support her theory on why ASL would hold my child back in communication and actually hurt her communication skills."

In the interviews, medical professionals appeared in the coding 20 times (4\%), cultural professionals appeared in the coding 5 times $(0.1 \%)$, and early intervention professionals appeared in the coding 58 times $(11 \%)$. One parent stated that her child's pediatrician knew nothing about deafness and was very focused on her child's lack of hearing when she (mom) felt “there's nothing wrong with him, he just can't hear that's all!" Another mother mentions her child's pediatrician as being the source of auditory oral information, as well as audiologists and ENTs, saying, "we went to two different audiologists over the first three years, and we saw one

of the most reputable ear, nose, and throat doctors in the Chicagoland area, and we were always pushed towards wearing a hearing device and using spoken language."

\section{Cultural Professionals.}

The actual mention of a deaf adult as a source of information was only mentioned once in the survey, "someone from the deaf community was in touch with me to establish a connection and help me navigate the options for my child for ASL" Another mentioned working with the Illinois School for the Deaf, which does have deaf professionals, but did not mention actually connecting with a deaf adult. Other cultural references in the survey were reflected as a desired source of information, "It would have been helpful if a deaf person showed up in my hospital room when I learned my child was deaf/hoh to tell me about ALL the options. Or more 
realistically a person from the deaf/hoh community calling me and being my person to help guide me through my options for my child. Like a deaf mentor for the parents."

In all four interviews, the developmental therapist-hearing (DTH) and speech language pathologist (SLP) were consistently mentioned as being the ones giving information specifically to sign language or ASL or more focused on the idea of communication to support language, which aligns with a cultural view of deafness. The mother who was deaf supported the idea of involvement of cultural professionals, as indicated in this comment, "That [deaf mentor] should be given to other families so the deaf mentor can help the parents learn ASL to communicate with their kids so they don't feel left out." One family met with and attempted regular meetings with a deaf mentor, but it did not work out in the long term. Another mother mentioned how she reached out to a deaf-led organization, connected with a deaf adult, and felt that was the most successful source of information regarding ASL options for her child.

\section{Early Intervention Professionals.}

In the survey, early intervention professionals were mentioned often as source of information. One respondent credited the early intervention professional as a major source of information, "We had an amazing EI specialist that was able to give us access to ALL resources regarding the deaf community/culture as well as communications options." Another shared, "Our DTH through EI was fantastic, easily approachable and very educated regarding

resources. She was our only source of deaf community support." One mother felt the system was not a good source of information, as she said, "I feel like I was surrounded by agencies who should have been aware of what we needed but they didn't. They failed us."

Within the interviews, three of the four mothers had many positive things to say regarding their DTH and early intervention team, however, one of them did have to ask for a new 
DTH as the first one was not a good fit for their family. All three regarded their DTH as a consistent source of information for learning about communication approaches. The fourth mother did not mention early intervention or a DTH at all.

\section{Self (Research/Prior Knowledge).}

The parents themselves emerged as a source of information, both as researchers or seekers of information or as a result of previous experience. Many comments were made in both the survey and interviews that indicated parents relied on themselves to seek out and obtain information through their own research or they had prior knowledge of communication approaches due to family history of deafness. However, of the known respondents with a family history (three in the survey and two in the interviews), there were still indications that they needed more information. In the survey, one person identified as hard of hearing and wrote, "There are so many communication challenges of being a CI [cochlear implant] user that I never anticipated (even though I myself am hard-of-hearing!)"

Two of the interview participants indicated prior knowledge of communication approaches. Both attributed that to family history, with one being deaf herself and the other having deaf family members so they were already aware of many different communication approaches. The hearing mother indicated that even though there was a family history, she still needed help navigating the process of seeking communication information to support her child, stating, "even though we had a bit of family history, we still were very lost. And we didn't know where to go, what to do, how to navigate, what was next." The mother who identified as being deaf shared that she was already aware of the various communication approaches but still wanted: 
to see what they offer so I can compare it to what I know. I know some people say they don't get the right information about deaf things, so I wanted to see what they have to tell me as a deaf person.

However, she did express concern that she felt her early intervention team held back from sharing communication information with her simply because she was deaf. She was curious if the information shared with her was the same that would be shared with a hearing parent. The survey had several examples of parents doing their own research to gather information:

I did all the research myself. I had to research and put myself out there-calling people, calling places, signing up online for different programs in order to obtain more information. I had to research different modes of communication and really put myself out there to obtain reliable and correct information.

One comment indicated that parents were learning as they researched so they would know how to seek out the appropriate information, "I did have to educate myself to know to ask for it." A survey respondent commented that new families should "start with your audiologist and therapists and then do your own research." When prompted to share advice with newly diagnosed families on the survey, there were multiple mentions of self-research and seeking out information on communication approaches, including:

You will need to do your own research so you can ask and get answers to your questions from your team. Don't be afraid to seek others for help to educate you more on different areas and approaches. Educating yourself is empowering and critical for all kids development. 
There were also many interview references to the idea of parents searching on their own for information related to communication approaches. They used the internet, reached out to deaf organizations and parent support organizations. From there, they got more information and referrals to contacts and other sources of information. When asked to share where she did her research, one mother simply stated, "I got information from all over the place." When describing her process of seeking information, another mother shared:

I did all the research myself. I had to research and put myself out there-calling people, calling places, signing up online for different programs in order to obtain more information. I had to research different modes of communication and really put myself out there to obtain reliable and correct information.

\section{Resources: References Items and Places}

References items were defined as tangible items such as videos, books, brochures, pamphlets, research, and newsletters. Within the survey, reference items appeared in the coding 2 times (1\%) and in the interviews 9 times (2\%). Reference places were defined as classes, organizations (non-profit, parent-led, deaf-led), conferences, playgroups, websites, hospitals, and private schools providing early intervention. Reference places appeared in the survey coding 5 times $(3 \%)$ and in the interview coding 21 times $(4 \%)$.

Throughout the survey and interviews, there were multiple comments indicating that printed material was overwhelming, confusing, hard to read, or lacking information. Many respondents appreciated actual connections with places and people and indicated this was the most impactful way of receiving information related to communication. Within the survey, one such comment was, “...if you had a person, not a pamphlet, to show you the normalcy of it, that that would be really helpful to the families." Also, at least 3 parents within the survey mentioned 
attending the annual parent conference at the Illinois School for the Deaf as a source of information. One mother interviewed said that her self-research led to various organizations and resulted in human connections, which she indicated was her most relied upon source of information.

\section{Influencing Factors}

The third research question examined factors influencing the decision-making process. This was looked at from two angles. The first part focused on how the information received influenced the decision-making in selecting a communication approach to use. This was defined as how or why the resulting decisions were made and what input was used to make that decision. The second part of this question focused on pressures parents may or may not have felt during this process of making a decision. This was defined as satisfaction or dissatisfaction with the process as well as adherence to any expected timelines. This question was covered by eight different codes.

\section{The Decision-Making Process}

In the survey, this question the asked participants to state how much they agreed with various statements that might be considered influential factors in the decision-making process related to selecting communication approaches to use in the home. These factors include pressure, speed and smoothness of the selection process, and adequacy of information. After reading five different statements, respondents were asked to select from a Likert-style scale of agreement, ranging from strongly agree to strongly disagree. They were also given the option to select 'don't know or doesn't apply.' The sample size was 21 for each statement and Table 20 shows the raw data whereas Table 21 summarizes the percentages (all degrees were grouped into one). 


\section{Table 20}

Decision-making Regarding Communication Approaches

\begin{tabular}{|c|c|c|c|c|c|c|c|c|c|}
\hline I felt.... & $\begin{array}{l}\text { Strongly } \\
\text { Agree } \\
(n=)\end{array}$ & $\begin{array}{l}\text { Agree } \\
(n=)\end{array}$ & $\begin{array}{l}\text { Somewhat } \\
\text { Agree } \\
(n=)\end{array}$ & $\begin{array}{c}\text { Neither } \\
(n=)\end{array}$ & $\begin{array}{c}\text { Somewhat } \\
\text { Disagree } \\
(n=)\end{array}$ & $\begin{array}{c}\text { Disagree } \\
(n=)\end{array}$ & $\begin{array}{c}\text { Strongly } \\
\text { Disagree } \\
(n=)\end{array}$ & $\begin{array}{c}\text { Don't } \\
\text { Know/Doesn't } \\
\text { Apply } \\
(n=)\end{array}$ & Total \\
\hline $\begin{array}{l}\text { Pressured to } \\
\text { choose ONE }\end{array}$ & 5 & 2 & 3 & 2 & 1 & 4 & 4 & 0 & 21 \\
\hline $\begin{array}{l}\text { Needed to choose } \\
\text { quickly }\end{array}$ & 6 & 4 & 3 & 1 & 0 & 4 & 2 & 1 & 21 \\
\hline $\begin{array}{l}\text { Had adequate } \\
\text { information } \\
\text { about } \\
\text { ALL }\end{array}$ & 3 & 3 & 1 & 2 & 1 & 6 & 5 & 0 & 21 \\
\hline Overwhelmed & 3 & 4 & 3 & 4 & 2 & 2 & 3 & 0 & 21 \\
\hline Smooth process & 3 & 3 & 6 & 3 & 0 & 3 & 3 & 0 & 21 \\
\hline Total & 20 & 16 & 16 & 12 & 4 & 19 & 17 & 1 & 105 \\
\hline
\end{tabular}

Note. Survey sample $\mathrm{n}=21$ 
Table 21

Decision-making Regarding Communication Approaches by Percentage

\begin{tabular}{lcccc}
\hline $\begin{array}{l}\text { I felt... } \\
\text { Strongly, Agree, } \\
\text { Somewhat }\end{array}$ & $\begin{array}{c}\text { Disagree: } \\
\text { Strongly, Agree, } \\
\text { Somewhat }\end{array}$ & Neither & $\begin{array}{c}\text { Don't } \\
\text { Know/Doesn't } \\
\text { Apply }\end{array}$ \\
\hline $\begin{array}{l}\text { Pressured to } \\
\text { Needed to } \\
\text { choose quickly }\end{array}$ & $48 \%$ & $43 \%$ & $9 \%$ & $0 \%$ \\
$\begin{array}{l}\text { Had adequate } \\
\text { information } \\
\text { about ALL }\end{array}$ & $33 \%$ & $28 \%$ & $5 \%$ & $5 \%$ \\
$\begin{array}{l}\text { Overwhelmed } \\
\text { Smooth process }\end{array}$ & $48 \%$ & $57 \%$ & $10 \%$ & $0 \%$ \\
\hline
\end{tabular}

Note. Strongly Agree, Agree, and Somewhat Agree were combined into one column. The same was done for Strongly Disagree, Disagree, and Somewhat Disagree.

\section{Factors Influencing Decision-Making}

Analysis of both the survey and interview responses indicated several codes of factors influencing decision-making. These include: Additional Disabilities, Input from Others and Self (wishes, desires, values), Availability of and Access to Opportunities, Satisfaction/Dissatisfaction and Expected Timelines. Table 22 shows the code prevalence in the survey and interview responses. The Type and Level of Hearing Status, Amplification and Technology, and Additional Disabilities codes were extremely low in both the survey and interview responses. Satisfaction/Dissatisfaction had the highest coding prevalence in the survey, while it tied with Input from Others as a top code in the interviews. 
Table 22

Code Frequency and Prevalence for Influences

\begin{tabular}{lcc}
\hline \multicolumn{1}{c}{ Code } & Survey & Interview \\
\hline Type and Level of Hearing & 4 & 2 \\
Status & $2 \%$ & $0.3 \%$ \\
Amplification and & 5 & 16 \\
Technology & $3 \%$ & $3 \%$ \\
Additional Disabilities & 2 & 11 \\
& $1 \%$ & $2 \%$ \\
Input from Others & 8 & 61 \\
& $4 \%$ & $12 \%$ \\
Wishes, Self-Desires, Values, & 17 & 37 \\
Previous Decisions & $9 \%$ & $7 \%$ \\
Access to Opportunities & 15 & 46 \\
& $8 \%$ & $9 \%$ \\
Satisfaction/Dissatisfaction & 30 & 62 \\
& $16 \%$ & $12 \%$ \\
Expected Timeline & 4 & 9 \\
& $2 \%$ & $2 \%$ \\
\hline
\end{tabular}

Note. Frequency of code appearance is shown as both a raw number and percentage.

\section{Additional Disabilities}

There were a few mentions of how additional disabilities factored into their decisionmaking. In the survey, one parent stated, "I feel like between the Audiologists and EI we didn't get much help. More so because my son is severely delayed." One of the mothers interviewed shared how the process of determining the presence of additional disabilities was clearly a source of concern for her: 
"Right now we're still not sure what his diagnosis is, autism or ADHD. Coronavirus interfered and forced us to stop with that process so I feel like I have a lot I still want to know. We're not sure right now what to do as he is still not picking up the language yet." While not specifically referencing additional disabilities, one parent did mention in the interview how the mere presence of a disability influenced her process of seeking information by saying, “you don't even realize until you're a parent and you have a child that has some form of a disability. The things that you don't know that you learn really, really quick."

\section{Input from Others and Self}

There were many references to input received throughout the decision-making process. Input was a broad category that included both familiarity with and understanding of information received as well as satisfaction or dissatisfaction with the information received. One survey response stated, "I think professionals are trying not to overwhelm parents. We were overwhelmed, but I know the earlier we can start communicating the better." Another person shared, "Once we made the decision for spoken English only, it was like we could never go back to choosing anything else. I was always using basic sign but told not to use them in front of our speech therapist." Another parent shared the impact of input from others, saying, "So I felt like I was being pulled in multiple directions for different reasons, you know?" There were a couple mentions that stated that their early intervention teams were great at sharing and providing information. One survey comment reflected the influence of input from others by encouraging other parents to educate themselves by talking to other people and finding out as much information as they can.

Those in the interview were directly asked if they felt pressured or pushed in the decision-making process. Three of the four respondents replied no, they did not feel pressured to 
make a decision regarding communication use. One of those parents commented that she did not feel pressured but rather had more of an internal gut feeling that she needed to explore options by saying, "I don't think the word would be pressured. I knew I had to find different options for her because for some reason I just knew something else needed to be added to her way of communicating, not just orally." Another mother shared, "the DTH did do a very good job of not wanting to offend or step on anyone's toes. Like, here's your options for communication. These are the different options, these are both what they entail.... the DTH was even-keeled. Didn't ever want to sway one side over the other...As far as in the program itself, early intervention program, no pressure whatsoever to choose a side or a particular form of communication, no." The same mother went on to say, “And so there's a lot of like-- and I'm sure you know, there's a lot of information. And there's a lot of research. And there's a lot of statistics, and things out there of people trying to say what they feel is better."

The fourth mother mentioned just feeling overall pressured from everyone, "I felt a tremendous amount of pressure from every different area from the deaf community, from the hearing community. I felt a lot of pressure from everybody." The same mother went on to say, "That is probably the worst experience-- part of the whole experience, was feeling the different pressures from the different programs, the different schooling programs from the deaf community, from the doctors..." She continued share her perspective of feeling pushed toward a specific approach: "...from the doctors that push auditory-verbal," "...got heavily pushed in the direction of total communication," "...we were always pushed towards wearing a hearing device and using spoken language." “...just assuming that people are going to want their child to wear a hearing device or be implanted with a hearing device to hear and speak and listen." 
Input from others was indicated in the interview with this statement, "And we just talked a lot about different things, and we often asked [DTH's] opinion on stuff." That same mother went on to describe a situation in which she took the DTH's advice on a topic related to pursuing speech therapy services. She also talked about the input received from her child's early intervention evaluation reports and how it was always so positive. The mother who was deaf also talked about how her early intervention team shared information about various communication approaches and she listened and then made her own decisions. Another mother shared how she was able to talk about Cued Speech with another parent and how that input influenced her next steps.

\section{Self: Wishes, Self-Desires, Values, Decisions}

Some comments indicted satisfaction with their decisions, such as, "I don't think there was ever a moment where we personally felt like we ever questioned what our decision was," and "I felt like we made the best decision for our child. She has done very well and has no delays currently." Another comment indicated a wish for more confidence, "No specific changes at this point - other than being more confident that we were following through with spoken language, not using signs right now." Other indicators of desire included, "At the time I thought I was making the right choice. In retrospect I didn't have enough information. And now 4 years later I wish we'd chosen differently," "I would have signed more at home," and "I would've been more insistent on pursuing sign supported English."

There were also several comments indicating a desire to provide options for the child and then allowing the child to use what worked as well as being willing to change, such as these comments, "Be open to other forms of communication. ASL is great but if it's not right for your 
child, that's ok too. Do what is best for your child," and "Within the year following implant surgery, I realized using some sign language was useful and important to us."

In the interview, one mother commented on her desire for her child, "I felt enormous pressure-- not only from myself, because that's-- while I always want to do the best thing for my child, and that's the number one pressure...." That same mother continued to share her thoughts and said:

So I think just in general, having a child that is deaf or hard of hearing, that in itself was new to me, so that was what was in my mind is, how do I make the best life for her, and how do I navigate this well for her? Because I was so uneducated in this area-- and I knew it. I knew I was uneducated, and I wanted to know more. And so for the first three years of her life, I really just told myself to keep an open mind and try all different things that I learned about, and see what fit best in her life and our life as a family.

Another mother shared what she wanted for her child, "We want our child to be deaf, we want him to be hard of hearing, we want him to literally be everything. And we're OK."

\section{Access to Opportunities}

There were several comments made in the survey referencing the availability of and access to various opportunities as influential. One parent simply said, "The resources available was also very important." Many comments related to this code were focused on the lack of resources to which impeded their ability to support their child. One parent from the survey shared, "I really felt that my child would benefit from learning ASL and that is the hardest thing to obtain, even to this day." Another parent commented, "We could have and still could use more family friendly (where children are involved) options of learning ASL and cued speech." There were several references to delays in accessing classes/providers or needing more DTHs and SLPs 
experienced in deafness. This was highlighted in this survey response, "we were told it'd be difficult to find a DTH who also signed, so we should just do all we can." Another mentioned the state school for the deaf as an available resource but not a realistic one because it was just too far away. Another mentioned that while they did have access to a provider using their preferred communication approach, the provider refused to use that approach with their child.

One mother did mention in her interview that she was given the opportunity for her child to try cued speech by participating in a local program that used it so she tried it because she "was willing to learn about all different modes of communication, and I wanted to see what it was about, and really learn and just involve myself in that environment to see if it worked for (my child)." All four mothers mentioned being pleased to have access to providers that used sign language, including the deaf mother. One mother said that access was an important influence in their search for a speech therapist, as they wanted one who could sign with their child. Another mother mentioned being invited to join a playgroup with other families and that is where they began learning sign language as well as speaking.

\section{Implications of a Reference Chart}

In the interviews, parents were shown a reference chart that shared information about communication approaches and asked to list the potential benefits to future families. While the survey did not ask this question or have the chart available, the concept did show up in the coding as a benefit in 4 statements (2\%). No drawbacks were evident in any survey responses. Within the interviews, the benefits of a reference chart was coded 21 times or $4 \%$ and the drawbacks were coded 3 times or $0.05 \%$. 


\section{Benefits: Access to Information}

The idea of a reference chart was specifically asked about in the interviews but not mentioned in the survey. However, there were four references to the idea of being given some sort of formal presentation of all of the communication approaches right away upon identification within the survey. The first comment said, “A comparison of all communication options and what level of hearing loss typically succeeds with what communication style (would have been helpful)." The second comment was "(it would have been helpful to have) a person from the deaf/hoh community calling me and being my person to help guide me through my options for my child." The third comment alluding to the concept of a chart was "It would have been helpful if right off the diagnosis of hearing loss, we were provided with our communication choices. We had to ask about it and didn't really know what to ask at first." The final comment was, "Specific information from EI regarding communication options for a child who is deaf or with a hearing loss would have been helpful."

In the interviews, three of the four mothers reacted positively after viewing the chart. The mother who was deaf read through the chart and thought it might be 'kinda' helpful for new families but overwhelming. She did state that knowing what other options are available is a good idea but that families should start with ASL first. Then if ASL did not work, the chart could help in knowing what to try next. The three hearing mothers immediately showed enthusiasm for the chart and indicated they wished they would have had one back at the beginning of their journey. In addition to being a source of information of all the communication approaches in one place, one mother said it would help with awareness of the variety of approaches. She said, "Because I think as a parent it's like, OK, hearing or not hearing. Like, talking or signing. Like there's no like-- I don't think people think about that there's all the other in-between, if that makes sense." 
Two mothers mentioned the benefit of side-by-side comparison as being beneficial, with one saying "having something to visually look at and have it side by side, explaining what each category is, and how it works, and how it comes together, and then what the next option is," and the other saying,

"And it's comparing them side by side. So I feel like the information is in the right place, where it's relatable, it's understandable, and it's easily defined, you know what I mean? It makes it easy for people to understand."

\section{Drawbacks: Access to Information}

Two comments indicated potential drawbacks of access to information or the use of a reference chart as being overwhelming. In the survey, one parent commented,

I only would have liked more information early on after his diagnosis. I think professionals are trying not to overwhelm parents. We were overwhelmed, but I know the earlier we can start communicating the better... I appreciate not feeling pressure to a specific type of communication, but this can also lead to not doing anything to intentionally communicate.

In the interview, the mother who was deaf read through the chart and stated she thought it might be 'kinda' helpful for new families but overwhelming. She did state that knowing what other options are available is a good idea but that families should start with ASL first. Then if ASL did not work, the chart could help in knowing what to try next.

\section{Thematic Analysis}

A thematic analysis was conducted, with a focus on the phenomena shared by parents in an attempt to address the main research question: how did parents perceive the process of receiving information about communication approaches for their deaf or hard of hearing child? 
The coding process and resulting prevalence rates (see Table 16), analysis of all open and closed set responses within the survey, and analysis of the interview responses were used to guide the thematic analysis. The top five codes were: Information Given, Satisfaction/Dissatisfaction with Information, Early Intervention Professionals, Input from Others, and Access to Opportunities. which uncovered three main themes:

Theme \#1: Information about communication is valued.

Theme \#2: Information from people is valued as a source.

Theme \#3: Access to Opportunities to see, use, experience communication is valued as an influence.

More information about these themes and resulting sub-themes and how they were organized can be found in Table 23. Categories that were developed within the coding process and the subsequent reviews of all of the interviews and survey comments yielded a funnel of data that fit into the three main themes. Examples of several comments mentioned by survey participants and parents were included to demonstrate specific examples of how each sub theme was categorized as well as how they relate together within the main theme. This information was brought to the coding team as part of the audit trail. Initially there were four themes grouped by research question and codes. After discussion with the coding team, it was agreed that the Matrix Use should be merged with the Information, as the idea of a matrix is a source of information specific to communication approaches. It was also agreed that Input from Others (as an influence) should be merged with Information from People since specific people were often references within that code. A discussion of the remaining research questions and findings determined that the three main themes, as shown in Table 23, adequately reflected the experience of the parents in this study as they shared their experiences of receiving information about 
communication approaches for their deaf or hard of hearing child for the parents in this study.

Table 23 also includes the prevalence of each code within the theme. 


\section{Table 23}

Factors that Influence Parent Communication Decisions for their Deaf or Hard of Hearing Child

\begin{tabular}{|c|c|c|c|}
\hline Themes & Sub-themes & $\begin{array}{l}\text { Specifically Mentioned by } \\
\text { Participants }\end{array}$ & Number of Codes \\
\hline \multirow[t]{6}{*}{$\begin{array}{l}\text { Information about } \\
\text { communication is valued }\end{array}$} & Information given & $\begin{array}{l}\text { Sign language, ASL, talk, oral, } \\
\text { speech, Lipread/speech read, } \\
\text { cueing, everything, all options }\end{array}$ & 93 \\
\hline & Information not given & $\begin{array}{l}\text { Nothing, no options discussed, } \\
\text { I didn't know }\end{array}$ & 36 \\
\hline & Reference items & $\begin{array}{c}\text { Books, brochures, } \\
\text { paper/pamphlet, newsletter, } \\
\text { research }\end{array}$ & 11 \\
\hline & Reference place & $\begin{array}{l}\text { Internet, organization or } \\
\text { program, conference, class, } \\
\text { playgroup, hospital, school, } \\
\text { private therapy }\end{array}$ & 26 \\
\hline & Matrix use: Benefits & $\begin{array}{l}\text { Comprehensive, side-by-side } \\
\text { comparison, information right } \\
\text { away, all in one place, access } \\
\text { to all information }\end{array}$ & 22 \\
\hline & Matrix use: Drawbacks & Overwhelming, kinda helpful & 3 \\
\hline
\end{tabular}


Table 23, Continued

\begin{tabular}{|c|c|c|c|}
\hline Themes & Sub-themes & $\begin{array}{l}\text { Specifically Mentioned by } \\
\text { Participants }\end{array}$ & Number of Codes \\
\hline \multirow[t]{5}{*}{$\begin{array}{l}\text { Information from people is } \\
\text { valued }\end{array}$} & Medical professionals & $\begin{array}{c}\text { Doctor, pediatrician, } \\
\text { audiologist, speech pathologist }\end{array}$ & 36 \\
\hline & Cultural professionals & Deaf adult, deaf mentor & 12 \\
\hline & $\begin{array}{l}\text { Early intervention } \\
\text { professionals }\end{array}$ & $\begin{array}{c}\text { Developmental therapist- } \\
\text { hearing, case worker/case } \\
\text { manager, speech pathologist, } \\
\text { EI specialist }\end{array}$ & 77 \\
\hline & Self, Previous Experience & $\begin{array}{c}\text { I did, I called, I talked to, I } \\
\text { reached out to, I searched for, } \\
\text { deaf family members, research, } \\
\text { family history }\end{array}$ & 47 \\
\hline & Input from others & $\begin{array}{l}\text { Other parents, deaf adults, } \\
\text { therapists, doctors, told me, } \\
\text { shared with me, I learned from, } \\
\text { heavily pushed, people trying } \\
\text { to say what they feel is better, } \\
\text { what I've been given, no } \\
\text { pressure to pick, told me about }\end{array}$ & 69 \\
\hline
\end{tabular}

(Table Continues) 
Table 23, Continued

\begin{tabular}{|c|c|c|c|}
\hline Themes & Sub-themes & $\begin{array}{l}\text { Specifically Mentioned by } \\
\text { Participants }\end{array}$ & Number of Codes \\
\hline \multirow[t]{7}{*}{$\begin{array}{l}\text { Access to opportunities to see, } \\
\text { use, experience } \\
\text { communication is valued }\end{array}$} & Satisfaction/Dissatisfaction & $\begin{array}{l}\text { Pressure from myself, didn’t } \\
\text { question our decision, happy, } \\
\text { amazing, I wish I would have } \\
\text { known, heavily pushed, no } \\
\text { help, didn't work out, good job }\end{array}$ & 92 \\
\hline & Access to opportunities & $\begin{array}{l}\text { Playgroup, conference, other } \\
\text { parents, classes, signing } \\
\text { therapist }\end{array}$ & 61 \\
\hline & Expected Timeline & $\begin{array}{c}\text { For the first three years, I knew } \\
\text { I had to move quickly, no time } \\
\text { to waste }\end{array}$ & 13 \\
\hline & $\begin{array}{l}\text { Wishes, Self-Desires, Values, } \\
\text { Previous Decisions }\end{array}$ & $\begin{array}{l}\text { I want what works best for my } \\
\text { child, }\end{array}$ & 54 \\
\hline & Additional Disabilities & $\begin{array}{l}\text { Autism, not developing } \\
\text { language, delay }\end{array}$ & 13 \\
\hline & Amplification and Technology & Cochlear implant, hearing aids & 21 \\
\hline & $\begin{array}{c}\text { Type and Level of Hearing } \\
\text { Status }\end{array}$ & Deafness, hard of hearing, & 6 \\
\hline
\end{tabular}




\section{CHAPTER V: DISCUSSION}

The purpose of this study was to examine the parent perspective of information received about communication approaches for their child and how that ties into the recommended guidelines related to informed choice, decision-making, and information sharing within the early intervention process. Specifically, this study aims to look at the information gathering and resulting decision-making process from the parent perspective and uncover relevant themes for this process as experienced in Illinois. This chapter includes a discussion of the major findings as related to each research question. In addition to the themes, limitations of the study and implications for future research will also be addressed.

Throughout the study and data analysis process, this main research question remained at the forefront of all considerations: how did parents perceive the process of receiving information about communication approaches for their deaf or hard of hearing child? Specifically, (a) what information did parents of young deaf and hard of hearing children in Illinois receive regarding communication approaches? (b) who or where did they receive information about communication approaches from? (c) how did this information factor into their decision-making process in selecting communication approaches for their child? and (d) how future parents might potentially benefit from the use of a reference chart or communication matrix when learning about, and ultimately selecting, communication approaches to use with their child?

In answering the research questions, the key findings from the survey and the interviews appear to support each other in many ways. The main research question sought to understand how parents in Illinois perceived the process of receiving communication approaches for their deaf or hard of hearing child. Ultimately, each of the parents had a unique story to share. While there were commonalities and variations, several considerations were unearthed regarding the 
information received, the source of information, factors influencing their decision-making, and the potential benefits of a reference chart. Three main themes were uncovered: information about communication is valued; information from people is valued as a source; and access to opportunities to see, use, experience communication is valued as an influence. These themes and a brief review of the overall findings (shown below in Table 24) set the tone for the discussion and implications that will follow.

\section{Table 24}

Study Findings

\section{Research Question $\quad$ Summary of Findings Reported in Chapter 4}

What information did parents of young deaf and hard of hearing children in Illinois receive regarding communication approaches?

Who or where did they receive information about communication approaches from?

How did this information factor into their decision-making process in selecting communication approaches for their child?
Parents in Illinois receive inconsistent information regarding communication approaches. While all of the communication approaches were mentioned within the study, not everyone received information about all the approaches.

Primary sources of information for parents in Illinois appear to be early intervention professionals and the parents themselves. Prior knowledge through family history impacts some families.

Access to opportunities in addition to satisfaction/dissatisfaction with the information emerged as top influencers in the process of making decisions related to communication approaches.

(Table Continues) 
Table 24, Continued

Research Question

Summary of Findings Reported in Chapter 4

How might future parents potentially benefit

from the use of a reference chart or

Overall, the idea of a reference chart or communication matrix was deemed desirable communication matrix when learning about, and ultimately selecting, communication approaches to use with their child? and beneficial. Benefits included summary and comparison of each communication approach provided in an accessible manner. One drawback mentioned was the potential to be overwhelming.

In comparing the previous themes found in the review of existing literature with the newly identifed themes of this study, they appear to align very well, with some overlap, which is presented in Table 25.

Table 25

Theme Comparison: Literature Review and Current Study
Literature Review Themes
Current Study Themes

\begin{tabular}{ll}
\hline Parent Values and Desires for Child's Future & $\begin{array}{l}\text { Information about communication is valued. } \\
\text { Needs of the Child }\end{array}$ \\
Accessibility & $\begin{array}{l}\text { Information from people is valued as a } \\
\text { source. }\end{array}$ \\
Sources of Information & $\begin{array}{l}\text { Access to Opportunities to see, use, } \\
\text { experience communication is valued as an } \\
\text { influence. }\end{array}$ \\
\hline
\end{tabular}

\section{Interpretation of the Findings}

While there was some variation within the resulting themes providing insight into each of the individual research questions, each one appeared to have an impact on how parents perceived the process of receiving information about communication approaches for their deaf or hard of hearing child. What follows is a discussion of the population sample and findings as related to each research question. 


\section{Population Sample}

It is important to consider the population sample when interpreting the findings. In this study, the sample size is small for both the survey $(n=21)$ and interviews $(n=4)$. Keeping in mind that the interviews were pulled from the survey, it is important to remember that the experiences of 21 parents cannot be representative of all families of deaf and hard of hearing children in Illinois at the beginning stages of their journey to seek out information related to communication. The respondents match the overall demographics of Illinois in some ways but not others. For example, every respondent reported education levels at college or higher, which is unlikely in the actual population of deaf and hard of hearing families. Geographically, the respondents primarily resided in the northern sector of Illinois while receiving early intervention services $(86 \%)$ while the others resided in central or southern Illinois. While it may seem disproportionate, this does align closely with the general population since northern Illinois contains $75 \%$ of the overall population (Wikipedia, n.d). It is also important to note that this survey sample appears to be a representative sample with approximately $86 \%$ of the children having hearing parents, which is similar to the commonly reported statistic that approximately $90-95 \%$ of deaf and hard of hearing children are born to hearing parents (Humphries et al., 2012). However, out of four interviewees, two of them had prior knowledge or experience with deafness, which is half. That does not align with current statistics indicating the majority of deaf and hard of hearing children being born to hearing parents (50\% in the study compared to $90-95 \%$ nationally). Therefore, the responses within the interviews really must be taken with caution and in consideration of representation and risk of overgeneralization.

As this study occurred during the COVID-19 global pandemic, recruitment was impacted. The survey and interview recruitment opened at the beginning of March 2020. In mid- 
March, the governor of Illinois ordered a lockdown of the state of Illinois. As a result, businesses and schools shut down and people for forced to remain home and only leave for essential business. One survey respondent initially requested to be interviewed but then declined due to feeling overwhelmed with her daily life as impacted by COVID-19. It is entirely plausible that due to the significant changes and unknowns resulting from COVID-19, there was less interest in participating in the study. These factors potentially limited the pool of study participants.

In terms of generalizability, this study aimed to be an exploratory study that might be used in the future to modify practices in the dissemination of information related to communication approaches as well as addressing potential gaps in service due to lack of providers with specifically trained skill sets in each of the communication approaches. In addition, this study may also be used in the future to explore the idea of training providers in the concept of shared decision-making and applying that in supporting families. With the population sample, the researcher would caution against overgeneralization of the findings due to the small size, the potential leading questions, and the geographical concentration. However, with the findings of inconsistent information dissemination, one may find the data to be compelling enough to implement further investigations into this phenomenon and address the needs for improving these practices within Illinois.

\section{Discussion of Findings}

\section{Information Received}

The first research question asked: What information did parents of young deaf and hard of hearing children in Illinois receive regarding communication approaches? The overarching theme that emerged in the findings within this area indicate that information about communication is valued. Study participants shared that they desired information, appreciated 
information that was received, and consistently indicated specific information that was obtained and information that was missing. Examination of the data from this study indicates that parents in Illinois receive inconsistent information regarding communication approaches. While all the communication approaches were mentioned by participants within the study, not everyone received information about all the approaches.

The type of information received was mixed. For example, when this research question was asked in an interview of a hearing mother, the mother immediately responded with a clarification question of her own, "Information that I asked for, or information that was freely given to me?" This question provided the primary researcher an insight into the struggle that some families appear to experience in their quest to gather information regarding communication approaches to use with their child and how this might influence any decisions made. Similar to this mother, the others indicated a mixture of results, with some information easily obtained and other information either a challenge to receive or simply not given.

When sharing information that was given related to communication approaches, there were varying terms used by the parents. The terms did not always match the terms used in Table 6 , but the descriptions given during the narratives matched those in the table. This leads to a discussion of terminology, specifically labels used to describe the various communication approaches. One parent did clarify, in regard to ASL, "when I say ASL, I'm combining Signed Exact English, ASL, and total communication into one, so I don't want to misspeak." This statement lends support to the need for specific definitions of each approach to be used across the field. Pittman and colleagues (2016) address the confusion created in the lack of standard terms and attempt to rectify this by suggesting the use standard labels. However, as indicated in the current study, there is no evidence of this concept being applied consistently at this time. Due to 
the publication date of 2016, it is possible that standard information was not readily disseminated in time to affect the families in this study. It is important to note that professionals often understand the various descriptions and labels used due, especially as they evolve over time, due to experience and parents new to the field have no way to quickly acquire this information in a short period of time.

Existing literature has shown the connection between amplification and communication (Ching et al., 2018; Jackson, Traub et al., 2008; Scarinci et al., 2018). That was somewhat evident in this study, with some participants indicating that information about speech, talking, listening, or auditory oral was also accompanied by information about hearing technology such as hearing aids and cochlear implants. This also algins with the idea of the medical view versus the cultural view of deafness (Matthijs et al., 2017), which leads to the potential impact of the professional discourse around communication approaches. These two views within the field will naturally present information that appears to be conflicting. Further analysis of comments in the study indicates this conflict has an impact on decision-making for families. One parent stated, "Our medical team (audiologist and SLP) had a different approach to communication than our EI team so that made the decision harder when we were new to the deaf and hard of hearing community.” Another parent reluctantly shared: not to say anything bad about another association, but with [redacted] they're not really big on the total communication aspect of it. They want speech to come in first, and then maybe the signing. Because there's all these theories that if you sign before you talk then you won't actually talk.

Perhaps applying the concept of standardization of terms to the process of information seeking might help alleviate some of the conflicting information experienced. If standardized terms are 
used within a standardized process of information sharing, perhaps some of the above-mentioned issues of conflict, missing information, and struggles to obtain information would be alleviated. In turn, this would allow for parents to receive all of the information, which ties into the theme uncovered in this study: information about communication approaches is valued.

\section{Sources of Information}

The second research question asked: Who or where did they receive information about communication approaches from? The overarching theme that emerged in the findings within this area indicate that information from people is valued as a resource. Analysis of data related to this question uncovered two primary sources of Information: People and References. These sources present within this study align very closely with the themes uncovered in the literature review conducted for this study: Sources of Information. In that review, every study except for one (Borum, 2012) mentioned professionals as a source of information, which was also identified as a theme in this study.

In interviews and survey comments, parents indicated they did receive information from a variety of professionals, including DTH, SLP, audiologist, pediatrician, and ENT. Table 19 shows the results of the survey asking parents to select who gave them information about each approach. The options included those mentioned above plus early intervention provider, early intervention service coordinator, teacher of the deaf, deaf/hard of hearing adult, other parent of deaf or hard of hearing child, other family member, or myself (parent). For each approach, the respondent was allowed to pick one person, which may have skewed the results as it is likely that more than one source provided information about the same communication approach. Interestingly enough, the survey did not return any results related to the pediatrician, deaf and hard of hearing adult, other parent of deaf or hard of hearing child, and other family member. 
However, in the interviews, pediatrician was mentioned as a source of information. In addition, there were mentions of either desire or gratefulness in connecting with deaf and hard of hearing adults and other parents.

As previously mentioned, the field of deafness tends to have two pathways, with signing and a focus on communication and language considered to be more cultural whereas a focus on speaking, listening, and hearing technology tend to be more medical (Matthijs et al., 2017). In the interview, one parent, who was deaf herself, alluded to this distinction. Her biggest concern with the medical/auditory sources was that they saw her child as having something wrong with his hearing while she saw him as normal, just deaf. This connects to the idea of professional discourse and its influence. On one hand, this discourse influences the type of approach shared, however, at this early stage, the hearing parents in this study did not seem to identify this as a cultural versus medical view. They appeared to connect it more with signing versus speaking and technology or as each group providing different information, which creates a challenge in the decision-making.

The concept of self-research as a source of information was mentioned often, which also aligns with existing literature in the literature review. There was a hint of feeling overwhelmed in having to seek out the information, but parents felt it was necessary to get access to all of the information. A few parents mentioned that they did not know what to ask for and sought support from their DTH and did self-research to address this.

Prior knowledge was mentioned by two mothers interviewed who indicated a family history of deafness. Both indicated that this prior knowledge contributed to a quick start with communication information and a general awareness of the various approaches. The deaf mother did indicate that she felt some professionals held back from sharing information because she was 
deaf. Because of this, she was not sure if she was getting the same kind of information hearing parents were getting. Professionals need to be aware of bias and possibly withholding and/or adjusting information for a variety of reasons. And while not related to prior knowledge, two parents mentioned the concept of withholding information with personal experiences of professionals purposefully not using an approach with the child, even though parents requested and perceived them as capable of doing so. Again, professionals need to be aware of their actions and words and how that is perceived by the parents as well as how it may affect parent choices.

Finally, another source of information mentioned was tangible items, usually in the format of some sort of printed material. Many parents expressed a desire for a connection with an actual person instead, including deaf adults, other parents, and trusted professionals. In this day of technology and digital information, we should consider how we can better foster these types of connections. Various Illinois organizations provide conferences, parent guides, deaf mentors, sign classes, family events, and other forms of connections. This ties directly into the theme of people being valued as an information source.

\section{Factors Influencing Decision Making}

The third research question asked parents: How did the information received factor into the decision-making process in selecting communication approaches for their child? Further analysis identified several factors influencing decision-making, including the following: Type and Level of Hearing Status, Amplification and Technology, Additional Disabilities, Input from Others and Self (Wishes, Desires, Values), Access to Opportunities, Satisfaction/Dissatisfaction, and Expected Timeline. Out of all of these factors, the data in this study indicates access to opportunities to see, use, experience communication is valued and is influential. As with the other themes, these were also uncovered in the literature review. 
A few parents mentioned a lack of access to resources, notably either in the form of learning to use a communication approach or in finding a professional using that approach to support their child. They admitted that due to this lack of access, they chose to look more closely at a different form of communication. As a state with a large rural population, this is not surprising and professionals in the field really need to examine this further to determine how to support equal access to these resources and opportunities. Sharing information about the communication approach but not having access to it is problematic. In addition, there is a lack of qualified professionals to meet the varying needs of this population. The concept of additional disabilities was brought up by one parent as a factor because her child was struggling to develop language, even though he was in a fully accessible environment (deaf family). The current global health pandemic and resulting lock down were interfering with her access to getting support in this area, which was affecting her confidence in decisions she was making. As well, the survey showed that the most commonly self-reported additional delay was speech/language at $81 \%$, followed by both motor and social/emotional delays at $35 \%$ each. Note that the survey used the word delay rather than diagnosis. Actual or perceived, the idea of additional disabilities impacting use of communication is very real.

Finally, there were mentions of feeling some kind of pressure that came from either an external or internal source. These ideas were also present in the existing literature. One parent commented significantly on the pressure she felt from professionals that was related to feeling pushed to select the approach suggested or preferred by the provider. This relates back to the idea of professional discourse and how it impacts parents. The recommended guidelines repeatedly mention the concept of 'supporting families' but being a source of pressure dies not following this guideline. Another source of pressure mentioned by some parents in this study 
was wanting to do the best thing for their child to ensure successful communication and language. Although not mentioned as often, another source of concern was the idea of the unknown and not knowing what to seek out or ask for. This creates additional work as parents must self-research to feel confident that they have all the information needed to make an informed decision. Again, this goes back to the idea of professional discourse and professional roles.

As mentioned previously, this professional discourse often leads to potential of conflicting information, simply due to the nature of a medical view versus a cultural view of deafness. One survey comment stated, "Our medical team (audiologist and SLP) had a different approach to communication than our EI team so that made the decision harder when we were new to the deaf and hard of hearing community." While a few parents specifically identified situations of conflict, either between their choices and the professional's viewpoint or within the information received, many others in this study did not use any words to indicate a perceived conflict. They merely indicated the information as related to signing or speaking and listening. We must consider how the professional discourse potentially contributes to this idea of conflicting information. One parent said the audiologist and ENT just gave a diagnosis while the DTH and SLP gave the communication information. This alludes to the role of the professional. Should all professionals working with families of deaf and hard of hearing children be well versed in both the cultural and medical approaches? Or should that be the role of one guiding person, such as the DTH?

While the information received was shown to influence parental decision making, access to opportunities to see, use, and experience communication approaches also emerged as another influencing factor within this study. In the survey, one parent shared: 
It was difficult to find ASL classes or places to learn in my area. I would have had to travel an HR (hour) to get to the nearest school that offered the classes. I was given access to an online course that was slightly helpful.

Another survey comment lamented that they did not know about Cued Speech and wished they would have known about it as an approach sooner. Yet another comment from the survey described how meeting with other parents or families using various communication approaches would be nice. A mother in one of the interviews mentioned how her daughter was able to learn sign language because they were invited to a deaf and hard of hearing playgroup by their speech therapist. Two of the mothers interviewed talked about their experiences in meeting with and learning from deaf adults or deaf mentors All of these experiences connect with the theme of access to opportunities to experience and use the communication approaches is valued.

\section{Implications of a Reference Chart}

The final research question asked: How might future parents potentially benefit from the use of a reference chart or communication matrix when learning about, and ultimately selecting, communication approaches to use with their child? Responses to this question were connected to the underlying theme of this study: information about communication is valued. Several comments were made about the desire to have early and consistent information in a visual format that was easy to find and easy to read. Some parents mentioned that they preferred human connections over printed materials as a source of information yet were very supportive of the idea of a reference chart, which is contradictory. Perhaps this is due to the appeal of having a comprehensive source of information that also creates a standard reference point for each approach as well as detailing the various underlying factors of each. All of the various books, pamphlets, brochures, and handouts summarized on one piece of paper could potentially reduce 
the amount of self-research parents do. In addition, such a reference chart has the potential to increase the concept of informed choice which contributes to more confidence in the overall decision-making process and ties into the theme of information being valued.

\section{Implications of Current Practice}

Based on the identified themes from this study, the next step was a brief comparison of the current information sharing practices and nationally recommended guidelines. Based on the practices indicated in this study from the parent perspective, several of the recommended guidelines, described earlier in Table 3, and recommended by the Division for Early Childhood (DEC, 2014), Joint Council on Infant Hearing (JCIH, 2000, 2007, 2013), and Family Centered Early Intervention (Moeller et al. 2013) are not being followed. Some of these are outlined below in Table 26. Recommendations are derived from the discussion of the findings within the current study. While only a few examples of noncompliance are discussed, it is an indicator that Illinois providers need to refamiliarize themselves with the recommended best practice guidelines regarding information sharing, informed choice, and decision-making and consider how they are being followed. Again, perhaps a look at the professional discourse and perceived roles will help determine what is preventing these guidelines from being fully implemented. It is important to note that while these recommendations may seem grim, there are several areas of the recommendations that show strengths in Illinois. Throughout the survey and interviews, there was high praise and appreciation for both the early intervention professionals, including the DTH, and the Deaf Mentors, or involvement with deaf adults with a desire for more of these connections. 
Table 26

Findings Compared to Recommended Practice

\begin{tabular}{|c|c|c|}
\hline Area & Finding & Recommendation \\
\hline $\begin{array}{l}\text { Practitioners provide the } \\
\text { family with up-to-date, } \\
\text { comprehensive and unbiased } \\
\text { information in a way that the } \\
\text { family can understand and } \\
\text { use to make informed choices } \\
\text { and decisions. } \\
\text { (DEC, 2014) }\end{array}$ & $\begin{array}{l}\text { Inconsistent information } \\
\text { given, with some information } \\
\text { lacking and biased based on } \\
\text { the provider }\end{array}$ & $\begin{array}{l}\text { Standardization of terms } \\
\text { Consistent provider training } \\
\text { on information } \\
\text { Use of coaching and shared } \\
\text { decision-making models }\end{array}$ \\
\hline $\begin{array}{l}\text { Develop a mechanism that } \\
\text { ensures family access to all } \\
\text { available resources and } \\
\text { information that is accurate, } \\
\text { well-balanced, } \\
\text { comprehensive, and conveyed } \\
\text { in an unbiased manner. } \\
\text { (JCIH, 2013) }\end{array}$ & $\begin{array}{l}\text { No pattern of information } \\
\text { seeking or provision was } \\
\text { found in this study, only } 33 \% \\
\text { of respondents agreed that } \\
\text { had access to ALL the } \\
\text { information }\end{array}$ & $\begin{array}{l}\text { Standardization of } \\
\text { information delivery } \\
\text { Provider training in coaching } \\
\text { families }\end{array}$ \\
\hline $\begin{array}{l}\text { Share information and } \\
\text { experiences from a variety of } \\
\text { sources that are } \\
\text { comprehensive, meaningful, } \\
\text { relevant, and unbiased to } \\
\text { enable informed decision } \\
\text { making. FCEI (Moeller et al., } \\
\text { 2013) }\end{array}$ & $\begin{array}{l}\text { Main source of information is } \\
\text { early intervention } \\
\text { professionals. Connections } \\
\text { with other parents, deaf } \\
\text { adults, and providers skilled } \\
\text { in various communication } \\
\text { approaches mentioned as } \\
\text { valuable but lacking }\end{array}$ & $\begin{array}{l}\text { Increased access to } \\
\text { opportunities to experience, } \\
\text { connect with, and use } \\
\text { communication } \\
\text { Increased opportunities for } \\
\text { connections with other } \\
\text { parents and deaf adults }\end{array}$ \\
\hline
\end{tabular}

\section{Study Limitations and Recommendations for Future Research}

\section{Limitations}

Several limitations of this study would advise caution in interpretation of the findings.

These include the small sample size, global events, and data collection techniques

(survey/interviews). Each of these had potential effects on the resulting data and interpretation of this study. 
The small sample size of 21 survey respondents and four interviews must be taken into consideration. The four interviewees were pulled from the 21 survey respondents. The Illinois EHDI Coordinator at the Illinois Department of Public Health stated that during the years of 2016, 2017, and 2018, a total of 563 children birth to three were enrolled in early intervention (G. Mullin, personal communication, March 26, 2020). Therefore, 21 study participants cannot be considered a true representative sample of the whole available population.

In addition, active data collection started in early March, just prior to the expansion of COVID-19, a global health pandemic, into the state of Illinois that resulted in a full state lockdown that lasted approximately two and a half months. During this time, families were mandated to stay at home with only essential operations continuing. As a result, many entered survival mode. It is suspected that this impacted the availability of families to participate in this study. One potential interviewee backed out due to being overwhelmed by the existing COVID19 impacts in her life.

Also requiring consideration is the use of surveys and interviews to collect data. While anonymous surveys may increase greater disclosure of personal information (Murdoch et al., 2014), there is no way to gather follow-up and clarification on open-ended comments. This hinders the ability to use member checking of open-ended responses with the participants to verify accuracy of the resulting interpretations. In addition, the use of interviews over focus groups may have limited the scope of information gathered. Participants are less likely to disclose and discuss sensitive information in a private interview and the resulting conversation may be more limited with only two people rather than being potentially enriched by a group of people sharing similar experiences (Guest et al., 2017). 
Another limitation is the word choice and use of leading questions within the survey and interviews. The words chosen, such as pressure (survey and interview), benefits (interview), and barriers (survey) are skewed, leading the participants in either a positive or negative direction. The goal of phenomenology is to elicit a true experience, which is hindered by the use of skewed words and leading questions. Also, within the survey, participants were limited to only selecting one source when asked to select who they received their information from. It is probable that parents received information from more than one source, as indicated in the interviews. A related limitation is not including the specific interview questions as open-ended questions on the survey. Doing so would have provided more consistency across the two methods as well as possibly gaining further insight into the research questions being investigated in this study.

As a result of these limitations, the identified themes and answers to the research questions must be used with caution. However, they do lead to potential research ideas with expanded parameters. Currently, the data collection was limited to Illinois and those who had exited the early intervention system within the past two years. The same research design could be used to include families currently enrolled in early intervention and potentially reduce the effects of maturation. As well, the geographical limitation could be expanded to include families in other states, similar to the EI Snapshot study (NCHAM, 2017) that included respondents in 10 states. The use of individual interviews could be replaced with focus groups to allow for the potential of a higher rate of disclosure of sensitive information as well as a more natural flow of conversation versus a structured interview.

In addition, the data analysis inclusion criteria of the current study prevented a discussion and analysis of the process of transitioning into the school system as it did not relate to communication approaches. Several parents mentioned frustrations and barriers with their 
experiences. A qualitative study exploring this could yield useful information that professionals could use in supporting families during this critical transition period.

\section{Future Research}

A potential future research study would be to conduct this study with the professionals and early intervention providers mentioned throughout this study and often associated with deafness. Conducting this study from the perspective of the giver of information (rather than the receiver) could yield some interesting results that might guide the discussion on how to implement best practices for communication and information sharing within the field. Especially useful might be the examination of the provider perspective on the use of a reference chart or communication matrix.

A second area of future research related to this current study would be to study how professionals can support families in the decision-making process itself. It was apparent in this study that there were many factors influencing the process of decision-making and several comments mentioned feeling overwhelmed. During the literature review conducted for this study, it was uncovered that parents might also need support in how to make decisions (Ching et al., 2018; Young et al., 2005). When thinking of the concept of informed choice, it was realized that making decisions is a two-fold process that includes receiving the information and then processing and understanding the information to apply it to current situations. Future research could center around this question and the concept of shared decision making as currently used in the clinical setting.

\section{Conclusion}

While the key findings and underlying themes uncovered in this study were already in alignment with the existing literature, this study was able to provide evidence specific to Illinois, 
albeit with a small sample size. Concerning issues include the lack of consistency in the information provided to parents regarding communication approaches and related terminology, the divide in the professional discourse and how it impacts the roles of providers as well as the provision of information, meeting the parent desire for human connections in obtaining comprehensive information on communication approaches, and increasing the opportunities for accessible experiences with communication approaches. In addition, there was support for the concept of a reference chart or communication matrix as a way to provide systematic information in an easily accessible and comparable format. The early intervention professionals of Illinois should consider how this may support recommended practices of informed choice and decision making. An honest examination of these issues may provide a pathway for methods of consistent high-quality information and uniform opportunities to support parents throughout the process of receiving information about communication approaches for their deaf or hard of hearing child. 


\section{REFERENCES}

Adler, K., Salanterä, S., Leino-Kilpi, H., \& Grädel, B. (2015). An integrated literature review of the knowledge needs of parents with children with special health care needs and of instruments to assess these needs. Infants \& Young Children, 28, 46-71. https://doi.org/10.1097/iyc.0000000000000028

Alsem, M. W., Ausems, F., Verhoef, M., Jongmans, M. J., Meily-Visser, J. M. A., \& Ketelaar, M. (2017). Information seeking by parents of children with physical disabilities: An exploratory qualitative study. Research in Developmental Disabilities, 60, 125-134. https://doi.org/10.1016/j.ridd.2016.11.015

American Academy of Pediatrics (AAP). (2013). Statement of endorsement: Supplement to the JCIH 2007 position statement: Principles and guidelines for early intervention after confirmation that a child is deaf or hard of hearing. Pediatrics, 131, e1324-e1349. https://doi.org/10.1542/peds.2013-0008

Barringer, D., Glover, B., Parlin, M. A., \& Johnson, D. (1998). Providing accessible statewide inservice training for practicing professionals and paraprofessionals working with infants, toddlers, and preschoolers who are deaf or hard of hearing and their families. SKI-HI Distance Education Project, Final Report.

Borders, C., Jones-Bock, S., \& Probst, K. (2016). A Review of educational practices for deaf/hard of hearing students with comorbid autism. Deafness \& Education International 18(4), 189-205. https://doi.org/10.1080/14643154.2016.1255416 
Borum, V. (2012). Perceptions of communication choice and usage among African American hearing parents: Afrocentric cultural implications for African American deaf and hard of hearing children. American Annals of the Deaf, 157, 7-15. https://doi.org/10.1353/aad.2012.1606

Bradham, T. S., Houston, K. T., Guignard, G. H., \& Hoffman, J. (2011). Strategic analysis of family support in EHDI systems. Volta Review, 111, 181-194.

Bruin, M., \& Nevøy, A. (2014). Exploring the discourse on communication modality after cochlear implantation: A Foucauldian analysis of parents' narratives. Journal of Deaf Studies and Deaf Education, 19, 385-399. https://doi.org/10.1093/deafed/enu003

Campbell, J. L., Quincy, C., Osserman, J., \& Pedersen, O. K. (2013). Coding in-depth semistructured interviews: Problems of unitization and intercoder reliability and agreement. Sociological Methods \& Research, 42(3), 294-320. https://doi.org/10.1177/0049124113500475

Centers for Disease Control and Prevention (CDC) (n.d.). Facts about birth defects. Retrieved from https://www.cdc.gov/ncbddd/birthdefects/facts.html

Centers for Disease Control and Prevention. (2017a). 2017 summary of infants identified with permanent hearing loss enrolled in early intervention (EI) before 6 months of age. Retrieved from https://www.cdc.gov/ncbddd/hearingloss/2017-data/documents/10-2017HSFS-EI-by-6-moPDF.pdf

Centers for Disease Control and Prevention. (2017b). Summary of 2017 national CDC EHDI data. Retrieved from cdc.gov/ncbddd/hearingloss/2017-data/documents/01-2017-HSFSData-Summary.pdf 
Chaiken, S., \& Ledgerwood, A. (2012). A theory of heuristic and systematic information processing. In P. A. M. Van Lange, A. W. Kruglanski, \& E. T. Higgins (Eds.), Handbook of theories of social psychology (p. 246-266). Sage Publications Ltd. https://doi.org/10.4135/9781446249215.n13

Ching, T. Y., Scarinci, N., Marnane, V., Sjahalam-King, J., Button, L., \& Whitfield, J. (2018). Factors influencing parents' decisions about communication choices during early education of their child with hearing loss: A qualitative study. Deafness \& Education International, 1-28. https://doi.org/10.1080/14643154.2018.1512393

Constas, M. A. (1992). Qualitative analysis as a public event: The documentation of category development procedures. American Educational Research Journal, 29(2), 253-266. https://doi.org/10.2307/1163368

Crowe, K., Fordham, L., McLeod, S., \& Ching, T. Y. (2014). 'Part of Our World': Influences on caregiver decisions about communication choices for children with hearing loss. Deafness \& Education International, 16(2), 61-85. https://doi.org/10.1179/1557069x13y.0000000026

Crowe, K., McLeod, S., McKinnon, D. H., \& Ching, T. Y. (2014). Speech, sign, or multilingualism for children with hearing loss: Quantitative insights into caregivers' decision-making. Language, Speech, and Hearing Services in Schools, 45, 234-247. https://doi.org/10.1044/2014_lshss-12-0106

Cowan, C. P., \& Cowan, P. A. (2000). When partners become parents: The big life change for couples. New York, NY: Routledge. 
Davis, K., \& Gavidia-Payne, S. (2009). The impact of child, family, and professional support characteristics on the quality of life in families of young children with disabilities. Journal of Intellectual and Developmental Disability, 34, 153-162. https://doi.org/10.1080/13668250902874608

Decker, K. B., \& Vallotton, C. D. (2016). Early intervention for children with hearing loss: Information parents receive about supporting children's language. Journal of Early Intervention, 38, 151-169. https://doi.org/10.1177/1053815116653448

Decker, K. B., Vallotton, C. D., \& Johnson, H. A. (2012). Parents' communication decision for children with hearing loss: Sources of information and influence. American Annals of the Deaf, 157, 326-339. https://doi.org/10.1353/aad.2012.1631

DeCuir-Gunby, J. T., Marshall, P. L., \& McCulloch, A. W. (2011). Developing and using a codebook for the analysis of interview data: An example from a professional development research project. Field Methods, 23(2), 136-155. https://doi.org/10.1177/1525822X10388468

DesGeorges, J. (2018). Family support \& cultural competence. In The NCHAM e-book: A resource guide for early hearing detection and intervention (Chapter 13).

Dirks, E., Uilenburg, N., \& Rieffe, C. (2016). Parental stress among parents of toddlers with moderate hearing loss. Research in Developmental Disabilities, 55, 27-36. https://doi.org/10.1016/j.ridd.2016.03.008

Division for Early Childhood. (2014). DEC recommended practices in early intervention/early childhood special education 2014. Retrieved from http://www.decsped.org/recommendedpractices 
Douglas, T., Redley, B., \& Ottmann, G. (2017). The need to know: The information needs of parents of infants with an intellectual disability — a qualitative study. Journal of Advanced Nursing, 73, 2600-2608. https://doi.org/10.1111/jan.13321

Dowling, C., Marquez, D., Moers, L., Richmond, M. A., \& Swann, M. (2011). It's about listening to our families and the needs of their children: The family education and early childhood department at the Maryland School for the Deaf. Odyssey: New Directions in Deaf Education, 12, 14-19. Retrieved from http://files.eric.ed.gov/fulltext/EJ944999.pdf

Dunst, C. J. \& Espe-Sherwindt, M. (2016). Family-centered practices in early childhood intervention. In Reichow, B., Boyd, B., Barton, E. E., \& Odom, S. L. (Eds.), Handbook of early childhood special education (pp. 37-55). Switzerland: Springer. Retrieved from https://ebookcentral.proquest.com

Early Childhood Technical Assistance Center (ECTA). (n.d.) Family-Centered Practices Checklist. Retrieved from http://ectacenter.org/ pdfs/decrp/FAM-1_FamCtrd_Practices_2018.pdf

Early Childhood Technical Assistance (ECTA). (2018). Supporting family member informed decision-making. [Practice Guide]. Retrieved from http://ectacenter.org/ pdfs/decrp/PGP_FAM2_decisionmaking_2018.pdf

Early Childhood Technical Assistance Center (ECTA) \& Center for IDEA Early Childhood Data Systems. (2020). IDEA Part C Early Intervention Family Survey Data for FFY2017. Retrieved from http://ectacenter.org/eco/pages/familyoutcomeshighlights.asp Education of Handicapped Children Act Amendments of 1986, Pub. L. No. 99-457, 100 Stat. 1145 (1986). https://www.govinfo.gov/content/pkg/STATUTE-100/pdf/STATUTE-100Pg1145.pdf 
Education of the Handicapped Act Amendments of 1990, Pub. L. No. 101-476, 104 Stat. 1103 (1990). https://www.govinfo.gov/content/pkg/STATUTE-104/pdf/STATUTE-104Pg1103.pdf\#page $=49$

Edwards, A., \& Elwyn, G. (Eds.). (2009). Shared decision-making in health care: Achieving evidence-based patient choice. Oxford, United Kingdom: Oxford University Press.

Eleweke, C. J., \& Rodda, M. (2000). Factors contributing to parents' selection of a communication mode to use with their deaf children. American Annals of the Deaf, 375383. https://www.jstor.org/stable/44393224

Eleweke, C. J., Gilbert, S., Bays, D., \& Austin, E. (2008). Information about support services for families of young children with hearing loss: A review of some useful outcomes and challenges. Deafness \& Education International, 10, 190-212. https://doi.org/10.1179/146431508790559715

Elwyn, G., Frosch, D., Thomson, R., Joseph-Williams, N., Lloyd, A., Kinnersley, P., Cording, E., Tomson, D., Dodd, C., Rollnick, S., Edwards, A., \& Barry, M. (2012). Shared decision-making: A model for clinical practice. Journal of General Internal Medicine, 27(10), 1361-1367. https://doi.org/10.1007/s11606-012-2077-6

Epley, P., Summers, J. A., \& Turnbull, A. (2010). Characteristics and trends in family-centered conceptualizations. Journal of Family Social Work, 13, 269-285. https://doi.org/10.1080/10522150903514017

Fitzpatrick, E., Angus, D., Durieux-Smith, A., Graham, I. D., \& Coyle, D. (2008). Parents' needs following identification of childhood hearing loss. American Journal of Audiology, 17(1), 38-49. https://doi.org/10.1044/1059-0889(2008/005) 
Fraenkel, J. R., Wallen, N. E., \& Hyun, H. H. (2016). How to design and evaluate research in education ( $9^{\text {th }}$ ed). New York: McGraw-Hill.

Fowler, S. A. (2011). The Illinois Early Intervention Program: A Guide for Families. Champaign, IL: Illinois Early Intervention Clearinghouse. Retrieved from http://www.dhs.state.il.us/OneNetLibrary/27897/documents/Brochures/4279R0518.pdf

Guest, G., Namey, E., Taylor, J., Eley, N., \& McKenna, K. (2017). Comparing focus groups and individual interviews: Findings from a randomized study. International Journal of Social Research Methodology, 20(6), 693-708.

Grant, N., Rodger, S., \& Hoffmann, T. (2016). Intervention decision-making processes and information preferences of parents of children with autism spectrum disorders. Child: Care, Health and Development, 42(1), 125-134. https://doi.org/10.1111/cch.12296

Henderson, R. J., Johnson, A. M., \& Moodie, S. T. (2016). Revised conceptual framework of parent-to-parent support for parents of children who are deaf or hard of hearing: A modified delphi study. American Journal of Audiology, 25, 110-126. https://doi.org/10.1044/2016_AJA-15-0059

Herrera-Viedma, E., Chiclana, F., Herrera, F., \& Alonso, S. (2007). Group decision-making model with incomplete fuzzy preference relations based on additive consistency. IEEE transactions on systems, man, and cybernetics. Part B, Cybernetics: A publication of the IEEE Systems, Man, and Cybernetics Society, 37(1), 176-189. https://doi.org/10.1109/tsmcb.2006.875872 
Hiebert-Murphy, D., Trute, B., \& Wright, A. (2011). Parents' definition of effective child disability support services: Implications for implementing family-centered practice. Journal of Family Social Work, 14(2), 144-158.

https://doi.org/10.1080/10522158.2011.552404

Illinois Department of Human Services (IDHS), Bureau of Early Intervention. (2016). IL part C FFY2015 state performance plan/annual performance report. Retrieved from http://www.dhs.state.il.us/page.aspx?item=87645

Illinois Department of Human Services (IDHS) Division of Family and Community Services \& Bureau of Early Intervention. (2016). Illinois Early Intervention Provider Handbook. Retrieved from http://www.wiu.edu/coehs/provider_connections/bureau/providerHandbook.php

Illinois Early Childhood Asset Map (IECAM). (n.d.). IDHS Early Intervention Program. Retrieved from https://iecam.illinois.edu/data-definitions/idhs-ei/

Individuals with Disabilities Education Improvement Act of 2004, 20 U.S.C. $§ 1400$ et seq. (2004).

https://uscode.house.gov/view.xhtml?path=/prelim@ title20/chapter33/subchapter3\&editi on=prelim

Jackson, C. W. (2009). Family involvement in early intervention for children who are deaf or hard of hearing. Early Childhood Services, 3, 77-97.

Jackson, C. W. (2011). Family supports and resources for parents of children who are deaf or hard of hearing. American Annals of the Deaf, 156(4), 343-362. https://doi.org/10.1353/aad.2011.0038 
Jackson, C., Cheater, F. M., \& Reid, I. (2008). A systematic review of decision support needs of parents making child health decision. Health Expectations, 11, 232-25. https://doi.org/10.1111/j.1369-7625.2008.00496.x

Jackson, C. W., Traub, R. J., \& Turnbull, A. P. (2008). Parents' experiences with childhood deafness: Implications for family-centered services. Communication Disorders Quarterly, 29, 82-98. https://doi.org/10.1177/1525740108314865

Jackson, C. W., Wegner, J. R., \& Turnbull, A. P. (2010). Family quality of life following early identification of deafness. Language, Speech, and Hearing Services in Schools, 41(2), 194-205. https://doi.org/10.1044/0161-1461(2009/07-0093)

Johnson, J. L., Adkins, D., \& Chauvin, S. (2020). A review of the quality indicators of rigor in qualitative research. American Journal of Pharmaceutical Education, 84(1)

Joint Committee on Infant Hearing (n.d.). http://www.jcih.org/default.htm

Joint Committee on Infant Hearing. (2007). Year 2007 position statement: principles and guidelines for early hearing detection and intervention programs. Pediatrics, 120,898 921. https://doi.org/10.1542/peds.2007-2333

Joint Committee on Infant Hearing, American Academy of Pediatrics, \& American SpeechLanguage-Hearing Association. (2000). Year 2000 position statement: principles and guidelines for early hearing detection and intervention programs. Pediatrics, 106, 798817. Retrieved from http://jcih.org/jcih2000.pdf 
Joint Committee on Infant Hearing, American Academy of Pediatrics, \& American SpeechLanguage-Hearing Association. (2019). Year 2019 position statement: Principles and guidelines for early hearing detection and intervention programs. The Journal of Early Hearing Detection and Intervention, 4(2), 1-44. Retrieved from https://digitalcommons.usu.edu/cgi/viewcontent.cgi $?$ article $=1104 \&$ context $=$ jehdi

Keen, D. (2007). Parents, families, and partnerships: Issues and considerations. International Journal of Disability, Development, and Education, 54, 339-349. https://doi.org/10.1080/10349120701488855

Kingsley, K., \& Mailloux, Z. (2013). Evidence for the effectiveness of different service delivery models in early intervention services. American Journal of Occupational Therapy, 67(4), 431-436. https://doi.org/10.5014/ajot.2013.006171

Knoors, H. (2015). Foundations for language development in deaf children and the consequences for communication choices. In Marschark, M. \& Spencer, P. E. (Eds.), The oxford handbook of deaf studies in language (19-29). New York, New York: Oxford University Press.

Kraus, L. (2017). 2016 Disability Statistics Annual Report. Durham, NH: University of New Hampshire.

Kyzar, K. B., Turnbull, A. P., Summers, J. A., \& Gómez, V. A. (2012). The relationship of family support to family outcomes: A synthesis of key findings from research on severe disability. Research and Practice for Persons with Severe Disabilities, 37(1), 31-44. https://doi.org/10.2511/027494812800903247 
Li, Y., Bain, L., \& Steinberg, A. G. (2003). Parental decision-making and the choice of communication modality for the child who is deaf. Archives of Pediatrics \& Adolescent Medicine, 157, 162-168. https://doi.org/10.1001/archpedi.157.2.162

Marschark, M. (2001). Language development in children who are deaf: A research synthesis. Alexandria, VA: National Association of State Directors of Special Education. ERIC ED 455 - 620. https://eric.ed.gov/?id=ED455620

Marschark, M. (2018). Raising and educating a deaf child: A comprehensive guide to the choices, controversies, and decisions faced by parents and educators ( $3^{\text {rd }}$ ed.). New York, NY: Oxford University Press.

Marschark, M. \& Hauser, P. (2012). How deaf children learn: What parents and teachers need to know. New York, NY: Oxford University Press, Inc.

Marteau, T. M., Dormandy, E., \& Michie, S. (2001). A measure of informed choice. Health Expectations, 4, 99-108. https://doi.org/10.1046/j.1369-6513.2001.00140.x

Mascia, K., \& Mascia, J. (2019). The Bioethics of Providing Cochlear Implants to Children: Informed Choices and Autonomous Decision-Making. JADARA, 45(2). Retrieved from https://repository.wcsu.edu/jadara/vol45/iss2/5

Matthijs, L., Hardonk, S., Sermijn, J., Van Puyvelde, M., Leigh, G., Van Herreweghe, M., \& Loots, G. (2017). Mothers of deaf children in the 21st century. Dynamic positioning between the medical and cultural-linguistic discourses. Journal of Deaf Studies and Deaf Education, 22, 365-377. https://doi.org/10.1093/deafed/enx021

Maxwell, J. A. (2013). Qualitative research design: An interactive approach (Vol. 41). SAGE Publications Ltd. 
McNee, C. M., \& Jackson, C. W. (2012). The experiences and involvement of grandparents in hearing detection and intervention. Topics in Early Childhood Special Education, 32(2), 122-128. https://doi.org/10.1177/0271121412443136

Meadow-Owens, K. P., Mertens, D. M., \& Sass-Lehrer, M. A. (2003). Parents and their deaf children: The early years. Washington, D.C.: Gallaudet University Press.

Merriam, S. B. \& Tisdell, E. J. (2016). Qualitative research: A guide to design and implementation. San Francisco, CA: Jossey-Bass

Miles, M. B., Huberman, A. M., \& Saldaña, J. (2014). Qualitative data analysis: A methods sourcebook. Los Angeles: SAGE Publications Ltd.

Moeller, M. P., Carr, G., Seaver, L., Stredler-Brown, A., \& Holzinger, D. (2013). Best practices in family-centered early intervention for children who are deaf or hard of hearing: An international consensus statement. Journal of Deaf Studies and Deaf Education, 18, 429445. https://doi.org/10.1093/deafed/ent034

Murdoch, M., Simon, A. B., Polusny, M. A., Bangerter, A. K., Grill, J. P., Noorbaloochi, S., \& Partin, M. R. (2014). Impact of different privacy conditions and incentives on survey response rate, participant representativeness, and disclosure of sensitive information: a randomized controlled trial. BMC Medical Research Methodology, 14(1), 90.

Muse, C., Harrison, J., Yoshinaga-Itano, C., Grimes, A., Brookhouser, P. E., Epstein, S., Buchman, C., Mehl, A., Vohr, B., Moeller, M. P., Martin, P., Benedict, B. S., Scoggins, B., Crace, J., King, M., Sette, A., \& Martin, B. (2013). Supplement to the JCIH 2007 position statement: Principles and guidelines for early intervention after confirmation that a child is deaf or hard of hearing. Pediatrics, 131, e1324-e1349. 
Narr, R. F., \& Kemmery, M. (2014). The nature of parent support provided by parent mentors for families with deaf/hard-of-hearing children: Voices from the start. Journal of Deaf Studies and Deaf Education. 20, 67-74. https://doi.org/10.1093/deafed/enu029

National Center for Hearing Assessment and Management (NCHAM). (n.d.). Early Hearing Detection and Intervention Components. Retrieved from http://www.infanthearing.org/components/

National Center for Hearing Assessment and Management (NCHAM). (2017). EI snapshot early intervention for children who are deaf or hard of hearing: Systematic nationwide analysis of program strengths, hurdles, opportunities, and trends. Retrieved from https://www.infanthearing.org/ei-snapshot/docs/ei-snapshot-final-report.pdf

O’Connor, C., \& Joffe, H. (2020). Intercoder reliability in qualitative research: Debates and practical guidelines. International Journal of Qualitative Methods, 19, 1-13. https://doi.org/10.1177/1609406919899220

Payne, J. W. (1976). Task complexity and contingent processing in decision-making: An information search and protocol analysis. Organizational behavior and human performance, 16(2), 366-387. https://doi.org/10.1016/0030-5073(76)90022-2

Pittman, P., Sass-Lehrer, M., \& Abrams, S. (2016). Sign language, sign systems, and other visual modalities. In M. P. Moeller, D. J. Ertmer, \& C. Stoel-Gammon (Eds.), Promoting language \& literacy in children who are deaf or hard of hearing (pp. 149-179). Baltimore, MD: Paul H. Brookes Publishing Co.

Poon, B. T., \& Zaidman-Zait, A. (2014). Social support for parents of deaf children: Moving toward contextualized understanding. Journal of Deaf Studies and Deaf Education, 19, 176-188. https://doi.org/10.1093/deafed/ent041 
Porter, A., Creed, P., Hood, M., \& Ching, T. Y. (2018). Parental decision-making and deaf children: A systematic literature review. Journal of Deaf Studies and Deaf Education, 23, 295-306. https://doi.org/10.1093/deafed/eny019

Raver, S. A. \& Childress, D. C. (2015). Family-centered early intervention: Supporting infants and toddlers in natural environments. Baltimore, MD: Brookes Publishing.

Resch, J. A., Mireles, G., Benz, M. R., Grenwelge, C., Peterson, R., \& Zhang, D. (2010). Giving parents a voice: A qualitative study of the challenges experienced by parents of children with disabilities. Rehabilitation Psychology, 55(2), 139-150. https://doi.org/10.1037/a0019473

Rhoades, E. A. (2010). Toward family-centered practice. In E. A. Rhoades \& J. Duncan (Eds.), Auditory-verbal practice: Toward a family-centered approach (pp. 167-186). Springfield, IL: Charles C. Thomas Publisher LTD.

Roberts, K., Dowell, A., \& Nie, J. B. (2019). Attempting rigour and replicability in thematic analysis of qualitative research data; a case study of codebook development. BMC Medical Research Methodology, 19(1), 66-73. https://doi.org/10.1186/s12874-019-0707y

Roberts, M. Y., Kaiser, A. P., Wolfe, C. E., Bryant, J. D., \& Spidalieri, A. M. (2014). Effects of the teach-model-coach-review instructional approach on caregiver use of language support strategies and children's expressive language skills. Journal of Speech, Language, and Hearing Research, 57, 1851-1869. https://doi.org/10.1044/2014_JSLHR-L-13-0113

Roulston, K. (2013). Analyzing interviews. In Flick, U. (Ed.), The SAGE handbook of qualitative data analysis. SAGE Publications Ltd. 
Saldaña, J. (2013). The coding manual for qualitative researchers ( $2^{\text {nd }}$ ed.). SAGE Publications Ltd.

Sass-Lehrer, M., Porter, A., \& Wu, C. L. (2016) Families: Partnerships in practice. In M. SassLehrer (Ed.), Early intervention for deaf and hard of hearing infants, toddlers, and their families: Interdisciplinary perspectives. (pp. 65-103). New York, NY: Oxford University Press.

Sass-Lehrer, M. (2018). Early intervention for children birth to 3: Families, communities, \& communication. In The NCHAM e-book: A resource guide for early hearing detection and intervention (Chapter 16). Retrieved from http://www.infanthearing.org/ehdiebook/2018_ebook/16\%20Chapter16EarlyIntervention2018.pdf

Scarinci, N., Gehrke, M., Ching, T. Y., Marnane, V., \& Button, L. (2018). Factors influencing caregiver decision-making to change the communication method of their child with hearing loss. Deafness \& Education International, 20, 1-31. https://doi.org/10.1080/14643154.2018.1511239

Schertz, H. H., Baker, C., Hurwitz, S., \& Benner, L. (2011). Principles of early intervention reflected in toddler research in autism spectrum disorders. Topics in Early Childhood Special Education, 31, 4-21. https://doi.org/10.1177/0271121410382460

Scott, J. A., \& Dostal, H. M. (2019). Language development and deaf/hard of hearing children. Education Sciences, 9(2), 135. https://doi.org/10.3390/educsci9020135

Scott, J. A., \& Henner, J. (2020). Second verse, same as the first: On the use of signing systems in modern interventions for deaf and hard of hearing children in the USA. Deafness \& Education International, 1-19. https://doi.org/10.1080/14643154.2020.1792071

SKI-HI Institute (n.d.). http://ski-hi.strikingly.com/ 
Spencer, P. E., \& Marschark, M. (2010). Evidence-based practice in educating deaf and hard-ofhearing students. New York, NY: Oxford University Press.

Steinberg, A., Bain, L., Li, Y., Delgado, G., \& Ruperto, V. (2003). Decisions Hispanic families make after the identification of deafness. Journal of Deaf Studies and Deaf Education, 8, 291-314. https://doi.org/10.1093/deafed/eng016

Stredler-Brown, A. (2012). Early intervention: Serving infants and toddlers. In C. DeCondeJohnson \& J. Seaton (Eds.), Educational audiology handbook (pp. 445-466). Clifton Park, NY: Delmar, Cengage Learning.

Strong, C. J., \& Clark, T. C. (1990). Project SKI* HI Outreach Programming for Hearing Impaired Infants and Families: Recertification Statement, Questions, Responses, and Approval. Retrieved from https://files.eric.ed.gov/fulltext/ED335809.pdf

Subbiah, K., Mason, C. A., Gaffney, M., \& Grosse, S. D. (2018). Progress in documented early identification and intervention for deaf and hard of hearing infants-CDC's hearing screening and follow-up survey, United States, 2006-2016. Journal of Early Hearing Detection and Intervention, 3, 1-7. https://doi.org/10.26077/6sj1-mw42

Syed, M., \& Nelson, S. C. (2015). Guidelines for establishing reliability when coding narrative data. Emerging Adulthood, 3(6), 375-387. http://doi.org/10.1177/2167696815587648

Trohanis, P. L. (2008). Progress in providing services to young children with special needs and their families: An overview to and update on the implementation of the Individuals with Disabilities Education Act (IDEA). Journal of Early Intervention, 30, 140-151. https://doi.org/10.1177/1053815107312050 
U.S. Department of Education. (2020). 41st annual report to Congress on the implementation of the Individuals with Disabilities Act, 2019. Retrieved from https://sites.ed.gov/idea/files/41st-arc-for-idea.pdf

U.S. Department of Education, Special Education-Technical Assistance on State Data Collection- IDEA General Supervision Enhancement Grant (2016). IDEA Section 618 Data Products: Static Tables, Part C Child Count and Settings, Table 1. Washington, D. C.: U.S. Department of Education. Retrieved from https://www2.ed.gov/programs/osepidea/618-data/static-tables/index.html

Wikipedia. (n.d.) Northern Illinois. Retrieved from https://en.wikipedia.org/wiki/Northern_Illinois

Woods, J. J., Wilcox, M. J., Friedman, M., \& Murch, T. (2011). Collaborative consultation in natural environments: Strategies to enhance family-centered supports and services. Language, Speech, and Hearing Services in Schools, 42, 379-392. https://doi.org/10.1044/0161-1461(2011/10-0016)

Workgroup on Principles and Practices in Natural Environments, OSEP TA Community of Practice: Part C Settings. (2008). Seven key principles: Looks like / doesn't look like. Retrieved from hhttp://www.ectacenter.org/ pdfs/topics/families/Principles_LooksLike_DoesntLookLik e3_11_08.pdf

Yoshinaga-Itano, C. (2013). Principles and guidelines for early intervention after confirmation that a child is deaf or hard of hearing. Journal of Deaf Studies and Deaf Education, 19, 143-175. https://doi.org/10.1093/deafed/ent043 
Young, A., Jones, D., Starmer, C., \& Sutherland, H. (2005). Issues and dilemmas in the production of standard information for the parents of young deaf children - Parents' views. Deafness \& Education International, 7, 63-76. https://doi.org/10.1179/146431505790560400

Young, A., Carr, G., Hunt, R., McCracken, W., Skipp, A., \& Tattersall, H. (2006). Informed choice and deaf children: Underpinning concepts and enduring challenges. Journal of Deaf Studies and Deaf Education, 11(3), 322-336. https://doi.org/10.1093/deafed/enj041

Young, A., \& Tattersall, H. (2007). Universal newborn hearing screening and early identification of deafness: Parents' responses to knowing early and their expectations of child communication development. Journal of Deaf Studies and Deaf Education, 12, 209-220. http://doi.org/10.1093/deafed/en1033

Zaidman-Zait, A. (2007). Parenting a child with a cochlear implant: A critical incident study. Journal of Deaf Studies and Deaf Education, 12, 221-241. https://doi.org/10.1093/deafed/enl032 
APPENDIX A: REFERENCE CHART

\section{Language and communication}

American Sign Language (ASL)

$$
\text { (Visual) }
$$

\begin{tabular}{|c|c|}
\hline Definitions & $\begin{array}{l}\text { - ASL is a natural, visual/manual language } \\
\text { totally accessible to thildren who are deaf, } \\
\text { that has its own grammar and linguistic } \\
\text { principles. } \\
\text { - The acquisitition of English is addressed } \\
\text { through the use of teaching strategies for } \\
\text { English as a Second Language. }\end{array}$ \\
\hline Primary goals & 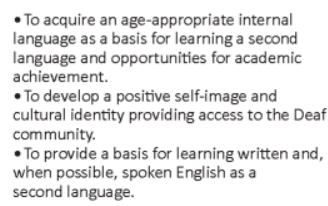 \\
\hline $\begin{array}{l}\text { Language } \\
\text { development } \\
\text { (receptive) }\end{array}$ & $\begin{array}{l}\text { The child develops early language } \\
\text { concepts as well as hiyher order } \\
\text { cogrintive skills by utilizing the visual nature } \\
\text { of ASL. }\end{array}$ \\
\hline $\begin{array}{l}\text { Expressive } \\
\text { language }\end{array}$ & $\begin{array}{l}\text {-ASL fluency and written English. } \\
\text { AAbility to to code switch from ASL to English } \\
\text { (signed, spoken or written as needed). }\end{array}$ \\
\hline $\begin{array}{l}\text { Hearing } \\
\text { (audition) }\end{array}$ & $\begin{array}{l}\text { - Encourages individual decision about } \\
\text { amplifiction. } \\
\text {-Amplification may provide access to } \\
\text { spoken language and allow the child more } \\
\text { opportunity to become bilingual. }\end{array}$ \\
\hline $\begin{array}{l}\text { Family } \\
\text { responsibilities } \\
\text { and guidance }\end{array}$ & 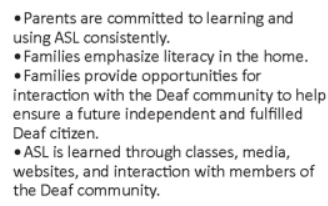 \\
\hline
\end{tabular}

(Auditory-verbal)

-An approach that emphasizes spoken
language develoment through listening.
- Child develops spoken langua ge through

-Child develops spoken language through

hearing with optimal amplification.
-Strives to make the most of a child's

ability to learn through listening:
therefore, the child does not rely on visuad
signals.

- To develop spoken language through
listening by following the stages and

sequence of typical development.
-To develop the skills necessary for

Juccessful mainstreaming in school and

Integration into the hearing community
To promote a positive selfismage thro

To promote a positive self-image through
natural family and social interactions using
spoken language.

-The child develops understanding of spoken

Inguage through early and consistent

through listening in a developmentally

-Oppoprimal listening opportunities require the use of appropriate hearing

Spoken and written English

\section{- Early, consistent and appropriate use of}

hearing technology (hearing aidids),

cochlear implant(s), bone-conduction
implants), hearing assistive technology
system) is is important with his aporogach.

- Requires ongoing auditory management

- Parents are expected to participate as
partners in sessions with therapist(s) to strategies and techniques that promote the

auditory learning of goals.

-Families need to carry verer the goals
established in therapy into the child's dally

routines and play activities.

"listening" learning environment.

- Parents must provide a language-rich
environment, to make learning through

environment, to make learning through
listening a meaningful part of allexperiencs
Listening and spoken language

(Auditory oral)

Cued speech

-An approach that teaches a child to use his/

her remaining hearing through

mplification and the use of

toaid the child's

- An auditory-visual communication

-Uses an English-based sign language

reading, fingerspelling, natural gestures and

A Anand shape (consonant groups) at a
location (vowel groups) cues a

syllable. This integration provides clear

access to all the phonemes (sounds)

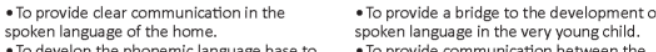

- To develop the phonemic language base to - To provide communication between the
achieve full literacy in conversation,

reading and writing.
JT Tosing sign language.

- To support speechreading, speech and
auditory skill development.
hearing ard thtegration into both the Deaf communitites.

communication skills

success and integration into the hearing

The child develops internal language through

early, consistent listening

appropriatet therapy, which includes speech-
reading and the use of hearing technology.

- The child absorbs language through early,
consistent, clear communication using Cued Speech s, lear reommancenton using Cued

- Cueing boosts auditory

The child develops language through

acombination of speech and signesuresed

systems in English order.

Spoken and written English

Cued, spoken and written Enolish or other

Spoken English using sign language in English
word order, and written English

Garly consistentand ano

-Early, consistent and appropriate use
hearing technology (hearing aid(s),

cochlear implant(s), bone-conduction
implant(s), hearing assistive technology
system) is isportant with this approgt

system) is important with this approach.

-Families are expected to provide

appropriate carry-over of goals, strategies
and techniques from the child's slassroom

setting and/or individual therapy sessions

into daily routines and play activities.'s

teacher(s) and/or therapist(s) to learn

strategies and techniques for developing
listening speechreading and speaking skills in
an oral learning environment.

- Consistent and appropriate use of

- Early, consistent and appropriate use of hearing technology (hearing aid(ts),

mplant(s), hearing assistive technology

Istem) is important with this approach

implant(s), hearing assistive technolog

system) is strongly encouraged.

- Parents are expected to learn to
speak-and-cue at all times in order for

critical to language and reading

- Familiess
need to provide consistent use of

cues and speech during daily routines and

play activities

-The system is taught in less than 20 hours
Consistent daily use and practice leads to

nt daily use and practice le
- Families are expected to learn and

English-based sign language system.

- Parents need to work with the child's

leacher(s) and/or therapist(s) to lea
strategies that promote language

expansion 


\section{APPENDIX B: COPYRIGHT PERMISSION}

\section{BRQKES \\ PUBLISHING C?}

Paul H. Brookes Publishing Co., Inc.

Post Office Box 10624, Baltimore, Maryland 21285-0624

PERMISSION TO REUSE BROOKES PUBLISIIING CO, MATERIAL

Karla Giese

Illinois State University
October 4, 2019

Invoice \#: PB19073

Reference this invoice number in all correspondence

RE; Request for permission to reprint Table 6.1 "Communication approaches" (pp. 151-152) from Promoting Language \& Literacy in Children Who Are Deaf or Hard of Hearing (2016), Moeller, Eittmer, \& Stoel-Gammon ("Work").

Paul H. Brookes Publishing Co., Inc. ("Brookes") is pleased to grant the request, contingent upon the following terms and conditions:

The abovementioned Brookes material ("Material") will appear in the dissertation tentatively tilled, Factors that Influence Parents' Communication Decisions for their Deaf or Hard of Hearing Child in Illinois, authored by Giese ("Dissertation"). It is understood that use of the Material shall be limited to the following:

- In the electronic format of the Dissertation, made available to Illinois State University's review board through the passwordprotected ProQuest ETD system.

- In one printed paper format personal copy for Giese.

A credit line acknowledging the Brookes publication must appear with or near the Material in the Dissertation. The credit line shall include the name(s) of the author(s)/editor(s) (for edited works), the copyright year, the title of the publication, our location: Baltimore, our full name: Paul H. Brookes Publishing Co., Inc., and the phrase: Reprinted by permission.

The permission fee for this use is waived.

Permission

- Is granted on a one-time only basis, and is non-exclusive and non-transferable.

- Is limited to the specific cdition of the Dissertation named herein.

- Is only for the abovementioned print version only of the Dissertation.

- Does not permit Giese/Illinois State University to sublicense use of the Material.

- Allows Giese/llinois State University to provide, without charge, copies of the Material, as needed, to comply with Illinois State University's accessibility policies for per'sons with disabilitics.

The Material may not be posted on the Internct under any circumstances, unless authorized in writing by Brookes.

For other and/or additional uses, copies, studies, presentations, events, courses, trainings, editions, ancillaries, versions, derivatives, mediums, languages, or formats, a separate permission request must be submitted, and a fec may be assessed. To extend permission or to use the Material again, submit a completed permission request form (http://vww.brookespublishing.com/customerservice/permissions/), along with a copy of this permission, at least 8 wceks prior to the new use.

All rights not explicitly expressed herein are retained by, Brookes.

For questions, or should you decide not to use part or all of the Material, contact rights@brookespublishing.com.

Mopr Dor $0 / 6 / 0$

Melissa A. Behm, Executive Vice President

410-337-9580 FAX 410-337-8539 www.brookespublishing.com rights@brookespublishing.com 


\section{APPENDIX C: SURVEY}

\section{PRE-SURVEY QUESTIONS}

If you can answer YES to all of these questions, you qualify to participate in the survey.

1. Are you the parent or primary caregiver of a child aged 3, 4, or 5 with an identified hearing loss?

2. Did you receive early intervention services in ILLINOIS for at least one year?

3. Have you exited the early intervention system within the past 2 years (24 months)?

\section{SURVEY QUESTIONS}

1. When was your child born? (month, year)

2. When was your child first identified as deaf or hard of hearing? (month, year)

3. What is their current, unaided hearing level? (indicate which ear $\mathrm{R} / \mathrm{L}$ )
a. none
b. mild
c. moderate
d. $\bmod /$ severe
e. severe
f. profound
g. unknown

4. What hearing technology is your child using? (indicate which ear R/L)
a. None
b. Hearing Aids
c. Cochlear Implant
d. Bone Conduction Aids 
e. Other

5. Does your child have any of the following? (rate as none, mild, moderate, severe, unknown)
a. Speech/language delay
b. motor delays
c. social/emotional delays
d. autism diagnosis
e. cognitive delays
f. vision issues
g. other

6. Rate the information you received about each communication approach when your child was FIRST identified: (rate as Excellent, Good, Poor, None)
a. Bilingual-bimodal (ASL \& English)
b. Simultaneous communication (Sim-Com)
c. Sign-supported speech
d. Pidgeon Signed English
e. Cued Speech
f. Auditory-oral
g. Listening and spoken language (Auditory-Verbal)

7. Who gave you information about each communication approach?
a. Early intervention provider
b. Speech therapist
c. Pediatrician 

d. Audiologist
e. Ear/nose/throat doctor
f. Early intervention service coordinator
g. Teacher of the Deaf
h. Deaf or hard of hearing adult
i. Other parent of deaf or hard of hearing child
j. Other family member
k. Myself

8. How much do you agree with the following statements about making decisions regarding communication with your child: (rate as strongly agree, agree, somewhat agree, neither agree or disagree, somewhat disagree, disagree, strongly disagree, don't know/doesn't apply)

a. I felt pressured to choose ONE communication approach over others.

b. I felt I needed to choose a communication approach to use at home quickly.

c. I felt I had adequate information about ALL of the communication approaches I could use with my child.

d. I felt overwhelmed by the information I obtained regarding communication approaches.

e. I felt the process of selecting communication approaches was smooth.

9. Please share any additional comments regarding your experience in obtaining information on communication approaches. 
10. Please indicate the information you received before your child was 3 years old: (rate as didn't need/want, needed and received easily, needed and had difficulty receiving, needed and never received)
a. Using American Sign Language
b. Using signs with spoken language
c. Developing spoken language
d. Developing listening skills
e. Cued speech
f. Supporting communication
g. Language development

11. Please share any comments regarding barriers you experienced in receiving information about the topics in question \#10.

12. Please share any comments regarding supports you experienced in receiving information about the topics in question \#10.

13. Knowing what you know now, what would you have done differently in obtaining information and making decisions related to communication approaches?

14. Is there anything you would have found helpful in obtaining information and making decisions related to communication approaches?

15. What is the most important advice you would give a parent whose child has been recently identified as deaf or hard of hearing related to communication information and approaches?

16. What is your relationship to the child who is deaf or hard of hearing?

a. Mother 

b. Father
c. Stepmother
d. Stepfather
e. Grandmother
f. Grandfather
g. Foster parent or guardian
h. Other relative

17. What is your highest education level?
a. less than high school (no diploma)
b. High school graduate or GED
c. Completed vocational/trade program
d. Some college
e. 2 year degree
f. 4 year degree
g. Professional degree
h. Doctorate

18. In the last year, what was your total household income before taxes?
a. Less than $\$ 25,000$
b. $\$ 25,000-\$ 34,999$
c. $\$ 35,000-\$ 49,999$
d. $\$ 50,000-\$ 74,999$
e. $\$ 75,000-\$ 99,999$
f. $\$ 100,000-\$ 149,999$ 
g. More than $\$ 150,000$

h. Prefer not to answer

19. What ethnicity/race is your deaf or hard of hearing child? Check all that apply.
a. White
b. Black or African American
c. American Indian or Alaska Native
d. Asian
e. Native Hawaiian or Pacific Islander
f. Hispanic, Latino, or Spanish origin
g. Other
h. Prefer not to answer

20. What is the gender of your deaf or hard of hearing child?
a. Male
b. Female
c. Not gender specific

21. Are any of your child's parents deaf or hard of hearing?
a. No
b. Yes, one parent
c. Yes, both parents

22. Are any of your child's siblings deaf or hard of hearing?
a. No
b. Yes, some siblings
c. Yes, all siblings 
23. What is the zip code where your deaf or hard of hearing child resided while receiving early intervention services in Illinois?

Thank you for your time in taking this survey! As a reminder, this survey is anonymous, and no names are shared. Your answers will be used to help us better understand your experience as a parent of a child who is deaf or hard of hearing. If you have questions about the survey or the study, please reach out to the researcher, Karla Giese at kgiese@ilstu.edu. Thank you and have a wonderful day! 


\section{APPENDIX D: INTERVIEW QUESTIONS}

1. What information did you receive regarding communication approaches to use with your deaf/hard of hearing child?

2. Who gave you this information or where did you get this information from?

3. How did this information factor into your decision-making process in selecting communication approaches to use with your child?

4. What kind of pressures did you feel as you went through the decision-making process?

5. Looking at this reference chart or communication matrix and based on your experience, how might future parents potentially benefit from using this when learning about, and ultimately selecting, communication approaches to use with their child? 


\section{APPENDIX E: INTERVIEW CONSENT}

You are being asked to participate in a research study conducted by Karla Giese, doctoral candidate, under the supervision of Dr. Stephanie Gardiner-Walsh and Dr. Christy Borders of the Special Education Department at Illinois State University.

The purpose of this study is to understand the perspectives and experiences of Illinois parents of deaf and hard of hearing children as they make communication decisions for their child. The goal is to look at the information gathering and decision-making process from the parent perspective to determine what factors influence decision-making and how future parents might potentially benefit from use of a reference chart or communication matrix during this process.

$\underline{\text { Why are you being asked? }}$

You have been asked to participate because you:

- are the parent of a child age 3-5 years old who is identified as deaf or hard of hearing,

- received early intervention supports and services in Illinois for at least one year, and

- $\quad$ have exited the early intervention system within the past two years.

Your participation in this study is voluntary. You will not be penalized if you choose to skip parts of the study, not participate, or withdraw from the study at any time.

What would you do?

If you choose to participate in this study, you will be invited to participate in a one-on-one interview with the researcher to discuss your perspectives and experiences in gathering information and making decisions related to communication approaches with your child. This interview will last approximately 60-90 minutes and will be audio and/or video recorded. If you choose to participate but prefer NOT be video recorded, you will be asked to sit off camera but your voice will still be recorded. 


\section{Are any risks expected?}

Due to the nature of the topic of communication approaches and decision-making, some participants may feel stress and/or have an emotional response. In addition, if you choose to participate in the interview, it will be audio and/or video recorded and your identity will be made known to the researcher and members of the research team. To manage these risks, you will be allowed to stop the interview at any time or choose not to answer or respond to a prompt. The researcher will maintain confidentiality before, during, and after the interview and your information will be protected as outlined below.

Will your information be protected?

We will use all reasonable efforts to keep any provided personal information confidential. Within the interview, full facial features will be recorded and you will be allowed to speak freely, sharing your name and other identifying information. All identifying information will be removed and fake names will be used for transcription and reporting purposes. Researchers will transcribe the interview for analysis. Coded and un-coded paper copy records will remain locked in a filing cabinet. Electronic copies and recordings will be password protected and remain on a closed network. All information obtained in this study is strictly confidential unless disclosure is required by law. Data will be destroyed three years after the completion of this study. Information that may identify you or potentially lead to reidentification will not be released to individuals that are not on the research team. The findings from this study may be presented in professional publications or presentations but no identifying information will be used.

However, when required by law or university policy, identifying information (including your signed consent form) may be seen or copied by authorized individuals.

Could your responses be used for other research? 
We will not use any identifiable information from you in future research, but your deidentified information could be used for future research without additional consent from you. Who will benefit from this study?

While you may not directly benefit from this study, your responses will help inform best research practices and develop guidelines for supporting parents of deaf and hard of hearing children as they seek information and make decisions regarding communication approach(es) for their child. Whom do you contact if you have any questions?

If you have any questions about the research or wish to withdraw from the study, contact Karla Giese at (847) 704-0006 via text or kgiese@ilstu.edu. You may also contact Dr. Stephanie Gardiner-Walsh at (309) 438-2837 or sjgardi @ilstu.edu.

If you have any questions about your rights as a participant, or if you feel you have been placed at risk, contact the Illinois State University Research Ethics \& Compliance Office at (309) 4385527 or IRB@ilstu.edu.

\section{Documentation of Consent}

If you are 18 or older and willing to participate in this study, please reply YES to this email. You can print this email for your records. 


\section{APPENDIX F: SURVEY CONSENT}

You are being asked to participate in a research study conducted by Karla Giese, doctoral candidate, under the supervision of Dr. Stephanie Gardiner-Walsh and Dr. Christy Borders of the Special Education Department at Illinois State University.

The purpose of this study is to understand the perspectives and experiences of Illinois parents of deaf and hard of hearing children as they make communication decisions for their child. The goal is to look at the information gathering and decision-making process from the parent perspective to determine what factors influence decision-making and how future parents might potentially benefit from use of a reference chart or communication matrix during this process.

Why are you being asked?

You have been asked to participate because you:

- are the parent of a child age 3-5 years old who is identified as deaf or hard of hearing,

- received early intervention supports and services in Illinois for at least one year, and

- have exited the early intervention system within the past two years.

Your participation in this study is voluntary. You will not be penalized if you choose to skip parts of the study, not participate, or withdraw from the study at any time.

What would you do?

If you choose to participate in this study, you will be asked to complete an anonymous online survey. This survey includes information about your child's age, identification, hearing level, technology and communication usage, and other descriptive information. The survey also asks you to answer questions related to what information you received about communicating with your child, who/where you received this information from, and how this information factored 
into your decision-making process in selecting communication approach(es) for your child. In total, your involvement in this study will last approximately 30-45 minutes at most.

Are any risks expected?

We do not anticipate any risks beyond those that would occur in everyday life.

Will your information be protected?

Your responses will be anonymous; nothing that will identify you will be linked to your responses. The findings from this study may be presented in conferences, meetings, and publications. When these findings are presented, your responses will be combined with the responses of other participants.

Who will benefit from this study?

While you may not directly benefit from this study, your responses will help inform best research practices and develop guidelines for supporting parents of deaf and hard of hearing children as they seek information and make decisions regarding communication approach(es) for their child. Whom do you contact if you have any questions?

If you have any questions about the research or wish to withdraw from the study, contact Karla Giese at (847) 704-0006 via text or kgiese@ilstu.edu. You may also contact Dr. Stephanie Gardiner-Walsh at (309) 438-2837 or sjgardi@ilstu.edu.

If you have any questions about your rights as a participant, or if you feel you have been placed at risk, contact the Illinois State University Research Ethics \& Compliance Office at (309) 4385527 or IRB@ilstu.edu.

\section{Documentation of Consent}

Check the box below if you are 18 years or older and willing to participate. If you do not want to participate, check no and you will exit the survey. 

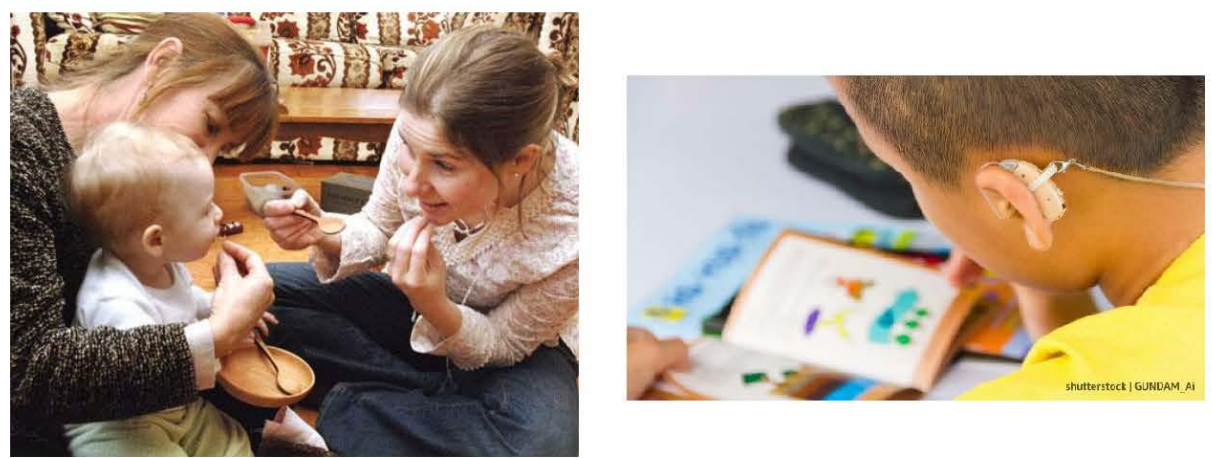

Invitation to participate in a research study for parents of 3,4 , and

\section{5-year-old children who are deaf and hard of hearing.}

We are interested in learning more about your perspective and experience in the information gathering and decision-making process in learning about the communication approaches used with deaf and hard of hearing children.

Who are we looking for? Parents or guardians who have a child that meets all of the following criteria:

- 3,4 , or 5 years old,

- identified as deaf or hard of hearing,

- received early intervention supports and services in Illinois for at least one year, and

- has exited the early intervention system within the past two years.

What does the study involve? You will be asked to complete an anonymous online survey to provide information about you and your child. The survey will take approximately $30-45$ minutes to complete. Upon completion of the survey, you will be given the option to participate in an individual interview with the researcher.

How do I start the survey or learn more? You can access the survey at https://illinoisstate.az1.qualtrics.com/jfe/form/SV 8AknZcQMFcaAdut

To learn more, email questions to Karla Giese at kgiese $(a$ ilstu.edu or Dr. Stephanie Gardiner-Walsh at sigardi@ilstu.edu.

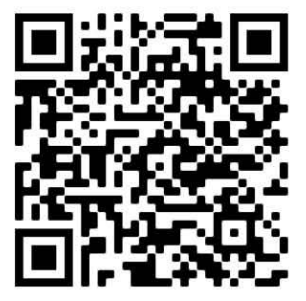




\title{
APPENDIX H: PERMISSION LETTERS
}

Mail - Giese, Karla - Outlook

\section{Re: Permission to recruit}

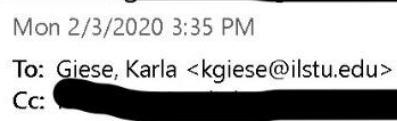

We can add you to our newsletters that go out to our constant contact listswr, you can post in our office and we can "share" any posts.

K

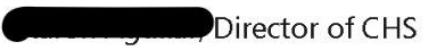

VP of Communication Access, Anixter Center

www.ChicagoHearingSociety.org

V: 773.248 .9121 ext. 307

VP: 773.904 .0100

On Feb 3, 2020, at 3:02 PM, Giese, Karla <kgiese@ilstu.edu> wrote:

\begin{abstract}
$\mathrm{HiC}$
I'm writing this email to ask for permission to use CHS/CHOICES for Parents listserv/social media platforms to recruit participants for my upcoming dissertation study. The study will focus on parents of deaf/hard of hearing children who are aged 3-5 years old and have received early intervention services in Illinois. This study will involve a confidential survey and an option to voluntarily participate in individual interviews. The purpose is to learn more about the parents' information gathering and decision-making process related to selecting and using communication approaches with their child.
\end{abstract}

At this point, I am only obtaining permission from you. When I have received final approval from the Institutional Review Board (IRB) at Illinois State University to conduct the study, then I will reach out again with the survey information to share.

Please respond to this email and let me know if CHS/CHOICES for Parents would be willing to work with me to recruit participants for my study.

Thank you!

Karla

Karla Giese

Doctoral Candidate in Special Education

NLCSD Scholar 


\section{Re: Permission to recruit}

Illinois Hands

Tue 2/4/2020 8:49 AM

To: Giese, Karla <kgiese@ilstu.edu>

[This message came from an external source. If suspicious, report to abuse@ilstu.edu]

Yes, just send everything through me and we will push it out through all channels.

Thanks,

On Mon, Feb 3, 2020 at 2:59 PM Giese, Karla < kgiese@ilstu.edu > wrote:

$\mathrm{Hi}$

I'm writing this email to ask for permission to use IL Hands \& Voices Guide By Your Side listserv/social media platforms to recruit participants for my upcoming dissertation study. The study will focus on parents of deaf/hard of hearing children who are aged 3-5 years old and have received early intervention services in Illinois. This study will involve a confidential survey and an option to voluntarily participate in individual interviews. The purpose is to learn more about the parents' information gathering and decision-making process related to selecting and using communication approaches with their child.

At this point, I am only obtaining permission from you. When I have received final approval from the Institutional Review Board (IRB) at Illinois State University to conduct the study, then I will reach out again with the survey information to share.

Please respond to this email and let me know if Illinois Hands \& Voices Guide By Your Side would be willing to work with me to recruit participants for my study.

Thank you!

Karla

Karla Giese

Doctoral Candidate in Special Education

NLCSD Scholar

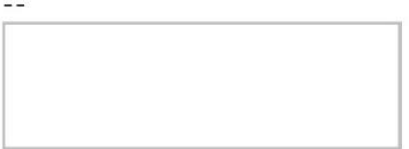

"What works for your child is what makes the choice right."

ilhandsandvoices.org

Follow us: facebook.com/illinoishandsandvoices 


\section{RE: Permission to recruit}

Wed 2/5/2020 10:32 AM

To: Giese, Karla <kgiese@ilstu.edu>

[This message came from an external source. If suspicious, report to abuse@ilstu.edu]

Karla,

ISD Outreach would be honored to work with you! Let me know what we can do.

From: Giese, Karla <kgiese@ilstu.edu>

Sent: Monday, February 03, 2020 3:05 PM

To:

Subject: [External] Permission to recruit

$\mathrm{Hi}$

I'm writing this email to ask for permission to use Illinois School for the Deaf Outreach Program listserv/social media platforms to recruit participants for my upcoming dissertation study. The study will focus on parents of deaf/hard of hearing children who are aged 3-5 years old and have received early intervention services in Illinois. This study will involve a confidential survey and an option to voluntarily participate in individual interviews. The purpose is to learn more about the parents' information gathering and decision-making process related to selecting and using communication approaches with their child.

At this point, I am only obtaining permission from you. When I have received final approval from the Institutional Review Board (IRB) at Illinois State University to conduct the study, then I will reach out again with the survey information to share.

Please respond to this email and let me know if Illinois School for the Deaf Outreach Program would be willing to work with me to recruit participants for my study.

Thank you!

Karla

\section{Karla Giese}

Doctoral Candidate in Special Education

NLCSD Scholar

State of Illinois - CONFIDENTIALITY NOTICE: The information contained in this communication is confidential, may be attorney-client privileged or attorney work product, may constitute inside information or internal deliberative staff communication, and is intended only for the use of the addressee. Unauthorized use, disclosure or copying of this 


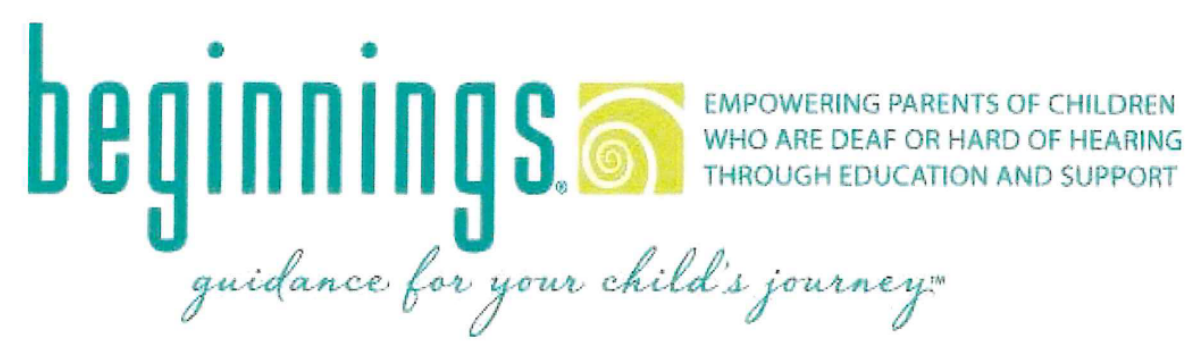

\author{
LICENSE AGREEMENT
}

\title{
PREAMBLE
}

BEGINNINGS for Parents of Children Who Are Deaf or Hard of Hearing, Inc., a North Carolina nonprofit corporation ("BEGINNINGS"), assists parents of children who are deaf or hard of hearing, deaf parents with hearing children, and professionals serving both by providing information and support to empower them as informed decision makers, helping them access services and promoting early identification of hearing loss and awareness of early intervention programs ("Mission"). Pursuant to its Mission, BEGINNINGS creates books, manuals, brochures, ephemera and other publications, which it distributes in print and digital media. BEGINNINGS encourages third-party research in fields related to its Mission. In furtherance thereof BEGINNINGS frequently grants licenses to researchers for reproduction and limited distribution of its publications. All licensed uses require BEGINNINGS' prior written consent. Thank you for your interest in acquiring such a license.

This license agreement (this "Agreement"), effective as of 9/4/19 (the "Effective Date"), is by and between BEGINNINGS and Karla Giese ("Licensee"), the individual described below.

\section{$\underline{\text { RECITALS }}$}

WHEREAS, BEGINNINGS is the creator and owner of copyright in the work identified below (the "Licensed Work");

WHEREAS, Licensee, a doctoral candidate at Illinois State University, is engaged in research in the field of Special Education and in connection therewith desires to obtain a license to reproduce the Licensed Work BEGINNINGS "Language And Communications" chart in whole as a constituent element of her written dissertation and to use hard copies of the BEGINNINGS "Language And Communications" chart as part of her focus group discussions subject to the terms and conditions of this Agreement; and

WHEREAS, BEGINNINGS desires to grant such a license to Licensee;

NOW, THEREFORE, in consideration of the foregoing recitals, incorporated herein by reference, the mutual covenants and agreements set forth herein, and other good and valuable consideration, the sufficiency of which is hereby acknowledged by each of the parties, the parties hereto agree as follows:

\section{General Terms and Conditions of Licenses Granted by BEGINNINGS}

- BEGINNINGS grants licenses on a nonexclusive, nontransferable, nonsublicensable, royalty-free, revocable basis unless otherwise agreed in advance by the parties in writing. In other words, such licenses are personal to the licensee, who is not permitted to grant rights in turn to any other party.

- Licensee is not permitted to revise, reformat, abridge, or otherwise alter the Licensed Work in any manner without Beginning's prior written consent. 
- Licensee is not permitted to distribute the Licensed Work other than as a constituent part of the Licensee's publication or doctoral dissertation, as the case may be (collectively, "Licensee's Publication").

- Every reproduction of the Licensed Work by Licensee must be accompanied by a notice of copyright that reads "Copyright 2016 BEGINNINGS for Parents of Children Who Are Deaf or Hard of Hearing, Inc." Such notice shall be printed in proximity to the Licensed Work as it appears in the Licensee's Publication.

- This Agreement is not assignable by Licensee. Third-party publication of the Licensee's Publication (e.g., in a scholarly journal or anthology) requires a separate license, which BEGINNINGS may grant or refuse to grant in its sole discretion.

- Online display of the Licensed Work online is strictly prohibited without BEGINNINGS' prior written consent.

- Licensee is responsible for all costs associated with its reproduction and distribution of the Licensed Work.

- BEGINNINGS reserves a right of prior written consent with respect to any translation of the Licensed Work into one or more foreign languages and requires a written assignment of copyright in any such translation to BEGINNINGS.

- If requested by BEGINNINGS, Licensee shall provide BEGINNINGS with one (1) complimentary copy of the Licensee's Publication no later than thirty (30) days following its first distribution.

- This Agreement may be terminated without cause at any time by mutual written consent of the parties. BEGINNINGS may terminate this Agreement if, after notice and thirty (30) days' opportunity to cure, Licensee fails to timely and fully perform her material obligations or breaches her representations, warranties or covenants hereunder. If this Agreement is terminated for any reason, all rights granted to Licensee hereunder shall be terminated.

\section{Nature of Licensee's Proposed Use}

Please tell us about your intended use of the Licensed Work.

Licensed Work: _ BEGINNINGS "Language and Communications" chart BEGINNINGS' publication date: 2016

Licensee: Karla Giese

Licensee's Organization, if any: $\underline{\text { A doctoral candidate at Illinois State University engaged in research in }}$ the field of Special Education

Contact: Email:_kgiese@ilstu.edu

Phone:

Title or description of Licensee's Publication: Communication Decisions by Parents of Deaf Children in

Illinois: Sources of Information and Influence

Nature of Licensee's Publication: Doctoral Dissertation

Portion of the Licensed Work to be reproduced by Licensee: BEGINNINGS "Language and

Communications" chart in whole

Expected publication date of the Licensee's Publication: $2019-2020$

Language(s): English

\section{Miscellaneous Provisions}

a. DISCLAIMER OF WARRANTIES. BEGINNINGS MAKES NO WARRANTIES, EXPRESS OR IMPLIED, AND HEREBY EXPRESSLY DISCLAIMS ALL IMPLIED WARRANTIES, INCLUDING, WITHOUT LIMITATION, THE IMPLIED WARRANTIES OF TITLE, NONINFRINGEMENT, MERCHANTABILITY AND FITNESS FOR A PARTICULAR PURPOSE. BEGINNINGS SHALL NOT BE 
REQUIRED TO INDEMNIFY LICENSEE WITH RESPECT TO ANY CLAIM OR CLAIMS, AS THE CASE MAY BE.

b. Entire Agreement; Amendment. This Agreement constitutes the entire Agreement between the parties and supersedes and cancels any and all prior agreements, written or oral, between them relating to the subject matter hereof and may not be amended except in a writing signed by both parties.

c. Assignment. Licensee may not assign this Agreement without the prior written consent of BEGINNINGS.

d. Binding Effect. This Agreement shall be binding upon and shall inure to the benefit of the parties hereto and their respective successors and permitted assigns.

e. Notices. Unless otherwise specified herein, all notices, demands and other communications that may be or are required to be given hereunder or with respect hereto shall be in writing and shall be given either by personal delivery, by overnight delivery service, or by e-mail, and shall be deemed to have been given or made when personally delivered, two (2) business days following the date such notice was sent by overnight delivery service, or upon receipt of confirmation of electronic transmission, as the case may be, and shall be addressed as follows:

\section{If to BEGINNINGS:}

BEGINNINGS for Parents of Children Who Are Deaf or Hard of Hearing, Inc. 156 Wind Chime Court, Suite A

Raleigh, North Carolina 27615

Attention: Executive Director

E-mail:

If to Licensee: Giese



f. Law Governing. This Agreement shall be governed by, construed and enforced in accordance with the laws of the United States and the State of North Carolina, without reference to the conflict-oflaws rules of such State. All disputes arising under or in connection with this Agreement shall be adjudicated exclusively in the state or federal courts of North Carolina. Each of the parties acknowledges that personal jurisdiction and venue shall be proper in such courts and expressly consents to such exclusive jurisdiction and venue.

g. Waiver of Provisions. The terms, covenants and conditions of this Agreement may be waived only by a written instrument executed by the party waiving compliance. The failure of either party at any time or times to require performance of any provision of this Agreement shall in no manner affect the right at a later date to enforce the same or to enforce any future compliance with or performance of any of the provisions hereof. No waiver by either party of any condition or other breach of any provision, term or covenant in this Agreement whether by conduct or otherwise, in any one or more instances, shall be deemed to be or construed as a further or continuing waiver of any such condition or the breach of any other provision, term or covenant of this Agreement.

h. Relationship of Parties. Nothing in this Agreement, its provisions, or the transactions, obligations and relationships contemplated hereby shall, in and of itself, constitute either party to this Agreement as the agent, employee or legal representative of the other party for any purpose whatsoever, nor shall either party to this Agreement hold itself out as such. This Agreement does not create and shall 
not be deemed to create a relationship of partners, joint venturers, associates or principal and agent between the parties. Each of the parties acknowledges that it is acting as a principal hereunder.

i. Captions. The captions of sections of this Agreement are for convenience of reference only and shall not control or affect the meaning or construction of any of the provisions of this Agreement.

j. Surviving Provisions. The following sections shall survive any termination or expiration of this Agreement: I and III.

IN WITNESS WHEREOF, the parties have caused their authorized representatives to execute this Agreement as of the Effective Date.

\section{BEGINNINGS FOR PARENTS OF CHILDREN WHO ARE DEAF OR HARD OF HEARING, INC.}

By:

Printed name

Executive Director
GIESE



Title 